OPEN ACCESS

Edited by:

Ravi Gupta,

Kookmin University, South Korea

Reviewed by:

Randeep Rakwal,

University of Tsukuba, Japan

Ki-Hong Jung,

Kyung Hee University, South Korea

*Correspondence: Mohammad Israil Ansari

ansari_mi@/kouniv.ac.in

Specialty section:

This article was submitted to Crop and Product Physiology, a section of the journal

Frontiers in Plant Science

Received: 14 July 2021 Accepted: 20 September 2021

Published: 15 October 2021

Citation:

lqbal Z, lqbal MS, Khan MIR and Ansari MI (2021) Toward Integrated Multi-Omics Intervention: Rice Trait Improvement and Stress Management.

Front. Plant Sci. 12:741419. doi: 10.3389/fp/s.2021.741419

\section{Toward Integrated Multi-Omics Intervention: Rice Trait Improvement and Stress Management}

\author{
Zahra Iqbal' ${ }^{1}$, Mohammed Shariq Iqbal' ${ }^{2}$, M. Iqbal R. Khan ${ }^{3}$ and \\ Mohammad Israil Ansari**
}

${ }^{1}$ Molecular Crop Research Unit, Department of Biochemistry, Chulalongkorn University, Bangkok, Thailand, ${ }^{2}$ Amity Institute of Biotechnology, Amity University Uttar Pradesh, Lucknow, India, ${ }^{3}$ Department of Botany, Jamia Hamdard, New Delhi, India, ${ }^{4}$ Department of Botany, University of Lucknow, Lucknow, India

Rice (Oryza sativa) is an imperative staple crop for nearly half of the world's population. Challenging environmental conditions encompassing abiotic and biotic stresses negatively impact the quality and yield of rice. To assure food supply for the unprecedented ever-growing world population, the improvement of rice as a crop is of utmost importance. In this era, "omics" techniques have been comprehensively utilized to decipher the regulatory mechanisms and cellular intricacies in rice. Advancements in omics technologies have provided a strong platform for the reliable exploration of genetic resources involved in rice trait development. Omics disciplines like genomics, transcriptomics, proteomics, and metabolomics have significantly contributed toward the achievement of desired improvements in rice under optimal and stressful environments. The present review recapitulates the basic and applied multi-omics technologies in providing new orchestration toward the improvement of rice desirable traits. The article also provides a catalog of current scenario of omics applications in comprehending this imperative crop in relation to yield enhancement and various environmental stresses. Further, the appropriate databases in the field of data science to analyze big data, and retrieve relevant information vis-à-vis rice trait improvement and stress management are described.

Keywords: genomics, metabolomics, omics, proteomics, rice, stress, transcriptomics

\section{INTRODUCTION}

Rice (Oryza sativa) is a staple crop for billions of the world population. World agriculture faces a daunting task to proportionally ramp-up rice production for meeting the enormous demand of human consumption (Khan et al., 2015). Concomitantly, adverse environmental conditions negatively impact rice production and cause significant yield loss. Biotic and abiotic stresses either in combination or individually prevent the attainment of full genetic potential for optimal rice growth and yield (Raza et al., 2019). According to the 2021 data of FAOSTAT (Food and 
Agricultural organization), rice is one of the highest globally harvested crops ${ }^{1}$. According to the latest census by FAOSTAT in the year 2019, around 160 million hectares of land is planted with rice which cumulatively produces approximately 750 million tons of rice worldwide (see text footnote 1). Asia is the leading producer of rice and contributes to about $90.6 \%$ of the production share (see text footnote 1 ).

Apart from the immense economic importance, rice has also emerged as a model crop (genome size $=4.3 \mathrm{MB}$ ) for monocots (Izawa and Shimamoto, 1996). The simple genome of rice led to easy and early genome sequencing of rice (Goff et al., 2002; Yu et al., 2002; Sasaki, 2005; Huang et al., 2013; Stein et al., 2018). For the two popular rice sub-species namely, O. sativa ssp. Japonica and $O$. sativa ssp. Indica, the pioneer draft genome was released in the year 2002 (Goff et al., 2002; Yu et al., 2002). Following the release of the draft genome, high-throughput technologies were employed to assemble the complete reference genome of rice (Sabot et al., 2011; Gao et al., 2013). Much recently, the genome availability of 13 domesticated and wild rice varieties has highlighted the genetic conservation across the genus Oryza (Stein et al., 2018).

In molecular biology and data science, the word "ome" refers to the study of special, temporal, and global changes occurring in an organism. Omics is a branch of science to gauge the functions and extract relevant biological information in a single or bunch of cells, tissues, or organs. The easy accessibility of whole-genome sequences from rice provides a platform for several omic studies like genomics, transcriptome, proteome, and metabolome (Delseny et al., 2001; Komatsu and Tanaka, 2005; Agrawal and Rakwal, 2011; Kyndt et al., 2012; Zheng et al., 2013; Chen et al., 2014; Lin et al., 2017; Li et al., 2018; Song S. et al., 2018; Zarei et al., 2018; Zhang et al., 2019; Peng Yuan et al., 2020). These techniques form the core components of omics technology. Over the years, substantial progress has been made in these methods in relation to almost all organelles, cells, tissues, and organs of rice. Rice genomics led to the discovery and functional characterization of pivotal genes that play crucial roles in improving rice productivity (Yano et al., 2016; Tang et al., 2019; Volante et al., 2020). The application of transcriptomics to rice has widened the understanding of complex molecular responsive mechanisms, differential gene expression, and regulatory pathways under varying conditions (Takehisa et al., 2012; Kumar and Dash, 2019; Sun et al., 2019). This information can be successfully processed for rice crop improvement. Similarly, proteomics and metabolomics has also contributed drastically for rice trait improvements (Oikawa et al., 2008; Agrawal and Rakwal, 2011; Calingacion et al., 2012; Kim S.T. et al., 2014; Baslam and Mitsui, 2020). The application of secretome for the identification of various novel secreted proteins and global mapping of phosphorylation sites is also worth mentioning (Cho and Kim, 2009; Agrawal et al., 2010; Que et al., 2012; Chen et al., 2016). Additionally, well-recognized proteomes have abetted in re-annotating the rice genome to unravel the proteins of unidentified functions. These relevant findings are implemented for genetic improvement in relation

${ }^{1}$ http://www.fao.org/ to agronomic traits and response to biotic/abiotic stresses. The major challenge ahead for functional genomics and system biology is to integrate genomics, transcriptomics, proteomics, and metabolomic information for a better understanding of cellular biology. The present review recapitulates the core omics techniques viz., genomics, transcriptomics, proteomics, and metabolomics to emphasize the advances achieved in rice omics research. Further, this review is aimed to reiterate the existing rice-omics scenario and how the implication of data science is gaining significance for rice trait improvement and stress management across the scientific community.

\section{GENOMICS AND TRANSCRIPTOMICS: AN OVERVIEW}

Genomics is defined as the study of structure, function, evolution, and interaction of genes which provides complete information about the genetic make-up of an organism. The core components of genomics include genetic engineering, DNA sequencing, and deep analysis of the functions of genome. Genetic code is considered the foundation of biological life. The prime resources for understanding the genome involve the sequencing of DNA code and studying the gene expression patterns. The complete genome sequencing of Arabidopsis thaliana (Kaul et al., 2000) ushered to the post-genomic era in plant research. In the year 2005, the rice genome was sequenced under International Rice Genome Sequencing Project (Sasaki, 2005). The neoteric advances in the DNA marker technologies for identifying Single Nucleotide Polymorphism (SNP) have resulted in uncovering desirable traits. Massive parallel sequencing commonly referred to as next generation sequencing (NGS) has revolutionized the research underlying plant sciences (Figure 1). NGS utilizing Illumina/Solexa, Ion Torrent Personal Genome Machine (PGM) and Pacific Biosciences (PacBio) techniques have completely transformed the genomic and transcriptomic studies through their accuracy and robustness (Dhondt et al., 2013; Heather and Chain, 2016). Genome-wide association studies (GWAS) and quantitative trait loci (QTL) mapping to comprehend the genetic variance and inheritance of complex quantitative traits have also gained considerable significance in the recent past (Bekele et al., 2013; Bao, 2014; Reig-Valiente et al., 2018). Thus, genomics delivers fast and accurate approaches for crop biotechnology by enabling methods for marker-assisted selection and molecular breeding.

Next, transcriptomics deals with the study of the entire transcriptome (sum of all RNA transcript) of an organism at a particular developmental stage or under a specific physiological condition (Blumenberg, 2019). Studying the transcriptomes of a variety of diverse populations aid in linking the genotype to a particular phenotype. Enormous population-wide transcriptome studies have been conducted on rice and other agronomic crops to understand the underlying mesh of networks in crop improvement (Kremling et al., 2018; Groen et al., 2020; Iqbal et al., 2020b). Nonetheless, due to the limitations associated with the sampling of below-ground tissues, the majority of transcriptomic studies are focused on above-ground tissues 


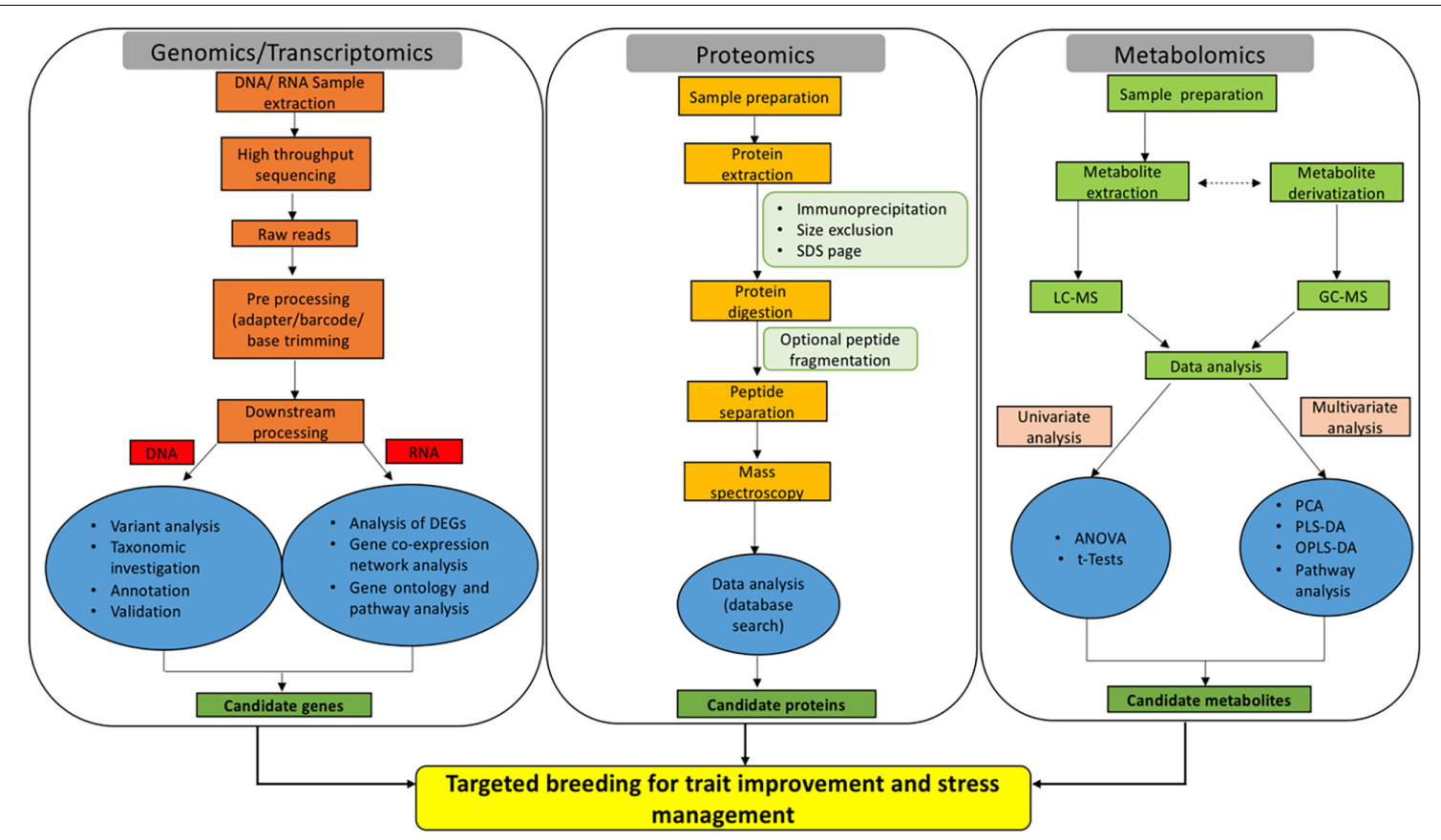

FIGURE 1 | Omics-based approaches are emerging as efficient tools for dissecting the key genes, proteins, and metabolites implicated in rice trait improvement and stress acclimation responses.

(Yoshino et al., 2019). In crux, transcriptomic studies allow the identification of mRNA, long non-coding RNAs, and small RNAs as well as the understanding of gene organizations and expression profiles (Figure 1; Wang et al., 2009). Generally, transcriptomic methods rely on sequencing [serial analysis of gene expressionSAGE (Moustafa and Cross, 2016), expressed sequence tags- ESTs (Parkinson and Blaxter, 2009) and RNA-seq (Wang et al., 2009)] or hybridization [suppression subtractive hybridization-SSH (Sahebi et al., 2015) and microarray (Hrdlickova et al., 2017)]. RNA-seq is considered as the best approach in comparison to other hybridization or sequencing-based methods, as far as the coverage and resolution are considered. ESTs (Zhou et al., 2003), SAGE (Bao et al., 2005), SSH (Chang et al., 2019), microarray (Wang et al., 2016), and RNA-seq (Ereful et al., 2020; Zainal-Abidin et al., 2020; Divya et al., 2021) have been linked extensively in the elucidation of complex mechanisms for rice trait improvement and stress management.

\section{Genomics and Transcriptomics in Rice Trait Improvement}

The major challenge ahead of rice breeders is to enhance rice productivity and improve related agronomic traits. This task becomes difficult to accomplish using traditional breeding techniques. The difficulty is further aggravated due to epistatic interactions of yield contributing genes (Mei et al., 2006). Taking into account the quality of rice, genomics and transcriptomics have offered several breakthroughs. Generally, the characteristics linked with rice quality include taste, gel consistency, amylose content, texture, aroma, nutritional value, gelatinization temperature, and resistant storage. Genetically modified methods have been frequently utilized to improve the above-mentioned characteristics. One of the early examples includes the generation of golden rice that contains significant levels of beta-carotene (Ye et al., 2000). Golden rice was produced by transforming the exogenous genes $p s y$, crtl, and lcy, along with their upstream elements. Beta-carotene is a known precursor in vitamin A synthesis and hence golden rice is considered nutritionally rich in comparison to white rice. Nonetheless, efficient technologies such as DNA markers for marker-assisted selection (MAS) of agronomic traits are pivotal to yield and quality improvement (Das et al., 2017). Minor and major QTLs for some yield components, viz., plant height, spikelets per panicle, length of panicle, length of grain, weight of grain, yield per grain, and harvest index have been identified (Table 1; Septiningsih et al., 2003; Bernier et al., 2007). The QTLs contributing for grain length ( $q G L 3)$, grain width and weight ( $q G W 2$ ), grain weight ( $q g w 3)$, grain number ( $q G n 1)$, grain length and weight ( $q G S 3)$, and plant height $(P h 1)$ are based on Mendelian factors (Li et al., 2004; Fan et al., 2006; Wan et al., 2006; Ashikari et al., 2007; Song et al., 2007; Qi et al., 2017). For example, the GW2 gene (RING-type protein) is localized on chromosome 2 that modulates the width and weight of rice grains (Song et al., 2007). GS3 (putative transmembrane protein) is localized on chromosome 3 that modulates grain width, weight, thickness, and length (Fan et al., 2006). Such important alleles and genes linked to DNA markers can be potentially utilized in MAS for improving rice yield and quality. The accessibility of sequenced rice genome accelerated the identification of polymorphic markers (Feltus et al., 2004; Shen et al., 2004). 
Centromeres of rice chromosomes have also been successfully sequenced and assembled. This information can be applied for the construction of artificial rice chromosomes (Nagaki et al., 2004; Wu et al., 2004). Such data can be directly linked to phenotypic traits and successfully used for functional analysis. In recent times, gene cloning and functional analysis linked to yield and quality in important rice cultivars have been significantly improved by various scrupulous approaches. These encompass mutant screening, comparative genome analysis, production of cross populations, and identification of wild variates with better qualitative and quantitative traits (Shomura et al., 2008; Jiang et al., 2012).

One of the early examples from QTL mapping involves dense and erect panicle 1 (DEP1) accountable for governing the number, weight, and size of rice grain (Ashikari et al., 2005; Huang, Feng et al., 2009). Furthermore, QTLs are also linked to ideal plant architecture (IPA) and wealthy farmer's panicle (WFP) (Jiao et al., 2010; Miura et al., 2010). IPA and WFP contribute to a greater number of panicles branching and higher grain yield in rice. Later, recombinant inbred lines (RILs) population was used to detect 27 QTLs on 10 rice chromosomes (Yan et al., 2014). The RILs in this study were obtained from a cross of Huahui 3 (Bt/Xa21) and Zhongguoxiangdao. 12 of these QTLs contributed to rice grain shape and yield. Intriguingly, the two already known genes, $B t$ gene (insect-resistant) and $X a 21$ gene (disease-resistant) were closely linked to QTLs responsible for grain shape and weight. In the Huahui 3 rice cultivar, $B t$ fragment insertion localized on chromosome 10 . The $B t$ fragment insertion might disrupt grain-related QTLs which resulted in compromised yields in transgenics (Yan et al., 2014). The introgression of Xa21 gene into Minghui 63 rice cultivar contained a donor linkage drag and affected QTL alleles to regulate the shape and yield of grain. This information can be utilized for breeding applications to recuperate rice grain shape and yield (Yan et al., 2014). Recently, another RIL population obtained from KRH2 (IR58025A/KMR3R) was utilized to identify QTLs governing crop yield (Kulkarni et al., 2020). A genetic map of $294.2 \mathrm{cM}$ with 126 simple sequence repeats (SSR) was made. Overall, 22 QTLs were recognized with phenotyping and genotyping data. The study reported a novel QTL linked to panicle length (qPL3-1). The other QTLs identified were total grain yield/plant (qYLD3-1), panicle weight ( $q$ PW3-1), plant height (qPH12-1), and flag leaf width ( $q F L W 4-1)$. Moreso, considerable epistatic interactions were detected for the length of panicle and grain yield per plant. In silico analysis of the QTLs highlighted the functions of candidate genes linked with preferred traits (Kulkarni et al., 2020). The high-yielding RILs harboring the yield associated QTLs were recognized as restorers. This indicates their probable deployment in the generation of excellent rice hybrids. Further, single-nucleotide polymorphism (SNP) data provides a strong foundation for exploring rice diversity and genetrait relationships that can be successfully implemented in crop improvement through linkage mapping (McNally et al., 2009; McCouch et al., 2010; Roy and Lachagari, 2017; Zainal-Abidin et al., 2019). SNP markers linked with rice grain yield have been well documented recently. GWAS was used for genotyping of 541
TABLE 1 | List of QTLs in rice trait improvement and stress management.

\begin{tabular}{|c|c|}
\hline QTL & Trait/stress \\
\hline $\begin{array}{l}\text { qYLD3-1, qPW3-1, } \\
\text { qPH12-1, qFLW4-1, and } \\
\text { qPL3-1 }\end{array}$ & $\begin{array}{l}\text { total grain yield, panicle } \\
\text { weight, plant height, flag } \\
\text { leaf width, panicle length }\end{array}$ \\
\hline qt/12.1/qDTY12.1 & $\begin{array}{l}\text { decreased number of } \\
\text { days to flowering, higher } \\
\text { harvest index, increased } \\
\text { biomass and plant height }\end{array}$ \\
\hline qDTY1.1 & $\begin{array}{l}\text { Grain yield under drought } \\
\text { and plant height under } \\
\text { drought }\end{array}$ \\
\hline $\begin{array}{l}\text { qDTY2.1, qDTY3.1, } \\
\text { qDTY2.2, qDTY9.1, and } \\
\text { qDTY12.1 }\end{array}$ & $\begin{array}{l}\text { grain yield under drought } \\
\text { stress }\end{array}$ \\
\hline $\begin{array}{l}\text { qDTY1.1, qDTY1.3, and } \\
\text { qDTY8.1 }\end{array}$ & $\begin{array}{l}\text { grain yield under drought } \\
\text { stress }\end{array}$ \\
\hline qRT9.1 and qRT5.1 & $\begin{array}{l}\text { Root trait under drought } \\
\text { stress }\end{array}$ \\
\hline qDTY1.1, qDTY3.3, and & grain yield across the \\
\hline qDTY6.3 & $\begin{array}{l}\text { seasons under severe } \\
\text { and moderate drought }\end{array}$ \\
\hline Saltol & Salt stress \\
\hline
\end{tabular}

References

Kulkarni et al., 2020

Bernier et al., 2007

Ghimire et al., 2012 Venuprasad et al., 2012b Vikram et al., 2016

Bernier et al., 2007; Venuprasad et al., 2009; Swamy et al., 2011; Mishra et al., 2013

Catolos et al., 2017

Catolos et al., 2017

Yadav et al., 2019

Gregorio, 1997; Bonilla et al., 2002; Niones, 2004; Thomson et al., 2010; Alam et al., 2011

qSKC-1 and qSNC-1

qSL2, qRL2.1, qSIS2 qSDW2, and qRL2.2

qCT3.12, qCT6.7, and qCT9.6

qLTGR4d-9-1, qLTGR4d-9-2, qLTGR2d-9-1, qLTGI-9-1, qLTGR2d-9-2, and qLTGI-9-2

qLTSR-9-2, qLTSR-9-1, qLTSR-9-1, qLTNSR-9, and qLTNSR-9

MQTL2.5, MQTL8.1, and MQTL9.1

qBL3

SUB1

AG1 and $A G 2$
Shoot potassium concentration and shoot sodium concentration

shoot length, root length, salt injury score, and shoot dry weight

QTL affecting cold tolerance associated with spikelet fertility (\%)

QTLs associated with seed germination under cold stress in the RIL population of rice

QTLs associated with cold tolerance of the RIL population of rice at the bud stage

significant count of $R$-genes contributing to sheath blight, rice blast, and bacterial blight resistance

Leaf and neck blast resistance Submergence stress

Zhou et al., 2013; Deng et al., 2015b; Jing et al., 2017

Amoah et al., 2020

Liang et al., 2018

Yang et al., 2020

Yang et al., 2020

Kumar and

Nadarajah, 2020

Devi et al., 2020

Xu et al., 2006;

Fukao and

Bailey-Serres,

2008; Chakraborty

et al., 2021

anaerobic germination under flooding 
rice accessions by 167470 SNPs. The study concluded 15 SNPs to be significantly related to grain yield (Pantalião et al., 2020). Additionally, trait-linked simple sequence repeat (SSR) markers were deployed to study an important rice agronomic trait-aroma (Jasim Aljumaili et al., 2018). The study quantified the genetic divergence using SSR markers in aromatic rice accessions. This led to the identification of promising accessions for introgression (Jasim Aljumaili et al., 2018). SSRs were also utilized to study colored rice germplasm (Black-Purple and Red Pericarp Color) (Park et al., 2019). Taking into account the nutritional quality, the genetic diversity of rice grain iron and zinc levels in the representative groups of local and exotic rice accessions was evaluated by SSR markers. Aromatic rice fine grain accessions contained high iron and zinc levels in brown rice in comparison to coarse grain accessions (Raza et al., 2020). Neoterically, GWAS and functional analysis of 520 rice accessions identified OsZIP18 as the prime genetic determinant for regulating branched-chain amino acid levels (Sun et al., 2020). Thus, OsZIP18 can be considered a potential gene for enhancing rice nutritional value. OsZIP18 can be of significant importance as humans are unable to synthesize branched-chain amino acids.

Plant breeders have suggested the IPA that comprises many important agronomic traits such as low tiller counts, more grains per panicle, few or no unproductive tillers, and thick and strong stems (Jiao et al., 2010; Li et al., 2012). Back in 2010, semidominant QTL, IPA1 (ideal plant architecture 1) was cloned and characterized. This QTL encodes a squamosa-promoter binding protein-like transcription factor (TF) named OsSPL14. OsSPL14 can regulate few relevant genes such as OsTB1 (negative regulator of lateral branching) (Takeda et al., 2003) and DEP1 (grain yieldrelated protein) (Huang, Qian et al., 2009). Moreover, OsSPL14 at the reproductive stage can facilitate higher grain yield and panicle branching at the reproductive stage (Jiao et al., 2010; Miura et al., 2010). Nonetheless, microRNA ( $m i R 156)$ negatively regulates OsSPL14 (Xie et al., 2006). The OsSPL14 mRNA is cleaved by $m i R 156$ to suppress it functions. Transgenic rice with IPA characteristics was generated by incorporating point mutation at the OsmiR156-targeted site in OsSPL14 (Jiao et al., 2010; Miura et al., 2010). Over-expressing miR156 also leads to fast leaf/tiller initiation and advanced leaf maturation in rice (Xie et al., 2012). GW8 gene positively regulates the yield and width of rice grains (Wang et al., 2012). A mutation in the promoter of GW8 gene was found in the indica Basmati rice varieties. This mutation lowered the GW8 expression and resulted in slender grain with a better appearance. Interestingly, GW8 encodes OsSPL16 protein which is a target of $m i R 156$. In this case also, MAS was implemented to concomitantly upgrade the appearance and enhance the grain yield (Wang et al., 2012). Additionally, OsmiR156 was reported to regulate the tillering-associated genes (TB1, LAX1, and DWARF 53) (Liu Q. et al., 2019). These studies demonstrated that $m i R 156$ is a crucial regulator in rice. Another miRNA, $m i R 172$ is associated with reduced seed weight, floral defects, and delayed transition of spikelet meristem to floral meristem in rice (Zhu et al., 2009). Furthermore, a miRNA/MADS/TCP/D14 (miMTD) regulatory system has also been reported to regulate tillering in rice (Guo et al., 2013). The expression of OsMADS57 is negatively regulated by OsMIR444a. This in-turn negatively modulates the expression of D14 to affect rice tillering. This mechanistic outline can be focused for high grain yield in rice breeding programs (Guo et al., 2013). OsmiR397 is an endogenous rice miRNA that is expressed in seeds (Xue et al., 2009; Chen et al., 2011), undifferentiated, and differentiated calli (Luo et al., 2006). Overexpression of miRNA gene-OsmiR397 is linked with grain size and panicle branching, eventually leading to increased rice grain production (Zhang et al., 2013). The miR397 targets OsLAC gene (linked to brassinosteroid sensitivity) to cleave its mRNA and disrupt the overall function (Zhang et al., 2013). On similar lines, miR159 targets OsGAMYB and OsGAMYBL1 (GAMYBLIKE 1) genes. The activity of mature miR159 was hindered by STTM (Short Tandem Target Mimic). This resulted in enhanced expression of OsGAMYB and OsGAMYBL1 with reduced size of organ, diameter of stem, length of flag leaf, size of grain panicle, and spikelet hulls (Zhao et al., 2017). On similar grounds, miRNA microarray profiling identified $m i R 319$ expression has a suppressive effect on rice plant height (Liu et al., 2017). In a recent study, transgenic rice with disrupted miR396-targeting site in OsGRF8; and knockout of miR396e and miR396f exhibited improved panicle branching and grain size (Zhang J. et al., 2020). Likewise, down-regulation of OsmiR1432 resulted in enhanced expression of Acyl-CoA thioesterase (OsACOT) to promote grain filling. The disruption of OsmiR1432 lead to heavier grains with improved yield by atleast $17 \%$ (Zhao et al., 2019).

Early efforts to decipher the entire transcriptome began in the 1990s (Lowe et al., 2017). During the last decade, RNA-seq method that uses deep-sequencing technologies has gained huge popularity for various crop improvement programs. Generally, in RNA-seq, total or fractionated RNA is made into a library of cDNAs fragments. Either one or both the cDNA ends are ligated with adapters. Each molecule is then sequenced in a high-throughput manner to obtain a short stretch of sequences either from one end (single-end sequencing) or both ends (pair-end sequencing) (Figure 1). The read length may vary from 30 to $400 \mathrm{bp}$ depending upon the sequencing technology. The sequenced reads are finally aligned either to a reference genome or assembled de novo to generate meaningful information (expression profile and transcriptional structure). As already discussed, transcriptomics aids in deciphering unannotated genes and analyzing gene expression patterns (Lowe et al., 2017). RNA-seq was performed to gain insights into the genome-wide transcription patterns of $O$. sativa japonica and indica subspecies (Lu et al., 2010). Whilst most of the RNAseq studies in rice are largely focused on stress management, few have also been conducted for improving agronomic traits. In this context, the RNA-seq approach was utilized to establish the involvement of alternative splicing in rice mineral nutrient homeostasis (Dong et al., 2018). This was further extended to large-scale GWAS and transcriptome studies to identify genes affecting the rice glycemic index (Anacleto et al., 2019). The glycemic index in rice is an important parameter for a large population of society suffering from Type II diabetes, obesity, and hypertension (Mohan et al., 2014). In a recent study, the rice genome annotation was improvised by RNA-seq experiments. The study resulted in the identification of 1584 new peptides and 101 new loci matched to novel peptides (Ren et al., 2019). The 
identification of these novel peptides and loci in the near future can be linked to traits of agronomic importance.

\section{Genomics and Transcriptomics in Rice Stress Management}

The prime objective of rice research is to improve crop yield and acclimatization to unfavorable environmental conditions. The rice genome had been sequenced years back, but highquality genome annotation of rice is necessary for the researchers working in this arena. In this direction, the accomplishment of Rice Annotation Project (RAP) database $e^{2}$ established on the new chromosome pseudomolecule Os-Nipponbare-ReferenceIRGSP-1.0 (a joint version of IRGSP and MSU pseudomolecules) (Kawahara et al., 2013) was imperative. The preliminary response of plants toward stress is the induction of signal transduction pathways. Generally, the second messenger molecules in signal transduction cascades are responsible for the regulation of stress-responsive genes. The induction or suppression of stressresponsive genes in-turn generates an appropriate response.

\section{Abiotic Stress}

The generation of transgenic plants for functional validation of genes associated with a particular trait heavily relies on genomics and transcriptomics. For instance, it had been shown that 5000 genes were upregulated and 6000 genes were downregulated upon drought exposure to rice (Bin Rahman and Zhang, 2016; Joshi et al., 2016). These genes are grouped into three main categories: membrane transport genes, signaling-related genes, and transcriptional regulatory genes (Upadhyaya and Panda, 2019; Kim et al., 2020). The expression of these genes in rice governs the biochemical, physiological, and molecular mechanisms under drought stress (Dash et al., 2018; Gupta et al., 2020). Further, considering the transgenic approach, numerous genes in rice are identified to be differentially expressed upon drought exposure (Kumar et al., 2017; Upadhyaya and Panda, 2019). The mode of regulation may be either ABA-dependent or ABA-independent (Du et al., 2018; Gupta et al., 2020). In this regard, OsJAZ1 in an ABA-dependent manner attenuates drought tolerance in rice (Fu et al., 2017). Similarly, LEA proteins and osmoregulatory genes confer drought tolerance to rice plants (Dash et al., 2018; Upadhyaya and Panda, 2019). OsPYL/RCAR5, EcNAC67 (Kim H. et al., 2014; Rahman et al., 2016), OsDREB2B, CYP735A, and OsDREB1F (Kim et al., 2020) are also involved in morphological adjustments of rice upon drought exposures. Additionally, the DREB2-like gene OsDRAP1 has been reported in modulating drought tolerance (Huang et al., 2018). Recently, an allele of the flowering gene OsMADS18 was shown to be a potential candidate in drought tolerance during breeding (Groen et al., 2020). An increase in rice grain yield upon drought exposure is also accomplished by transgenic approaches. This includes generation of transgenics with genes namely, OsLEA31 (Xiao et al., 2007), OsbZIP71 (Liu C. et al., 2014), OsWRKY47 (Raineri et al., 2015), OsbZIP46 (Tang et al., 2012), and OsNAC10 (Jeong et al., 2010). In a similar vein, in response to salinity stress, OsCOIN, OsDREB2A, OsMYB2, OsbZIP71, OsbZIP23 are

\footnotetext{
${ }^{2}$ http://rapdb.dna.affrc.go.jp/
}

reported as key players in the accretion of osmoprotectants and antioxidants, enhanced transporter activity for sodium and potassium ions (Liu et al., 2007; Xu et al., 2008; Sun et al., 2010; Takasaki et al., 2010; Yang et al., 2012; Gumi et al., 2018), regulation of other salt-responsive genes (Nakashima et al., 2007; Wang et al., 2008; Jan et al., 2013; Liu C. et al., 2014), improved fresh weight (Huang et al., 2007), stomatal closure (Hu et al., 2006), and high seedling survival (Hu et al., 2008; Mallikarjuna et al., 2011). The gain of function of these saltresponsive genes permits the transgenic rice plants to have adequate osmoregulation and less oxidative damage. A recent study advocates that OsSTAP1 is an AP2/ERF transcriptional activator that positively controls salt tolerance. OsSTAP1 works by reducing the sodium/potassium ratio and sustaining cellular redox homeostasis (Wang et al., 2020). Taking cold stress into consideration, OsbHLH1 (Wang et al., 2003), OsDREB1G (Moon et al., 2019), OsCTZFP8 (Jin et al., 2018), OsICE1 and OsICE2 (Deng et al., 2017) are few of the many rice genes implicated in cold acclimatization and tolerance. Furthermore in rice, methylation profiles and transcriptional responses to cold at the seedling stage have also been reported in the recent past (Guo et al., 2019).

As discussed in the previous section DNA markers and MAS are indispensable components of plant breeding (Das et al., 2017). Grain yield upon stress exposure is the chief trait associated with breeding programs (Bernier et al., 2007; Venuprasad et al., 2007; Kumar et al., 2008). Identifying QTLs linked with stress tolerance or susceptibility can assist breeders to choose desired genotypes with less yield compensation (Table 1; Shanmugavadivel et al., 2017). Grain yield itself is a complex trait and in combination with stress, becomes enormously challenging. Thus, the selection and determination of traits for QTL mapping under unfavorable environmental cues is crucial. A major QTL for grain yield upon drought exposure was identified in 2007 (Bernier et al., 2007). Under drought conditions, a sum total of $436 \mathrm{~F} 3$ derived lines from Vandana and Way Rarem were QTL mapped. A major QTL (qtl12.1/qDTY12.1) was identified between SSR markers, namely RM28048 and RM511. This QTL was linked with decreased number of days to flowering, higher harvest index, increased biomass, and plant height (Bernier et al., 2007). Later, in 2009 the influence of qtl12.1 was evaluated under varied target population of environments (Bernier et al., 2009). The results were consistent with the same effect on grain yield upon drought across various environments. Nonetheless, the uniformity of major yield QTL under adverse conditions in different genetic backgrounds is equally important. Eventually, 3 rice populations (N22/IR64, N22/MTU1010, and N22/Swarna) were evaluated and mapped for a major grain yield QTL, qDTY1.1 (Vikram et al., 2011). Across all the 3 populations, qDTY1.1 was mapped on chromosome 1 and was considered appropriate for marker-assisted breeding. Moreso, bulk segregant analysis identified $q D T Y 1.1$ in the genetic background of Swarna and IR64 rice cultivars (Ghimire et al., 2012). Upon drought exposure, $q D T Y 1.1$ accounted for 32 and $9.3 \%$ of the phenotypic variation in Swarna and IR64 respectively for grain yield (Ghimire et al., 2012). Additionally, qDTY1.1 was found to be associated with plant height $(s d 1)$ in Vandana/IR64 populations 
(Venuprasad et al., 2012b). Consequently, in large segregating populations recombinant alleles with un-associated $s d 1$ and qDTY1.1 might generate drought-tolerant varieties with shorter height (Vikram et al., 2016). Similarly, qDTY2.1, qDTY3.1, $q D T Y 2.2, q D T Y 9.1$, and $q D T Y 12.1$ are also reported for grain yield under drought stress (Bernier et al., 2007; Venuprasad et al., 2009; Swamy et al., 2011; Mishra et al., 2013). Another QTL, qDTY6.1 mapped on chromosome 6 in the genetic backgrounds of Apo/Swarna, Apo/IR72, and Vandana/IR72. qDTY6.1 explains the genetic variance $(40-66 \%)$ for grain yield under aerobic conditions and enhanced the performance of Swarna and IR72 (drought-susceptible cultivars) under aerobic conditions (Venuprasad et al., 2012a). Catolos et al. (2017), further identified 3 major QTLs contributing to grain yield, namely qDTY1.1, $q D T Y 1.3$, and $q D T Y 8.1$ as well as 2 major QTLs for root trait, namely $q R T 9.1$ and $q R T 5.1$. The mapping population was produced by crossing Dular (drought-tolerant) and IR 64_21 (drought-sensitive). Neoterically, high-density linkage map of rice was constructed by genotyping-by-sequencing (Yadav et al., 2019). The linkage map was generated by employing two $\mathrm{BC}_{1} \mathrm{~F}_{3}$ mapping populations namely Swarna*2/Dular and IR11N121*2/Aus196. The study identified six $q D T Y$ QTLs (three consistent effect QTLs) in Swarna*2/Dular and eight $q D T Y$ QTLs (two consistent effect QTLs) in IR11N121*2/Aus 196 mapping population. The relative analysis further identified four stable new QTLs, namely $q D T Y 2.4, q D T Y 3.3, q D T Y 6.3$, and $q D T Y 11.2$ accounting for 8.62 to $14.92 \%$ phenotypic variance. Three QTLs ( $q D T Y 1.1, q D T Y 3.3$, and $q D T Y 6.3$ ) were linked to grain yield across the seasons under severe and moderate drought (Yadav et al., 2019). Contrary to drought, submergence stress is a phenomenon associated with exposure of plants to excessive water for longer periods. An important QTL associated with submergence tolerance is SUB1 (submergence 1) (Xu et al., 2006; Fukao and Bailey-Serres, 2008). A recent study affirmed that SUB1 influences concomitant leaf gas film thickness and surface hydrophobicity (Chakraborty et al., 2021). Leaf gas film provides improved ethylene dissipation and decreased in-planta accumulation. This eventually results in the delay of ethyleneinduced leaf senescence upon submergence stress (Chakraborty et al., 2021). Another flooding stress-related condition involves the exposure of plants to hypoxia. QTLs for hypoxia tolerance in rice were identified during the germination stage (Kim and Reinke, 2018). Genotypic data from Illumina 6K SNP chip was used to identify QTLs related to tolerance of anaerobic germination (AG). Rice lines with $q A G 1 b+q A G 1 a+q A G 8$ possessed 50\%, qAG1b + qAG1a lines possessed 36\%, while $q A G 1 b+q A G 8$ possessed $32 \%$ of survival rate under anaerobic conditions (Kim and Reinke, 2018). In yet another study, responses of AG1 and AG2 QTL ILs were assessed during anaerobic germination under flooding. The study revealed that genotypes with $A G 1$ and $A G 2$ had greater seedling emergence and faster elongation in flooded soils (Mondal et al., 2020).

Much alike drought, salinity tolerance is a genetically and physiologically complex trait that is governed by a distinctive set of QTLs (Moradi et al., 2003). It is well established that salinity tolerance is autonomous at the seedling stage and reproductive stage (Mohammadinezhad et al., 2010). The major salt-tolerant
QTL identified is Saltol QTL which has been extensively deployed worldwide to generate better performing rice cultivars (Gregorio, 1997; Krishnamurthy et al., 2020; Yadav et al., 2020). Saltol QTL was identified in IR29 (sensitive variety) and Pokkali (tolerant variety) RIL population which mapped on chromosome 1. AFLP markers (P3/M9-8 and P1/M9-3) flanks the Saltol QTL resulting in $64.3-80.2 \%$ of the phenotypic variance. This QTL is associated with low sodium levels in plants. Saltol QTL has been further fine mapped between the SSR markers RM1287 and RM7075 (10.71 and $15.12 \mathrm{Mb}$ ) that comprise the SKC1 locus (Bonilla et al., 2002; Niones, 2004; Thomson et al., 2010; Alam et al., 2011). Several other QTLs had been identified for traits such as shoot sodium concentration (SNC), shoot potassium concentration (SKC), and shoot sodium/potassium ratio (Lin et al., 2004; Ren et al., 2005; Haq et al., 2010; Pandit et al., 2010; Zheng et al., 2015). Bimpong laboratory (Bimpong et al., 2014a,b) fine mapped QTLs for salinity stress tolerance deploying Hasawi as a salt-tolerant donor parent. They used SNPs for genotyping and linkage map preparation. Furthermore, the QTLs namely, $q S K C-1$ and $q S N C$ - 1 were mapped in F2 mapping populations derived from rss 2 and $r s s 4$ (Nipponbare) as well as Zhaiyeqing8 (indica) (Zhou et al., 2013; Deng et al., 2015b). Later in 2017, qSKC-1 was finely mapped between the markers RM578 and IM8854 within $45 \mathrm{~kb}$ region in F2 populations derived from Nipponbare/ZYQ8 and rss4/ZYQ8 (Jing et al., 2017). Similarly, rst1 mutant (rice salt-tolerant 1) was used to reveal that $r s t 1$ is regulated by a recessive gene (Deng et al., 2015a). QTL mapping was performed between rst1 and Peiai 64 to identify the possible loci of the rst 1 gene, which was found on chromosome 6 (Deng et al., 2015a). Additionally, RILs obtained from IR29 (salt-sensitive) and Hasawi (salt-tolerant) were used by Bizimana et al. (2017) to identify the QTLs on chromosomes 1, 2, 4,6, 8, 9, and 12. None of the Saltol or QTLs were found near this position. This indicated that tolerance in the cultivar Hasawi is attributed to new QTLs which are different from Saltol/SKC1 (Bizimana et al., 2017). Apart from QTLs/genomic regions linked to salt tolerance based on biparental mapping populations, an association panel following GWAS approaches to study marker-trait association has also been used (Emon et al., 2015; Kumar et al., 2015). 20 SNPs were identified to be significantly linked with sodium/potassium ratio (Kumar et al., 2015). Also, this study could identify the Saltol region, which accounts for salinity tolerance as a prime link with sodium/potassium ratio (Kumar et al., 2015). In an identical manner, Wn11463, an STS marker for SKC1, and RM22418 on chromosome 8 were identified at the seedling stage to be linked with salinity tolerance (Emon et al., 2015). Very recently, $308 \mathrm{~F}_{4}$ families from Sahel 317/Madina Koyo were evaluated using SNPs for salt tolerance at the early seedling stage (Amoah et al., 2020). The genotypic data were regressed on to their phenotype to detect the QTLs, and a high-density genetic map was prepared with 3698 SNPs. Multiple interval mapping revealed 13 QTLs associated with shoot length, root length, salt injury score, and shoot dry weight on chromosomes $2,3,4,6$, 7, 10, and 12. On chromosome 2, three QTLs ( $q S L 2, q R L 2.1$, and $q S I S 2)$ and two QTLs ( $q S D W 2$ and $q R L 2.2$ ) were tightly linked, while on chromosome 7, another two QTLs ( $q S D W 7$ 
and qSL7) were strongly associated (Amoah et al., 2020). Taking cold tolerance into account, RILs derived from Dasanbyeo (indica)/TR22183 (japonica) crosses in Yanji (high-latitude area), Kunming (high-altitude area), Chuncheon (cold water irrigation) and Suwon (normal) were used to study the influence of QTL and epistatic QTL (E-QTL) with respect to cold-related traits at the reproductive stage. In three different cold treatment locations, six QTLs for spikelet fertility were detected. Furthermore, 57 QTLs and 76 E-QTLs were identified for nine cold-associated traits; out of them 19 QTLs and E-QTLs had substantial interaction of QTLs with environments (QEIs). This study illustrated that epistatic effects and QEIs are imperative for QTLs linked with cold tolerance (Jiang et al., 2011). QTLs controlling cold tolerance were also studied at germination and early seedling stages with RILs derived from crosses between japonica and indica subspecies. Composite interval mapping revealed five QTLs at the germination stage with 5.7-9.3\% phenotypic variance explained, while nine QTLs were found at the early seedling stage with 5.8-35.6\% phenotypic variance explained. The study reported only one common QTL, probably indicative of growth-stage specificity of cold tolerance (Ranawake et al., 2014). Another study performed at the reproductive stage in rice involved 84 $\mathrm{BC}_{2}$ cold tolerance introgression lines (ILs) that were generated through backcrossing. These cold tolerance ILs along with 310 random ILs were deployed for studying genetic networks fundamental to cold tolerance in rice. The segregation distortion method revealed seventeen major QTLs for cold tolerance in five selective introgression populations (Liang et al., 2018). Recently, RILs obtained from indica rice H335 (low temperaturetolerant) and indica rice CHA-1 (low temperature-sensitive) were used to detect QTLs linked with low-temperature tolerance at bud and germination stages. A high-density genetic map revealed 11 QTLs; among which six QTLs accounted for 5.139.42\% phenotypic variation explained at the germination stage, while five QTLs accounted for 4.17-6.42\% phenotypic variation explained at the bud stage (Yang et al., 2020).

Next generation sequencing that can robustly ascertain approximately all the RNAs in cells has been extensively deployed for miRNA analysis, particularly in identifying new or ricespecific stress-responsive miRNAs. A number of rice miRNAs are expressed upon encountering biotic and abiotic stresses (Table 2). The majority of stress responsive miRNAs are conserved and possess an analogous effect among rice and other plant species. For example, rice miR398 modulate the expression of Os-CSD1 and Os-CSD2 (similar to its targets in Arabidopsis thaliana - $\mathrm{Cu}$ or $\mathrm{Zn}$ superoxide dismutases) as well as responses to abiotic and biotic stresses (Li et al., 2011). A prominent report of drought-induced miRNA in rice involves $m i R 169 \mathrm{~g}$. miR $169 \mathrm{~g}$ is notably up-regulated upon drought exposure (Zhao et al., 2007; Jian et al., 2010; Zhou et al., 2010). Apart from the established role of $m i R 169 \mathrm{~g}$ in drought tolerance, it is also reported to be induced by salt stress to cleave mRNA of the NF-YA TF (Zhao et al., 2009). Moreso, miR169g negatively regulates rice immune responses against the blast fungus (Li et al., 2017). Similarly, miR393 is also induced by both, salinity and drought conditions (Gao et al., 2011; Xia et al., 2012; Lu et al., 2018). In addition, $m i R 319$ is down-regulated upon cold stress
(Lv et al., 2010), however, when over-expressed it could increase cold tolerance after chilling acclimation in rice (Yang et al., 2013; Wang et al., 2014). Furthermore, the reproductive tissues of rice treated with drought, salt, and cold stresses were used to prepare small RNA libraries. The RNA libraries were sequenced to gain insights into the involvement of miRNAs is stress responses (Barrera-Figueroa et al., 2012). A number of stressmodulated miRNAs were identified by matching the expression patterns under control and stress conditions. This paved the discovery of new miRNAs that might play important roles in stress responses associated with rice (Barrera-Figueroa et al., 2012). Thus, a single miRNA can regulate the signaling crosstalk between various pathways related to environmental stresses and can be linked with several traits, indicating a pleiotropic effect. Contrary to the pleiotropic effect, distinct miRNAs might contribute to a common function. For instance, miR169, miR397, miR528, miR827, miR1425, miR319a.2, and miR408-5p are all linked with $\mathrm{H}_{2} \mathrm{O}_{2}$-oxidative stress ( $\mathrm{Li}$ et al., 2011). In an identical manner, Illumina sequencing revealed 29 known and 32 novel miRNAs to be differentially expressed upon salt stress in Oryza glaberrima (Mondal et al., 2018). Nonetheless, small RNA libraries sequenced from rice seedlings subjected to cadmium stress revealed a set of miRNAs, all of which contributed to stress regulation (Huang S.Q. et al., 2009; Ding et al., 2011). A report by Zhang et al. (2018) suggested that the miRNA166 knockout rice mutants exhibited higher drought tolerance and smaller xylem diameter (Zhang et al., 2018). A recent study also used small RNA sequencing to identify osa-miR12477 (Parmar et al., 2020). The osa-miR12477 regulates the expression of $L A O$ (L-ascorbate oxidase) for salt tolerance in the plant.

\section{Biotic Stress}

Taking biotic stress into consideration, 13 and 16 blast resistance QTLs were recognized in Jin23B/CR071 and Jin23B/QingGuAi3 rice populations, respectively. The study revealed major and minor QTLs interactions as the basic genetic mechanism for blast resistance in CR071 and QingGuAi3 rice lines (Jiang et al., 2020). Lately, pi 66(t) was recognized as one of the recessive genes governing rice blast (Liang et al., 2016). Furthermore, the status and diversity of 12 major blast resistance genes were studied amongst 80 different rice varieties (Yadav et al., 2017). Molecular markers for genes Pi54, Pib, Piz, Piz-t, Pik, Pi-kh, Pik-p, PikmPik-h, Pita/Pita-2, Pi2, Pi9, Pi1, and Pi5 were utilized in this investigation. Recently in Oryza glumaepatula, characterization of a wide effect QTL showed Pi68(t) as a potential gene for field resistance and neck blast in rice (Devi et al., 2020). Another very recent study focused on the meta-analysis of QTL with multiple disease resistance in rice (Kumar and Nadarajah, 2020). The study revealed MQTL2.5, MQTL8.1, and MQTL9.1 have a significant count of $R$-genes which denotes $10.21,4.08$, and $6.42 \%$ of the total genes respectively. The defense-related genes contribute approximately $3.70,8.16$, and $6.42 \%$ of the total number of genes in MQTL2.5, MQTL8.1, and MQTL9.1, respectively. The study further led to the recognition of QTL hotspots for sheath blight, rice blast, and bacterial blight resistance. The potential gene candidates within these regions might be implemented for rice crop improvement via the intervention of genetic engineering. 
With the increasing advent of high-throughput technologies, researchers have used microarrays and NGS/deep sequencing to accomplish genome-wide expression analysis to identify stressregulated miRNAs (Table 2; Baldrich and San Segundo, 2016; Nadarajah and Kumar, 2019; Kar and Raichaudhuri, 2021). Xu et al. (2014) deployed microarray to study miRNA expression profiles in black-streaked dwarf virus (SRBSDV)-infected rice. They uncovered 56 miRNAs and 24 target genes to be potentially linked with diseased conditions. NGS was used to study small RNA expression profiles of rice seedlings infested with rice dwarf virus (RDV) and rice stripe virus (RSV). Campo et al. (2013) relied on high-throughput RNA sequencing to unravel a novel

TABLE 2 | List of miRNAs in rice trait improvement and stress management.

\begin{tabular}{|c|c|c|}
\hline miRNA & Function & References \\
\hline $\operatorname{miR} 156$ & $\begin{array}{l}\text { fast leaf/tiller initiation and advanced leaf } \\
\text { maturation in rice; regulate the } \\
\text { tillering-associated genes (TB1, LAX1 } \\
\text { and DWARF 53) }\end{array}$ & $\begin{array}{l}\text { Xie et al., 2012; } \\
\text { Liu Q. et al., } 2019\end{array}$ \\
\hline $\operatorname{miR} 172$ & $\begin{array}{l}\text { reduced seed weight, floral defects and } \\
\text { delayed transition of spikelet meristem } \\
\text { to floral meristem in rice }\end{array}$ & Zhu et al., 2009 \\
\hline $\operatorname{miR} 397$ & $\begin{array}{l}\text { grain size and panicle branching, } \\
\text { eventually leading to increased rice grain } \\
\text { production }\end{array}$ & Zhang et al., 2013 \\
\hline $\operatorname{miR} 159$ & $\begin{array}{l}\text { reduced size of organ, diameter of stem, } \\
\text { length of flag leaf, size of grain panicle, } \\
\text { and spikelet hulls }\end{array}$ & Zhao et al., 2017 \\
\hline $\operatorname{miR319}$ & suppressive effect on rice plant height & Liu et al., 2017 \\
\hline miR396 & $\begin{array}{l}\text { improved panicle branching and grain } \\
\text { size }\end{array}$ & Zhang J. et al., 2020 \\
\hline $\operatorname{miR} 1432$ & $\begin{array}{l}\text { enhanced expression of OSACOT to } \\
\text { promote grain filling }\end{array}$ & Zhao et al., 2019 \\
\hline $\operatorname{miR398}$ & $\begin{array}{l}\text { modulate the expression of Os-CSD1 } \\
\text { and Os-CSD2 as well as responses to } \\
\text { abiotic and biotic stresses }\end{array}$ & Li et al., 2011 \\
\hline $\operatorname{miR} 169 g$ & Drought, salt, and blast fungus & $\begin{array}{l}\text { Zhao et al., 2007, } \\
\text { 2009; Jian et al., } \\
\text { 2010; Zhou et al., } \\
\text { 2010; Li et al., } 2017\end{array}$ \\
\hline miR393 & Drought, salinity, and cold & $\begin{array}{l}\text { Lv et al., 2010; Gao } \\
\text { et al., 2011; Xia et al., } \\
\text { 2012; Lu et al., } 2018\end{array}$ \\
\hline $\operatorname{miR} 169, n$ & $\mathrm{H}_{2} \mathrm{O}_{2}$-oxidative stress & Li et al., 2011 \\
\hline
\end{tabular}

miR528, miR827,

$\operatorname{miR} 1425$,

miR319a.2 and

$\operatorname{miR} 408-5 p$

miRNA166

drought tolerance and smaller xylem diameter

$\begin{array}{ll}\text { miR12477 } & \text { regulates the expression of } L A O \\ \text { ( } L \text {-ascorbate oxidase) for salt tolerance }\end{array}$

miR7695 negatively controls an alternatively spliced transcript of OsNRAMP6, while

its over-expression improves the resistance to $M$. oryzae

miRNA169 decreased rice immunity against

M. oryzae

miRNA164a negatively regulates rice immunity against $M$. oryzae
osa-miR7695. This miRNA negatively controls an alternatively spliced transcript of OsNRAMP6 (natural resistance-associated macrophage protein 6), while its over-expression improves the resistance to Magnaporthe oryzae (Campo et al., 2013). In yet another study for the blast fungus M. oryzae, miRNA169 was shown to inhibit the expression of its target nuclear factor Y-A genes. This resulted in decreased rice immunity against the pathogen (Li et al., 2017). A comparable effect was detected against the blast fungus with Osa-miRNA164a that targets OsNAC60 gene (Wang Z. et al., 2018).

\section{PROTEOMICS AND METABOLOMICS: AN OVERVIEW}

Proteomics is a robust and powerful discipline that involves large-scale identification and quantification of proteins including, their structure and physiological functions. Precisely, proteome denotes a set or the entire complement of proteins within a cell, tissue, or organism. Proteome provides a data-rich panorama of regulation of expressed proteins under specific conditions. The word proteomics is an amalgamation of two words (protein and genome) and was first coined in 1994 by Mark Wilkins (Shah and Misra, 2011). Proteomics appendages the other omics techniques i.e., genomics, transcriptomics, and metabolomics to cognize the function and structure of the protein of interest. Proteomics has proven to be a forte for the rice research community. Proteogenomics (large-scale proteome information is processed for genome annotation refinement) has greatly assisted in this direction (Helmy et al., 2011). Proteomes are available for almost all rice tissues and organs under normal or stressed conditions (Agrawal and Rakwal, 2011; Kim S.T. et al., 2014). Proteomics-based techniques are used in different capacities for crop improvement and deciphering environmental stress mechanisms. Nonetheless, the field of proteomics is exceedingly dynamic in nature due to the intricate regulatory systems governing the protein expression levels. Mass spectrometry (MS) with liquid chromatography (LC-MS-MS) and matrix-assisted laser desorption/ionization (MALDI-TOF/TOF) are central to current proteomics. The classical techniques for protein purifications involve ionexchange chromatography (IEC), affinity chromatography, and size exclusion chromatography (SEC) (Agrawal et al., 2010; Agrawal et al., 2013). Enzyme-linked immunosorbent assay (ELISA) and western blotting are used for studying selective proteins (Yang and Ma, 2009; Kim et al., 2013). Sodium dodecyl sulfate-polyacrylamide gel electrophoresis (SDS-PAGE), twodimensional differential gel electrophoresis (2D-DIGE), and twodimensional gel electrophoresis (2-DE) techniques are routinely utilized for separation of complex protein mixtures (Choudhary et al., 2009; Pandey et al., 2010; Jaiswal et al., 2013). These techniques can be efficiently utilized to analyze a small set of proteins and are incapable of measuring protein expression levels. The technique 2-DE allows the study of differentially expressed proteins with the simultaneous detection and quantification of several protein spot isoforms, encircling post-translational modifications. Nevertheless, 2-DE based proteomics is biased 
against low abundance and hydrophobic proteins. For highthroughput protein expression analysis protein microarrays or chips have been established. However, it cannot be utilized to determine the function of complete proteome (Han et al., 2014a)., Edman degradation, MS, isotope-coded affinity tag (ICAT) labeling, stable isotope labeling with amino acids in cell culture (SILAC), multidimensional protein identification technology (MudPIT), and isobaric tag for relative and absolute quantitation (iTRAQ) are the few techniques for quantitative proteomic (Dong et al., 2014; Han et al., 2014b; Li Y. et al., 2014; Liao et al., 2014; Zhang et al., 2014; Li et al., 2015). Likewise, X-ray crystallography and nuclear magnetic resonance (NMR) spectroscopy are the main high-throughput technologies to determine the 3-D structure of a protein (Liao et al., 2014; Liu C.W. et al., 2014; Zhang et al., 2014). High-throughput data yields large quantities of proteomics data which is analyzed by various bioinformatics databases (Figure 1). Proteomics analysis in rice are grouped into gel-based (1-DE, 2-DE, and 2-DIGE), gelfree (LC-MS/MS, MudPIT, iTRAQ), and a coalescence of these two methods (Agrawal et al., 2013). Thus, proteomics enables to globally decipher the protein expression profiles and their analogous post-translational modifications.

Metabolomics is the systematic analysis of chemical processes including metabolites, substrates, intermediates, and products of cellular metabolism. Precisely, metabolomics involve the characteristic fingerprints that discrete cellular processes lay down resulting in a unique metabolic profile (Daviss, 2005; Gong et al., 2013). Genomics, transcriptomics, and proteomics reveal the expression pattern or cellular function of a gene within the cell. However, metabolomics offers a straight functional read-out of the physiological state associated with an organism (Daviss, 2005). The tools and techniques deployed for metabolomic data recording and processing have been proved to be more sophisticated than ever. The studies encircling the metabolome data have been long ramification of "hypothesis generator," which remains a subject of further evaluation (Hall, 2006). Taking rice metabolomics in particular, it is a high-throughput technique to profile metabolites implicated directly or indirectly in metabolic processes (Figure 1). Further, it is widely deployed to monitor and evaluate the cellular metabolic state and quality of rice (Okazaki and Saito, 2016). Generally, metabolomics involves optional separation of small metabolites by gas chromatography (GC), high-performance liquid chromatography (HPLC), and liquid chromatographymass spectrometry (LC-MS); followed with MS to identify and quantify metabolites. Crude extracts are utilized to profile metabolites in a non-targeted approach; thus, chromatographic separation is often essential to analyze fractionated compounds (Fukushima and Kusano, 2014). GC-MS is particularly the method of choice for the study of low molecular-weight metabolites. The process of chemical derivatization makes low molecular-weight metabolites acquiescent to GC. The major advantage of GC-MS is capacity metabolite profiling and targeted metabolite quantitation. This aids in the study of several metabolites in a single GC-MS-MS multiple reaction monitoring (MRM) run. MS is a stand-alone technique that is highly sensitive and specific. Alternately, the sample material with no prior separation is directly infused into the mass spectrometer. MS itself imparts adequate selectivity to separate and detect metabolites. Advanced techniques such as NMR, LCMS, GC-MS, inductively coupled plasma (ICP)-MS, HPLC, and direct flow injection (DFI)-MS have significantly contributed to metabolic profiling (Uawisetwathana and Karoonuthaisiri, 2019). Fourier transform infrared spectroscopy (FTIR) is also popular in metabolomics for its capacity to simultaneously analyze and characterize intricate building blocks (Junot and Fenaille, 2019). Shortly, integrating metabolomics with genomics and proteomics has assisted in a proficient dissection of genetic, phenotypic, and protein level information in rice. Thus, the rice metabolome generates a "fingerprint" of diverse rice samples to ascertain the varieties that are crucial to rice trait improvement and stress management (Wei et al., 2018).

\section{Proteomics and Metabolomics in Rice Trait Improvement}

One of the major traits associated with rice is the aroma. Two genes, betaine-aldehyde dehydrogenase (Bradbury et al., 2008) and glyceraldehyde-3-phosphate dehydrogenase B form (Lin et al., 2014) are involved with fragrance in rice. Moreover, aromatic rice has a flavor compound, 2-acetyl-1-pyrroline (2AP). Proteomic analysis of two isogenic lines of Thai jasmine rice was performed to gain insights into the $2 \mathrm{AP}$ biosynthetic pathway. 2-DE was performed on both isogenic lines which identified aldehyde dehydrogenase, a key enzyme responsible for 2AP production (Wongpia et al., 2016). Rice grains are also known to contain low quantities of storage proteins (glutelins, prolamins, albumins, and globulins). Few of them are allergens ( $\alpha$-amylase/trypsin inhibitor, globulins, $\beta$-glyoxylase, and glutelins). Proteins from 4 different rice varieties were analyzed by $2 \mathrm{D}-\mathrm{GE}$. Further investigation revealed, few of the differentially abundant proteins as allergenic proteins. Particularly, a deletion in the 1000 bp upstream region of the globulin gene has been recognized, probably contributing to the varied abundance of the protein in the Karnak cultivar. This is useful for cultivar identification in commercial samples (Graziano et al., 2020). In another interesting study, three cytochrome P450 homoeologs (Os03g0603100, Os03g0568400, and GL3.2) and OsBADH2 were edited with the CRISPR/Cas9 to produce novel rice mutants. Evidently, CRISPR/Cas9 has revolutionized the arena of plant sciences (Iqbal et al., 2020a). The mutants exhibited elevated yields and enhanced aroma. RNA-seq and proteomic analysis were done to unravel the underlying modifications. Mutants showed increased grain size, grain cell number, and high 2AP content. RNA sequencing and proteomic analysis showed the involvement of genes and proteins linked to the cytochrome P450 family, grain size and development, and cell cycle (Usman et al., 2020). Anthocyanin and proanthocyanin are flavonoids that are present in good quantities in black and red rice. To decipher the molecular pathways, a study was performed to understand the flavonoid biosynthetic pathway in red, black, and white colors rice cultivars. A comprehensive profile of mRNA and expressed proteins in diverse colored rice varieties was obtained by RNA sequencing of caryopsis and iTRAQ analysis. A total of 3417, 
329, and 227 genes were distinctive for red, white, and black rice, respectively. Furthermore, the proteomes of black, white, and red rice contained 13,996 distinctive peptides corresponding to 3916 proteins. Interestingly, 32 genes were shown to be implicated in the flavonoid biosynthesis pathway. From those 32 genes, only CHI, F3H, ANS, and FLS were ascertained by iTRAQ (Chen et al., 2019). A similar study on two black rice cultivars (BALI and Pulut Hitam 9), two red rice cultivars (MRM16 and MRQ100), and two white rice cultivars (MR297 and MRQ76) using label-free liquid chromatography Triple TOF 6600 tandem mass spectrometry (LC-MS-MS) was conducted. The study profiled and ascertained the proteins associated with nutritional values (antioxidant, folate, and low glycemic index) and quality (i.e., aromatic) based on peptide-centric scoring from the Sequential Window Acquisition of All Theoretical Mass Spectra (SWATH-MS) approach (Sew et al., 2020). Recently, the effect of germination (post $24 \mathrm{~h}$ ) on nutrition-associated proteins in 4 rice cultivars was studied using shotgun proteomics. In-gel digestion coupled with tandem mass spectrometry (GeLC-MS/MS) was performed on 4 rice cultivars to analyze the total proteins from non-germinated seeds and $24 \mathrm{~h}$ germinated seeds. Total phenolic content was also measured post 0,24 , and 48 h of germination by Folin-Ciocalteu assay. The study revealed that seed nutrition-related proteins, particularly phenolic proteins increased post-germination. A 2.20 - 15.90 folds increment in the expression of phenylalanine ammonia-lyase, serine carboxypeptidase-like protein, isoflavone7-O-methyltransferase, isoflavonoid glucosyltransferase, glycosyltransferase family 61 protein, and UDP-glucose flavonoid 3-O-glucosyltransferase was observed post-germination. The study supported the notion that rice germination for $24 \mathrm{~h}$ influences the enhanced nutrition of brown rice and the phenolic biosynthetic pathway (Maksup et al., 2020).

Genetic engineering intervention in the generation of genetically modified rice cultivars is well illustrated by "Golden rice" (Khan et al., 2015). Wild-type rice is devoid of vitamin A or its precursor-beta-carotene. Its deficiency affects the human population that consumes rice as a staple food. The rice genome was genetically engineered with a multigene biochemical pathway to synthesize beta-carotene that is eventually metabolized by humans to synthesize vitamin A (Baranski, 2013; Khan et al., 2015). Pleiotropic effects, mutation, and inactivation of endogenous genes are the basis for the generation of such cultivars with unintended phenotypes (Matsaunyane and Dubery, 2018). Genetic alteration of phytoene synthase (Psy) and phytoene desaturase (crtI) that leads to metabolic regulation and adaptation of "golden rice" has been extensively studied (Gayen et al., 2016). Transgenic and nontransgenic seeds of golden rice were collected for proteomic and metabolomic studies. HPLC analysis identified significantly high levels of carotenoids in the transgenics. The higher level of carotenoid in the transgenics is attributed to Psy and crtI expressions. Also, the GC-MS approach was deployed to detect the changes in the carbohydrate metabolism pathway in the transgenics (Decourcelle et al., 2015). The transgenics accumulated higher amounts of galactose, fructo furanose, D-glucoronate, and D-sorbitol. Surprisingly, the proteomic results were found to be in correlation with the metabolomic data as greater activities for enzymes (pullulanase and UDPglucose pyrophosphorylase) were found in the transgenics. These enzymes are imperative to carbohydrate metabolism and are linked with the biosynthesis of carotenoids (Chen et al., 2007; Gayen et al., 2016). Additionally, the activity of pyruvate phosphate dikinase implicated in pyruvate biosynthesis (precursor of carotenoid) was also found to be higher in the transgenics (Gayen et al., 2016). Song J.M. et al. (2018) conducted an interesting study on rice leaves and grains to further accentuate the role of metabolomics in rice research (Song E.H. et al., 2018). The metabolic profile of two rice cultivars (early maturing rice cultivar- EMC and late maturing rice cultivarLMC) was assessed by an NMR- based metabolomics ( ${ }^{1} \mathrm{H}$ NMR). Distinct metabolic profiles in leaves and grains at all growth stages of EMC and LMC were detected. For rice grains, significantly elevated levels of sucrose, amino acids, and fatty acids were observed in EMC than LMC. Thus, the nutritional value in EMC rice grains was higher than LMC rice grains (Song E.H. et al., 2018). In a recent study, phenolics, especially flavonoids and antioxidants in two rice varieties (Oryza sativa-Os and Zizania latifolia-Zl) were studied. A UHPLC-QqQ-MS-based metabolomics approach revealed that $\mathrm{Zl}$ possessed higher levels of phenolics, flavonoids, proanthocyanidins, and antioxidant activity. Out of 159 identified flavonoids, 78 showed differential expression (72 up-regulated and 6 down-regulated in the $\mathrm{Zl}$ ). The majority of flavonoids in $\mathrm{Z} 1$ were related to anthocyanin biosynthesis owing to its better nutrition profile (Yu et al., 2021). A more holistic study on rice metabolomics involved 17 cultivars from 7 different countries (Zarei et al., 2018). The group of metabolites and metabolome significantly varied amongst the cultivars. On average, 411 metabolites per cultivar were annotated and 71 metabolites were different between them. Prior, a similar study depicting the disparities between indica and japonica sub-species had been conducted ( $\mathrm{Hu}$ et al., 2014). Among the 92 significantly variable metabolites, 66 were up-regulated in japonica while 26 were up-regulated in indica cultivars. Asparagine had higher quantities in the indica sub-species and was regarded as the most variable of all the metabolites according to the Random Forest ranking. The metabolites of interest demarcating the two sub-species were associated with nitrogen metabolism, translocation, inorganic nutrition storage, and stress responses. Trait-associated metabolites with respect to biosynthetic and catabolic pathways will deepen the knowledge toward rice trait improvement (Table 3). Yet another study focused on the pathways related to the aroma in fragrant rice (Daygon et al., 2017). As stated earlier, 2AP in rice is a pivotal aroma compound. The analysis by Daygon et al. (2017) using GC × GC-TOF-MS showed 6-methyl, 5-oxo-2,3,4,5tetrahydropyridine (6M5OTP), 2-acetylpyrrole, pyrrole and 1pyrroline were related with the synthesis of $2 \mathrm{AP}$ in aromatic rice cultivars. Further, the GWAS indicated that all the above 4 compounds were linked with a single QTL that harbors the FGR gene linked with GABA production (Daygon et al., 2017). Recently, GC-MS based approach has also been used to assess rice grain quality through profiling of volatiles and metabolites in rice grains (Llorente et al., 2019). Thus, proteomics and metabolomics have contributed significantly in comprehending 
the underlying pathways and compounds associated with rice trait improvement.

\section{Proteomics and Metabolomics in Stress Management:}

Proteomics and metabolomics-based studies are expected to improve rice plant responses toward fluctuating environmental conditions. In the past few years, the contribution of omics sciences has been immense in rice research for studying the pathways, metabolites, and proteins involved in combating stress. Some case studies with respect to abiotic and biotic stresses are discussed below.

\section{Abiotic Stress}

The application of proteomics in rice stress management includes the study of physiological and proteomic analysis of the rice mutant coleoptile photomorphogenesis 2 (cpm2-disrupted in allene oxide cyclase). The study revealed negative regulation of jasmonic acid (JA) in drought tolerance (Dhakarey et al., 2017). Tandem mass tagging and Nano-LC-MS-MS was performed to comprehend the involvement of JA under drought at the molecular level. The histological, metabolite and proteomebased transcript analysis revealed the favorable adaptations and responses against drought stress, mainly coordinated by the absence of JA in the cpm2 roots (Dhakarey et al., 2017). In a similar vein, proteomic analysis of drought-responsive proteins by LC-MS-MS revealed photosynthesis-related adaptations via $\mathrm{NADP}(\mathrm{H})$ homeostasis to drought (Chintakovid et al., 2017). Recently, 8 genotypes of japonica and indica sub-species at the late vegetative stage were studied with nano LC-MS-MS (nanoflow liquid chromatography-tandem mass spectrometry) for drought stress (Hamzelou et al., 2020). Label-free quantitative shotgun proteomic analysis of 8 rice genotypes subjected to drought unraveled 1253 non-redundant proteins under wellwatered and drought conditions. In all the 8 genotypes, 8 proteins were induced under drought stress (Hamzelou et al., 2020). A more comprehensive study by Du J. et al. (2020) involved proteomics, metabolomics, and physiological analyses upon heavy nitrogen exposure before (NBD) and after drought (NAD) on rice (Du J. et al., 2020). The proteomic experiments were carried by tandem mass tagging of rice leaves subjected to NBD and NAD. The samples were analyzed by LC-MS-MS with the amount of qualitative protein and quantitative protein being 4254 and 3892 respectively. Upon drought exposure, NBD had higher chlorophyll content and photosynthetic rate, enhanced activities of antioxidant enzymes such as superoxide dismutase (SOD), peroxidase, and catalase, and declined malondialdehyde (MDA) content (Du J. et al., 2020). Next, the application of multi-omics in salinity stress involves an analysis by $\mathrm{Xu}$ et al. (2017) utilizing the techniques 2-DE and MALDI TOF (Xu et al., 2017). The relative proteomic analysis was performed amongst the dry and imbibed seeds of salt-tolerant japonica landrace Jiucaiqing with $150 \mathrm{mM} \mathrm{NaCl}$. A total of 14 proteins were identified to be implicated in seed imbibition. Many of the identified proteins were involved in energy supply and storage. Upon analysis, 2,3-bisphosphoglycerate-independent
TABLE 3 | List of proteomics and metabolomics techniques in rice trait improvement and stress management.

\begin{tabular}{lll}
\hline Method & Key finding & References \\
\hline 2 -DE & $\begin{array}{l}\text { proteins related with aroma } \\
\text { compound biosynthesis }\end{array}$ & Wongpia et al., 2016 \\
2D-GE & $\begin{array}{l}\text { Development of a molecular marker } \\
\text { useful for the analysis of } \\
\text { commercial products }\end{array}$ & \\
& cytochrome P450 family, grain size & Usman et al., 2020
\end{tabular}

HPLC Fractionation cytochrome P450 family, grain size Usman et al., 2020 and LC-MS/MS and development, and cell cycle

Analysis

iTRAQ analysis flavonoid biosynthesis pathway Chen et al., 2019

LC-MS-MS and Nutritional and quality traits Sew et al., 2020

SWATH-MS

GeLC-MS-MS

enhanced nutrition of brown rice

Maksup et al., 2020 and the phenolic biosynthetic pathway

GC-MS carbohydrate metabolism pathway Decourcelle et al., 2015

GC-MS endosperm specific carotenoid Gayen et al., 2016 pathways

${ }^{1}$ H NMR intrinsic physiology and potential Song E.H. et al., 2018 eating quality

UHPLC-QqQ-MS better nutrition profile Yu et al., 2021

UPLC-MS-MS rice gene-bran metabolite Zarei et al., 2018 relationships

UPLC-MS-MS and Metabolic variation between

Hu et al., 2014

GC-MS japonica and indica rice cultivars

GC $\times$ GC-TOF-MS Aroma in fragrant rice Daygon et al., 2017

GC-MS rice grain quality through profiling of Llorente et al., 2019 volatiles and metabolites

Tandem mass involvement of JA under drought at Dhakarey et al., 2017 tagging and molecular level

Nano-LC-MS/MS

LC-MS-MS photosynthesis-related adaptations Chintakovid et al., 2017 via $\operatorname{NADP}(H)$ homeostasis to drought

nLC-MS-MS Drought stress

Hamzelou et al., 2020

LC-MS-MS

Rice growth and grain yield with heavy nitrogen application before and after drought

2-DE and MALDI seed imbibition under salt stress TOF

ITRAQ

LC-MS-MS

1D LDS-PAGE, in-gel digestion, and LC-MS-MS

2-DE and MALDI-TOF-MS

nLC-MS-MS

early salinity response

Rice yield under salinity stress

Du J. et al., 2020

${ }^{1} \mathrm{H}$ NMR and

GC-MS

GC-MS

GC-MS

cold tolerance response

Xu et al., 2017

Lakra et al., 2019

Li et al., 2020

Lee et al., 2017

cold tolerance response

Ji et al., 2017

cold tolerance response

Wang J. et al., 2018

drought tolerance via GABA

Nam et al., 2016

biosynthesis, sucrose metabolism

and antioxidant defenses.

drought and heat stress in the field Lawas et al., 2019

metabolic pathways associated

with photosynthesis upon drought

exposure

GC-MS Salinity stress

GC-MS Salinity stress

GC-TOF-MS Salinity stress
Ma et al., 2016

Xie et al., 2020

Gupta and De, 2017

Wanichthanarak et al., 2020

(Continued) 
TABLE 3 | (Continued)

\begin{tabular}{|c|c|c|}
\hline Method & Key finding & References \\
\hline LC-MS-MS & $\begin{array}{l}\text { rice metabolic network underlying } \\
\text { OsDRAP1-mediated salt tolerance }\end{array}$ & Wang et al., 2021 \\
\hline EESI-MS & Cold stress & Du S. et al., 2020 \\
\hline $\begin{array}{l}\text { 2D Nano LC } \\
\text { MS-MS, 2-DE, } \\
\text { In-gel digestion and } \\
\text { MALDI-TOF MS }\end{array}$ & $\begin{array}{l}\text { accumulation of photosynthesis } \\
\text { and defense associated proteins by } \\
\text { Pseudomonas fluorescens and } \\
\text { Sinorhizobium meliloti }\end{array}$ & $\begin{array}{l}\text { Kandasamy et al., } \\
\text { 2009; Chi et al., } 2010\end{array}$ \\
\hline $\begin{array}{l}\text { UHPLC- } \\
\text { DAD/ESIQTOF }\end{array}$ & $\begin{array}{l}\text { metabolomics signatures such as } \\
\text { decreased alkylresorcinol quantities } \\
\text { and the differential induction of } \\
\mathrm{N} \text {-p-coumaroylputrescine and } \\
\mathrm{N} \text {-feruloylputrescine (antimicrobial } \\
\text { compounds) }\end{array}$ & Valette et al., 2020 \\
\hline HPLC & exudation of salicylic acid & $\begin{array}{l}\text { Kandaswamy et al., } \\
2019\end{array}$ \\
\hline LC-MS/MS & $\begin{array}{l}\text { Pseudomonas aeruginosa is linked } \\
\text { with the synthesis of SAR related } \\
\text { compounds such as siderophores } \\
\text { and antibacterial compounds }\end{array}$ & Yasmin et al., 2017 \\
\hline iTRAQ & $\begin{array}{l}\text { regulatory response to } M \text {. oryzae in } \\
\text { durable resistant vs. susceptible } \\
\text { rice genotypes }\end{array}$ & Ma Z. et al., 2020 \\
\hline QTOF-UPHPLC & $\begin{array}{l}\text { Bayogenin 3-O-cellobioside confers } \\
\text { non-cultivar-specific defense } \\
\text { against Pyricularia oryzae }\end{array}$ & $\begin{array}{l}\text { Norvienyeku et al., } \\
2021\end{array}$ \\
\hline $\begin{array}{l}\text { 2-DE and MALDI- } \\
\text { TOF-MS-MS }\end{array}$ & $\begin{array}{l}\text { accumulation of novel proteins } \\
\text { potentially involved in defense } \\
\text { against Rhizoctonia solani }\end{array}$ & Karmakar et al., 2019 \\
\hline iTRAQ & $\begin{array}{l}\text { rice immunity to infection by } \\
R \text {. solani }\end{array}$ & Ma H. et al., 2020 \\
\hline $\begin{array}{l}\text { Tandem mass } \\
\text { tagging with } \\
\text { LC-MS/MS }\end{array}$ & $\begin{array}{l}\text { interaction between rice and } \\
X . \text { oryzae }\end{array}$ & Zhang F. et al., 2020 \\
\hline iTRAQ & $\begin{array}{l}\text { defense response to } M \text {. oryzae in } \\
\text { rice with blast resistance gene Piz-t }\end{array}$ & Tian et al., 2018 \\
\hline
\end{tabular}

phosphoglycerate mutase (BPM), glutelin (GLU2.2 and GLU2.3), glucose-1-phosphate adenylyltransferase large subunit (GAS8), and cupin domain-containing protein (CDP3.1 and CDP3.2) were close to QTLs for seed dormancy, seed reserve utilization, and seed germination. Interestingly, CDP3.1 co-localized with $q I R-3$ for imbibition rate. The study further established the function of CDP3.1 in regulating seed germination upon salinity stress (Xu et al., 2017). Later, iTRAQ was deployed to analyze the disparities in the proteome of salt-sensitive (IR64) and salttolerant (Pokkali) seedlings upon salt exposure (Lakra et al., 2019). Significantly higher levels of proteins implicated in photosynthesis (oxygen evolving enhancer proteins OEE1 and OEE3, PsbP) and stress tolerance (ascorbate peroxidase, SOD, peptidyl-prolyl cis-trans isomerases, and glyoxalase II) were found in the shoots of Pokkali. Upon salinity exposure, ribulose bisphosphate carboxylase/oxygenase activase and glutamate dehydrogenase were found to be highly induced in Pokkali (Lakra et al., 2019). Further, Li et al. (2020) performed a shotgun proteomic analysis of germinated rice under salinity conditions. Seven Thai rice cultivars (Pathumthani, Phitsanulok2, RD31salt tolerant cultivars; RD29, RD41, Riceberry- moderately salt tolerant cultivars; and RD47- salt susceptible cultivar) were germinated under $200 \mathrm{~mm} \mathrm{NaCl}$ for $96 \mathrm{~h}$. Shotgun proteome analysis from all the seven cultivars identified 1339 proteins. A total of 51 proteins (involved in protein modification, signal transduction, stress response, transport, and transcription) were exclusively expressed only in salt tolerant cultivars ( $\mathrm{Li}$ et al., 2020). Shotgun proteome analysis was also done on rice anthers from a cold-tolerant variety, Dianxi 4 . Normal anthers and cold exposed anthers at the young microspore stage were compared for protein expression. A total of 3835 non-redundant proteins were detected, of which 441 proteins were expressed differentially. The study identified C2 domain proteins, and GRPs as promising signaling factors for cold tolerance response (Lee et al., 2017). A more holistic proteomic study on rice seedlings subjected to cold stress was performed using 2-DE and MALDI-TOF-MS on cold sensitive line 9311 and cold tolerant variety Fujisaka 5. In total, 59 proteins associated with cold resistance were observed in this study (Ji et al., 2017). Moreover, cold-sensitive cultivar 9311 and cold-resistant hybrid wild rice DC907 with a 9311 genetic background were utilized to perform quantitative proteomic analysis with tandem mass tags. In DC907, 366 distinct proteins were identified which were primarily implicated in ATP synthesis, photosystem, reactive oxygen species (ROS), stress response, cell growth, and integrity (Wang J. et al., 2018).

Nuclear magnetic resonance analysis was used to evaluate the metabolomic changes in watered and drought-exposed transgenic rice grains. A demarcating metabolic profile was observed under different watering conditions in transgenic and wild-type rice grains. Upon drought exposure, significantly elevated levels of GABA (244.6\%), fructose (155.7\%), glucose (211.0\%), glycerol (57.2\%), glycine (65.8\%), and aminoethanol (192.4\%) were found in the transgenics (Nam et al., 2016). GABA is one of the pivotal metabolites often linked to abiotic stresses in rice. It is known to induce oxidative injuries in rice arising due to various stresses such as osmotic, salinity, or senescence (Ansari et al., 2005; Sheteiwy et al., 2019). The role of GABA in stress regulation has been recently reviewed extensively (Ansari et al., 2021; Khan et al., 2021). Similar to the NMR-based approach, a GC-MS-based metabolomics approach was deployed to study the metabolite profile of rice cultivars at different developmental stages under drought and heat conditions. More than $50 \%$ of identified metabolites were different in two of the three cultivars (Anjali, Dular, and N22). The drought, heat, and combined drought and heat susceptibleAnjali; the drought, heat, and combined drought and heat tolerant- N22; the drought tolerant, heat and combined drought and heat susceptible-Dular were analyzed for drought and heat responses (Lawas et al., 2019). A GC-MS metabolomic approach along with transcriptome analysis was also used to study the key metabolic pathways associated with photosynthesis upon drought exposure. The study was designed on drought-sensitive cultivar IRAT109 and the drought-tolerant cultivar IAC1246 to determine the transcript and metabolic responses upon longterm drought exposure (Ma et al., 2016). For recent metabolic studies encircling salt stress in rice, GC-MS was utilized to profile metabolites in five rice varieties with a comparable genetic 
background and varying growth performances under salt stress. The study showed enriched levels of amino acids in salt-tolerant lines (G58, G1710, and IR64) in comparison to salt sensitive lines (G45 and G52) under non-stress conditions. In all five varieties, the levels of Sorbitol, melezitose, and pipecolic acid were enhanced significantly upon salinity stress. This probably indicated that these compounds might be responsible to regulate salt stress responses in rice. Moreover, the sensitive varieties experienced more noticeable enhancement in metabolites levels during early stress treatment in comparison to the tolerant varieties (Xie et al., 2020). An analogous study by Gupta and De (2017) revealed similar results upon salt stress in rice. The study employed GC-MS for assessing the metabolic profile; and found serotonin and gentisic acid as the key metabolites (Gupta and De, 2017). In yet another study, metabolomics (GCTOF-MS) and transcriptomics (RNA-seq) were jointly utilized to decipher pathways, metabolites, and metabolic hotspots in rice upon salinity stress (Wanichthanarak et al., 2020). A very recent report also combined metabolomic (LC-MS-MS) and transcriptomic (RNA-seq) approaches to study the rice metabolic network underlying OsDRAP1-mediated salt tolerance (Wang et al., 2021). Over-expressing OsDRAP1 results in differential expression of intrinsic salt tolerance genes. Moreso, proline, valine glyceric acid, phosphoenolpyruvic acid, and ascorbic acid accumulated at higher concentrations in the over-expressing lines, depictive of their role in salinity tolerance. Much alike drought and salt stress, the implementation of metabolomics is also extended to cold stress (Zhao et al., 2013). A recent study in this context involves electrospray ionization mass spectrometry (EESI-MS) to profile the metabolic changes of Qiutianxiaoting (chilling-tolerant variety) and 93-11 (chillingsusceptible variety) under low-temperature stress (Du S. et al., 2020). The study revealed that phenylpropanoid biosynthesis, flavone, and flavonol biosynthesis pathways were activated in 93-11 upon low-temperature exposures. In Qiutianxiaoting, lowtemperature exposures activated methyl jasmonate biosynthesisassociated genes, which probably mitigated the chilling damage making it the more tolerant cultivar (Du S. et al., 2020).

\section{Biotic Stress}

Metabolomics and proteomics of rice biotic stress at their homeostasis or adverse environmental condition is used to extract system information. The underpinning mechanisms of biotic stress responses in rice are well elucidated by targeted biochemical, metabolic, and proteomic analysis of host-pathogen interactions (Ahuja et al., 2012; Liu Y. et al., 2019; Vo et al., 2021). In view of this several relevant studies have been made. Plant growth-promoting rhizobacteria (PGPR) aids plants in nutrient uptake and phytohormone synthesis. Early studies involving proteomics revealed photosynthesis and defense associated proteins accumulation by Pseudomonas fluorescens and Sinorhizobium meliloti (Kandasamy et al., 2009; Chi et al., 2010). Similarly, an early metabolomics study encircling PGPR was performed on two rice varieties infested with Azospirillum lipoferum 4B and Azospirillum sp. B510 (rice-associated Azospirillum species). The study found alterations in flavonoids and hydroxycinnamic derivatives which were predominantly dependent on the cultivar-PGPR strain interaction (Chamam et al., 2013). Moreover, 10 different PGPR strains inoculation of Nipponbare resulted in metabolomics signatures such as decreased alkylresorcinol [5-tridecyl resorcinol, 5-pentadecyl resorcinol, 5 (12-heptadecyl) resorcinol] quantities and the differential induction of $\mathrm{N}$-p-coumaroylputrescine and $\mathrm{N}$-feruloylputrescine (antimicrobial compounds) (Valette et al., 2020). Additionally, Pseudomonas is a known PGPR that acts as a bioagent to combat rice diseases. HPLC of rice roots infested by Pseudomonas putida revealed enrichment of salicylic acid (Kandaswamy et al., 2019). Likewise, Pseudomonas aeruginosa is linked with the synthesis of systemic acquired resistance (SAR) related compounds such as siderophores (1-hydroxy-phenazine, pyocyanin, and pyochellin) and antibacterial compounds (4-hydroxy-2-alkylquinolines and rhamnolipids) (Yasmin et al., 2017). The recent proteomics and metabolomics researches encircling rice response to disease causing pathogens have been intensively reviewed (Azizi et al., 2019; Meng et al., 2019). Metabolomics mostly highlighted the disparities of necrotrophic and biotrophic stages which included the accretion of metabolic photosynthetic compounds at biotrophic stage or phenolic compounds at necrotrophic stage (for review, see Azizi et al., 2019). A neoteric study for rice blast iTRAQ revealed that the pathogen-associated molecular pattern (PAMP)-triggered immunity might be induced at the transcriptome level but was suppressed at the protein level in susceptible rice varieties (Ma Z. et al., 2020). The study also revealed that probenazole-inducible protein 1 (PBZ1) and phenylpropanoid accumulated in both resistant and susceptible cultivars (Ma Z. et al., 2020). Intriguingly, a QTOF-UPHPLC based metabolomic study found a saponin, Bayogenin 3-O-cellobioside as a novel saponin identified in rice (Norvienyeku et al., 2021). Consequently, Bayogenin 3O-cellobioside is well related with rice blast resistance against Pyricularia oryzae.

Sheath blight in rice is triggered by a necrotrophic fungusRhizoctonia solani, which is linked with cell death at the early stages of infection. Photosynthesis and sugar metabolism alters drastically upon Rhizoctonia solani infection (Lee et al., 2006). Further, two other metabolomic reports revealed the elevated levels of glycolysis and TCA cycle compounds (succinate, pyruvate, and aconitate), reduced levels of sugar (sucrose, glucose, fructose, glucosone, turanose, galactose, hexopyranose, maltose, and glucopyranose), accumulation of ROS, salicylic acid, jasmonic acid, aromatic aliphatic amino acids, phenylpropanoids, and suppression of myo-inositol (Suharti et al., 2016; Ghosh et al., 2017). Additionally, Karmakar et al. (2019) performed 2-DE and MALDI-TOF-MS-MS on control and AtNPR1-transgenics before and after R. solani infestation to study the proteome and metabolome profiles (Karmakar et al., 2019). Mitogen-activated protein kinase 6, probable protein phosphatase $2 \mathrm{C} 1$, probable trehalose-phosphate phosphatase 2 , and heat shock protein were primarily recognized as the main compounds related to $R$. solani infection in rice. Moreover, the iTRAQ technique highlighted the difference in ROS modulation between the tolerant and susceptible varieties (Ma H. et al., 2020). The proteins were implicated in 


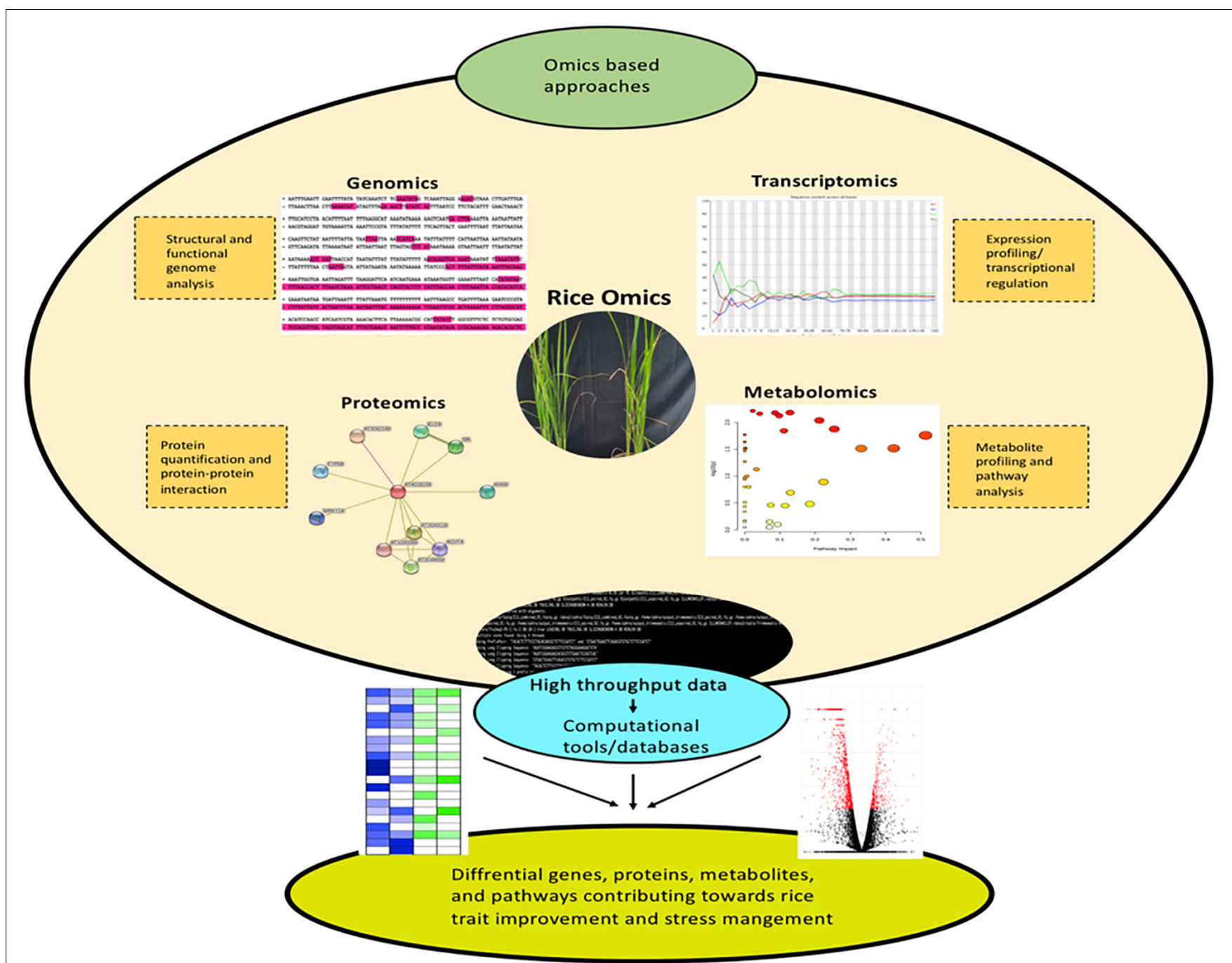

FIGURE 2 | Overview of omics techniques with respective databases and tools in rice trait improvement and stress management. Databases and tools used include: genomics-PlantCARE, transcriptomics-FASTQC, proteomics-STRING, metabolomics-MetaboAnalyst 5.0. For volcano plot R was used, while MAPMAN was used to generate the heatmap.

the regulation of glyoxylate and dicarboxylate metabolism, glycine, serine, and threonine metabolism, unsaturated fatty acid biosynthesis, and glycolysis/gluconeogenesis pathways. Several studies have investigated the differences in rice proteomes after challenging two major rice pathogens; $M$. oryzae, Xanthomonas oryzae, and/or their elicitors (Jha et al., 2007; Pandey and Sonti, 2010; Wu et al., 2016; Meng et al., 2019). For example, iTRAQ analysis was performed to study rice blast using Piz- $t$ transgenic lines (Piz- $t$; rice blast $R$ gene). Comparative proteome profiling on the Piz-t transgenic Nipponbare line (NPB-Piz-t) and wild-type Nipponbare (NPB) revealed differentially expressed proteins related to defense, stress, hormone, pathogenesis, and cytochrome P450 (Tian et al., 2018). Similarly, comparative proteomic profiling highlighted novel insights into the interaction between rice and X. oryzae (Zhang F. et al., 2020). The above examples constitute a few of the contemporary developments made by proteomics and metabolomics in response to abiotic/biotic stresses (Table 3).

\section{DATABASES FOR RICE OMICS RESEARCH}

The omics data sources include whole-genome sequencing data, RNA-sequencing data, protein-protein interaction data, and whole metabolome analysis data. Systematic accessibility, retrieval, and storage of omics data is the fundamental prerequisite for rice research. Omics-based research generates massive volumes of data that coincides with bioinformatics for meaningful processing of biological information. Accordingly, the subject of prime importance in molecular biology is how proficiently large volumes of data can be processed to retrieve meaningful information. This underlines the extreme 
need for molecular biology databases. Omics-based databases are not just the assembly of data in a system, but a platform from which information can be searched easily and quickly. Efficient molecular biology databases usually have the following functionality. First, data is linked to other meaningful information. For instance, sequence information linked to genetic resources can assist in genome-wide studies. Second, the search is intuitive and is key-word based. Third, large volumes of data can be downloaded easily without errors. Apart from the above features, open access is also an important requirement. Open access helps the users to browse and download the same data multiple times without any charges. Thus, data download, upload, and accessibility are essential for biological databases.

\section{Genomics and Transcriptomics Bioinformatics Tools and Databases}

The availability of rice genome sequencing data from several species and cultivars has led to enormous research encircling the biological diversity of rice (Li J.Y. et al., 2014). Many tools and databases are established over the years to store, retrieve, and interpret big omics data. Extensive genome databases have been developed since the establishment of the Rice Genome Annotation Project (RGAP) (Ouyang et al., 2007) and Rice Annotation Project Database (Ohyanagi et al., 2006; Sakai et al., 2013). The functional genomics of rice is often studied with the OryGenesDB (Droc et al., 2006) and rice functional genomics express database (RiceGE). Both these databases utilize flanking sequence tag (FST) information for genome interpretation. Similarly, the RiceGE database provides relevant information on mutants. To gain access to genome data for various cultivars, the ricepan-genome browser (RPAN) (Sun et al., 2017) and Rice Information Gateway (RIGW) (Song J.M. et al., 2018) are prevalently used. Additionally, the Information Commons for Rice (IC4) database provides data regarding sequence variation and transcriptome profiles. For GWAS studies, HapRice- an SNP haplotype database (Yonemaru et al., 2014) and Ricebasegenome information platform for molecular markers such as SSRs (Edwards et al., 2016) are routinely deployed by bioinformaticians. Few other databases for SNP searches include OryzaGenome v2 (Ohyanagi et al., 2016), RiceVarMap (Zhao et al., 2015), and the SNP-Seek database (Alexandrov et al., 2015). GWAS data is often converted into a high-density rice array (HDRA) to cover 39,045 non-transposable elements in rice (McCouch et al., 2016). A Manhattan plot for the HDRA data is generated by GWAS viewer. This kind of analysis generally requires programming skills. However, graphic user interface (GUI) interface platforms such as Intelligent Prediction and Association Tool (iPat) (Chen and Zhang, 2018) and the rice imputation server (Wang D.R. et al., 2018) are also available for GWAS studies.

In the past few years, transcript-assembly algorithms have revolutionized the arena of rice transcriptomic research. Generally, the databases dedicated to transcriptome provides information regarding genome-wide expression profiles. An extremely important database in this context is OryzaExpress (Hamada et al., 2011). This database contains expression data from 1206 samples of 34 experimental series of GPL6864 (Agilent $4 \times 44 \mathrm{~K}$ microarray platform) and 2678 samples of 153 experimental series of GPL2025 (Affymetrix Rice Genome Array platform). In addition, Rice Oligonucleotide Array Database (ROAD) contains 1867 publicly available rice microarray data (Cao et al., 2012). Another database named Collections of Rice Expression Profiling database (CREP) provides access to data from 190 Affymetrix GeneChip Rice Genome Arrays from 39 tissues (Wang et al., 2010). The information regarding rice field/development, plant hormone, and cell/tissue type can be retrieved from the RiceXpro database (Sato et al., 2013a,b). Additionally, the uniformed viewer for integrated omics (UniVIO) database can be utilized to analyze 43 hormonerelated compounds (Kudo et al., 2013). For biotic stressrelated studies in rice, the plant expression database (PlexDB) (Dash et al., 2012) and EXPath database (Chien et al., 2015) are commonly used. Likewise, EXPath provides tissue/organ specific expression, gene ontology (GO), and Kyoto Encyclopedia of Genes and Genomes (KEGG) pathway analysis for six model crops, including rice. The Rice eFP browser (Winter et al., 2007) intuitively displays expression values using color gradients. Large volumes of rice mRNA sequencing data in different conditions is also accessible via the Transcriptome Encyclopedia of Rice database (Kawahara et al., 2016). Moreso, the Rice Expression Database (RED) is a reservoir of gene expression profiles from different rice tissues under varying environmental conditions (Xia et al., 2017). Together with RED, Expression Atlas is often used to access the gene expression profiles from recent researches (Papatheodorou et al., 2018). Genevestigator is yet another database that allows curation, visualization, and analysis of microarray or RNA sequencing data (Hruz et al., 2008). Nonetheless, large volumes of transcriptome data from different tissues or under different conditions also allow co-expression analysis. PlantArrayNet (Lee et al., 2009), the plant co-expression database (Yim et al., 2013), and the CoP database (Ogata et al., 2010) are useful for rice coexpression studies. These web-based tools use a standard pipeline to offer useful knowledge about the genes co-expressed with a gene of interest. Apart from these tools, the ATTED-II database provides co-regulated gene relationships to deduce gene functions (Obayashi et al., 2018). Additionally, NetMiner is a standalone tool for exploratory analysis and visualization of network data (Yu et al., 2018). The transcriptome analysis is frequently coupled with promoter analysis for identifying the cis-regulatory elements. The representative databases to study the motif organization include plant cis-acting regulatory DNA elements (PLACE) (Higo et al., 1999), plant cis-acting regulatory elements (PlantCARE) (Lescot et al., 2002), plant promoter database (PPDB) (Yamamoto and Obokata, 2007), and plant promoter analysis navigator (PlantPAN) (Chow et al., 2016). A rice-specific promoter analysis database is the Osiris database (Morris et al., 2008). It is a repository for promoter sequences and probable TF binding sites for 24,209 rice genes. Although it has now become obsolete. However, the MEME suite (Bailey et al., 2009) is now generally the choice of researchers for performing web-based motif identification. Further, several databases have been developed lately to dissect 
the gene expression patterns regulated by non-coding RNA (ncRNA). The pyrosequencing generated small-RNA sequences for rice and maize are routinely accessed via the Cereal Small RNA Database (Johnson et al., 2007). For miRNA-based studies, plant non-coding RNA database (PNRD) (Yi et al., 2015) and miRBase (Kozomara et al., 2019) are dedicated data resources. PNRD stores data from 166 plant species to generate valuable information regarding miRNAs, intronic long ncRNAs (lncRNA), and unknown ncRNAs. Likewise, the miRbase contains miRNAs information from 271 organisms. The rice miRNA information can be accessed on miRbase with a file named osa.gff3. On similar lines, annotations of 287 eukaryotic lncRNAs are provided by the Long Non-coding RNA database (lncrnadb) (Quek et al., 2015). The data for multiple miRNA variants from eight species, including rice is provided by IsomiR bank database (Zhang et al., 2016). Moreover, the plant ceRNA database (PceRBase) (Yuan et al., 2017) and plant circular RNA database (PlantcircBase) (Chu et al., 2017) cover information regarding competing endogenous RNA (ceRNA) and circular RNA (circRNA) respectively.

\section{Proteomics and Metabolomics Bioinformatics Tools and Databases}

In context to systems biology, protein-protein interactions are pivotal to large complex networks (Rao et al., 2014). Several interactome datasets have been hosted to study the proteinprotein interactions in rice. Such resources are distinct in relation to number of interactions, source of the embedded interactome, and accessible organisms. One of the methods for envisaging protein-protein interactions is the interolog approach. According to interolog approach, the function of a protein is conserved and passed through its orthologs in evolutionaryrelated species. Thus, the orthologs of interacting proteins in one organism conserve their interactions in a different organism. Based on the interolog approach, 37112 interactions amongst 4567 proteins are summarized approach by the Rice Interactions Viewer (RIV) database. Amongst these interactions, 1671 are selfinteractions while 35441 are hetero-interactions (Ho et al., 2012). The predicted rice interactome network (PRIN) is yet another rice database that uses interolog approach (Gu et al., 2011). It annotates 76585 non-redundant rice protein interaction pairs amongst 5049 rice proteins. Meaningful interactions are validated by PRIN upon fetching the gene expression data, sub-cellular localization information, and GO annotation. Additionally, the database of interacting proteins in Oryza sativa (DIPOS) uses the interolog approach and domain-based predictions to depict the protein-protein interactions. This database hosts 14614067 pairwise interactions amongst 27746 proteins (Sapkota et al., 2011). Further to outspread the interactome, several approaches namely text-mining, neighborhood analysis, coexpression analysis, fusion analysis, and co-occurrence analysis are prevalently deployed (Szklarczyk et al., 2016). For extensive interactome coverage, the STRING database utilizes a broad range of sources available, from text-mining to computational predictions (Szklarczyk et al., 2016). STRING database provides both predicted and indirect interactions networks, where the nodes represent the proteins while the edges are the predicted functional association. The information for 2031 organisms is present on the STRING database. One of the latest versions of STRING (v10.5) supports network connections for 26428 japonica proteins and 18789 indica proteins. Interactions are based on combined scores which are calculated by combining the probabilities from different evidence channels. Moreso, protein-protein interactions are also deduced by the RiceNet database (Lee et al., 2015). This database offers gene prioritization based either on network direct neighborhood or contextassociated hubs.

Apart from protein-protein interaction databases, the resources that host annotated proteomes are also crucial for proteome-wide studies. The protein sequences and their corresponding annotations are frequently updated by the UniProt database. For rice, annotations of 48916 japonica proteins are hosted on UniProt (Bateman et al., 2015; Consortium, 2019). Additionally, OryzaPG-DB based on the short-gun proteogenomics concept is a proteogenomics database for the annotation of rice proteome. It provides peptide-based expression profiles with corresponding genomic origin along with the annotation of novelty for each peptide (Helmy et al., 2012). Manually Curated Database of Rice Proteins (MCDRP) digitizes protein-related experiments. The process of digitization has overcome the limitations associated with text-based curation. MCDRP is periodically updated and currently contains data for approximately 1800 rice proteins (Gour et al., 2014). To study protein functions based on their structures, the plant protein annotation suit database (Plant-PrAS) is used. Various physiochemical parameters, structural properties, novel functional regions, transmembrane helices, and signal peptides from the genomes of six model plants (including rice) are provided by Plant-PrAS (Kurotani et al., 2015).

Orthologous proteins provide valuable information about unannotated proteins. GreenPhyl DB v5 is a web-based tool for functional and comparative genomics for 27 reference genomes (including rice). It facilitates comparative analysis of species and protein domains. Metabolic pathway-related information can also be accessed via GreenPhyl DB. 44786 out of 60647 rice sequences present on GreenPhyl DB have an InterPro domain (Rouard et al., 2011). Another database that enables cross-species proteomic comparative analysis is the Putative Orthologous Groups 2 Database. This database supports three other species (Arabidopsis thaliana, Zea mays, and Populus trichocarpa) along with rice to integrate the data from predicted proteomes into putative orthologous groups. Interpro domain keyword or ID, gene model or transcript accessions, known or predicted intracellular location can be used to query the database. It provides information on probable protein localization, gene descriptions, and domain organizations (Tomcal et al., 2013). Similarly, the InParanoid database assesses the orthologs based on the InParanoid algorithm. For a specific protein, the orthologs can be searched by gene identifier, protein identifier, or by a blast search against InParanoid protein dataset (Sonnhammer and Östlund, 2015). Likewise, orthologous matrix (OMA) is a database to infer orthologs among complete genomes (Altenhoff et al., 2018). The PANTHER (Protein Analysis Through 
TABLE 4 | Omics tools and databases.

\begin{tabular}{|c|c|c|c|}
\hline Database name & Omics & Description & URL \\
\hline RiceGE & Genomics & It is a rice functional genomics express database & http://signal.salk.edu/cgi-bin/RiceGE \\
\hline $\begin{array}{l}\text { Oryza sativa genome } \\
\text { Database }\end{array}$ & Genomics & $\begin{array}{l}\text { It provides a sequence-centered genome view for Oryza sativa (ssp. } \\
\text { japonica), }\end{array}$ & http://www.plantgdb.org/OsGDB/ \\
\hline MSU-RGAP & Genomics & $\begin{array}{l}\text { It provides sequence and annotation data for the rice genome } \\
\text { (Nipponbare subspecies) }\end{array}$ & http://rice.uga.edu/ \\
\hline RAP-DB & Genomics & $\begin{array}{l}\text { It facilitates the analysis of genome structure and function of rice on the } \\
\text { basis of the annotation. }\end{array}$ & https://rapdb.dna.affrc.go.jp/ \\
\hline Gramene & $\begin{array}{l}\text { Comparative } \\
\text { Genomics }\end{array}$ & $\begin{array}{l}\text { It is an open-source data resource for comparative functional genomics } \\
\text { in crops and model plants }\end{array}$ & http://www.gramene.org/ \\
\hline Oryzabase & Genomics & $\begin{array}{l}\text { It is a comprehensive rice database providing information of classical } \\
\text { rice genetics to recent genomics }\end{array}$ & https://shigen.nig.ac.jp/rice/oryzabase/ \\
\hline OryGenesDB & Genomics & $\begin{array}{l}\text { It displays sequence information such as the T-DNA and Ds flanking } \\
\text { sequence tags (FSTs) }\end{array}$ & https://orygenesdb.cirad.fr/index.html \\
\hline $\begin{array}{l}\text { TIGR rice genome } \\
\text { annotation } \mathrm{DB}\end{array}$ & Genomics & $\begin{array}{l}\text { It is a group of databases for searching with the BLAST programs } \\
\text { blastn, blastx, tblastn, or tblastx. }\end{array}$ & $\begin{array}{l}\text { http://blast.jcvi.org/euk-blast/index.cgi? } \\
\text { project=osa1 }\end{array}$ \\
\hline MOsDB & Genomics & It is a resource for publicly available sequences of the rice & $\begin{array}{l}\text { https://pgsb.helmholtz-muenchen.de/plant/ } \\
\text { rice/index.jsp }\end{array}$ \\
\hline Rice mutant DB & Genomics & $\begin{array}{l}\text { It contains the information of approximate } 129,000 \text { rice T-DNA insertion } \\
\text { (enhancer trap) lines generated by an enhancer trap system. }\end{array}$ & http://rmd.ncpgr.cn/ \\
\hline $\begin{array}{l}\text { Information Commons for } \\
\text { Rice (IC4R) }\end{array}$ & Genomics & $\begin{array}{l}\text { It is a database contributing to rice genome sequences, updating rice } \\
\text { gene annotations and integrating multiple omics data }\end{array}$ & http://www.ic4r.org/ \\
\hline RiceVarMap & Genomics & It is a database for rice genomic variation and its functional annotation. & http://ricevarmap.ncpgr.cn/ \\
\hline RiceFrend & Genomics & It is a gene coexpression database in rice & https://ricefrend.dna.affrc.go.jp/ \\
\hline $\begin{array}{l}\text { Rice Transcription Factor } \\
\text { Phylogenomics DB }\end{array}$ & Genomics & $\begin{array}{l}\text { It combines various data types present in public databases encircling } \\
\text { the structural features, orthologous relationships, availability of mutants } \\
\text { and gene expression patterns for TF families }\end{array}$ & http://ricephylogenomics-khu.org/tf/home.php \\
\hline Rice transporter database & Genomics & It contains information for all putative rice transporters & $\begin{array}{l}\text { https://ricephylogenomics.ucdavis.edu/ } \\
\text { transporter/genlnfo.shtml }\end{array}$ \\
\hline $\begin{array}{l}\text { The Rice Information } \\
\text { GateWay (RIGW) }\end{array}$ & Genomics & $\begin{array}{l}\text { It provides the sequenced genomes and related information in } \\
\text { systematic and graphical ways }\end{array}$ & https://rice.hzau.edu.cn/rice_rs3/ \\
\hline Rice Pan-genome Browser & Genomics & $\begin{array}{l}\text { It provides sequences and gene annotations for the rice pan-genome } \\
\text { and Gene presence-absence variations (PAVs) of rice accessions }\end{array}$ & https://cgm.sjtu.edu.cn/3kricedb/ \\
\hline SNP-Seek & Genomics & Provides information related to rice SNPs & https://snp-seek.irri.org/ \\
\hline Ricebase & Genomics & $\begin{array}{l}\text { It is a rice breeding and genetics platform integrating molecular } \\
\text { markers, pedigrees, and whole-genome data }\end{array}$ & https://www.ricebase.org/ \\
\hline Rice imputation server & Genomics & $\begin{array}{l}\text { It utilizes genetically and geographically diverse accessions to impute } \\
\text { rice datasets out to 5.2M SNPs using the IMPUTE2 software. }\end{array}$ & http://rice-impute.biotech.cornell.edu/ \\
\hline Ensemble_rice & $\begin{array}{l}\text { Comparative } \\
\text { Genomics }\end{array}$ & $\begin{array}{l}\text { It is used for genome assembly, comparative genomics, and gene } \\
\text { annotation }\end{array}$ & $\begin{array}{l}\text { http: } \\
\text { //plants.ensembl.org/Oryza_sativa/Info/Index }\end{array}$ \\
\hline $\begin{array}{l}\text { Rice Diversity: GWAS } \\
\text { Viewer }\end{array}$ & Genomics & Comprehensively view GWAS data & $\begin{array}{l}\text { http://rs-bt-mccouch4.biotech.cornell.edu/ } \\
\text { GWAS_Viewer/plot/ }\end{array}$ \\
\hline PLAZA & $\begin{array}{l}\text { Comparative } \\
\text { Genomics }\end{array}$ & $\begin{array}{l}\text { It is an access point for plant comparative genomics centralizing } \\
\text { genomic data produced by different genome sequencing programs. }\end{array}$ & $\begin{array}{l}\text { https://bioinformatics.psb.ugent.be/plaza/ } \\
\text { versions/plaza_v4_monocots/ }\end{array}$ \\
\hline PlantGDB & $\begin{array}{l}\text { Comparative } \\
\text { Genomics }\end{array}$ & It is used for sequence assemblies and annotation & http://www.plantgdb.org/ \\
\hline Phytozome & $\begin{array}{l}\text { Comparative } \\
\text { Genomics }\end{array}$ & $\begin{array}{l}\text { It is used for accessing, visualizing and analyzing sequenced plant } \\
\text { genomes, as well as selected genomes and datasets }\end{array}$ & https://phytozome.jgi.doe.gov/pz/portal.html \\
\hline ROAD & Genomics & It is a rice oligonucleotide array database & $\begin{array}{l}\text { http: } \\
\text { //ricephylogenomics-khu.org/road/home.php }\end{array}$ \\
\hline FIT-DB & Transcriptomics & $\begin{array}{l}\text { It provides result of statistical modeling of transcriptomic dynamics in } \\
\text { the field condition }\end{array}$ & https://fitdb.dna.affrc.go.jp/ \\
\hline EXPath 2.0 & Transcriptomics & $\begin{array}{l}\text { It is a database that collects and uses expression profiles derived from } \\
\text { microarray under various conditions to infer metabolic pathways }\end{array}$ & http://expath.itps.ncku.edu.tw/ \\
\hline Rice eFP & Transcriptomics & One of the major functions of Rice eFP is gene expression analysis & $\begin{array}{l}\text { http: } \\
\text { //bar.utoronto.ca/efprice/cgi-bin/efpWeb.cgi }\end{array}$ \\
\hline RiceXPro & Transcriptomics & $\begin{array}{l}\text { It is a repository of gene expression profiles derived from microarray } \\
\text { analysis of tissues/organs }\end{array}$ & https://ricexpro.dna.affrc.go.jp/ \\
\hline
\end{tabular}


TABLE 4 | (Continued)

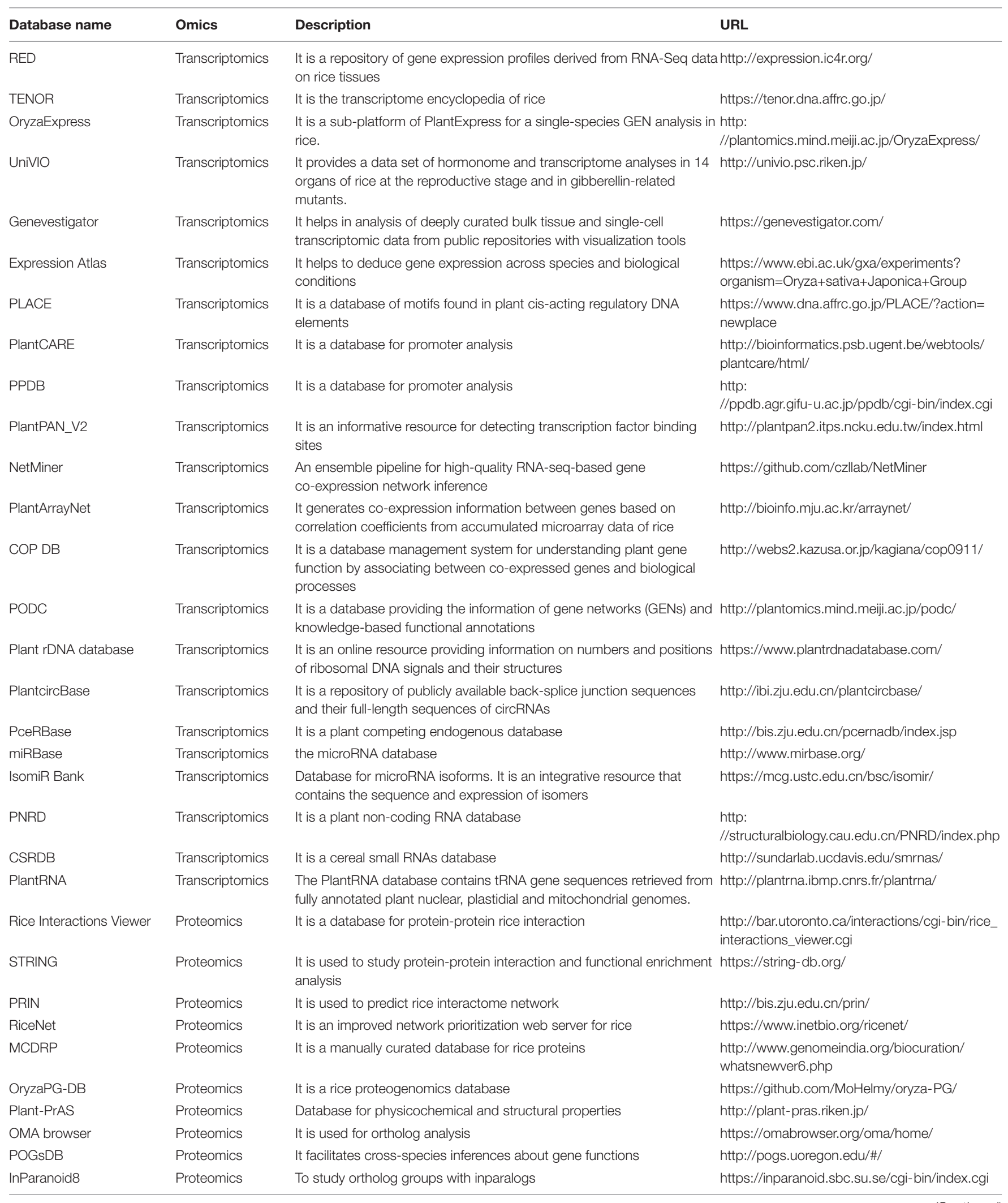


TABLE 4 | (Continued)

\begin{tabular}{|c|c|c|c|}
\hline Database name & Omics & Description & URL \\
\hline GreenPhyl v4 & Proteomics & It is a database for species, genomes and pan-genomes & https://www.greenphyl.org/cgi-bin/index.cgi \\
\hline Panther & Proteomics & $\begin{array}{l}\text { It is used to perform Protein ANalysis THrough Evolutionary } \\
\text { Relationships }\end{array}$ & http://www.pantherdb.org/ \\
\hline PhosphoRice & Proteomics & It is a meta-predictor of rice-specific phosphorylation site & https://github.com/PEHGP/PhosphoRice \\
\hline MassBank & Metabolomics & Metabolite annotation and MS-MS database & https://massbank.eu/MassBank/ \\
\hline METLIN & Metabolomics & $\begin{array}{l}\text { It is a collection of MS/MS data and incorporates the NIST MS/MS } \\
\text { library and search software }\end{array}$ & $\begin{array}{l}\text { https://www.sisweb.com/software/ms/wiley- } \\
\text { metlin.htm }\end{array}$ \\
\hline KNApSAcK & Metabolomics & Comprehensive Species Metabolite Relationship Database & http://www.knapsackfamily.com/KNApSAcK/ \\
\hline MetaboLights & Metabolomics & It is a database for metabolomics experiments and derived information & https://www.ebi.ac.uk/metabolights/ \\
\hline Plant Reactome & Metabolomics & Used to find reactions and pathways & $\begin{array}{l}\text { https://plantreactome.gramene.org/index.php? } \\
\text { lang=en }\end{array}$ \\
\hline OryzaCYC & Metabolomics & To study plant metabolic network & https://plantcyc.org/databases/oryzacyc/6.0 \\
\hline KEGG_rice & Metabolomics & To decipher pathway maps & $\begin{array}{l}\text { https: } \\
\text { //www.genome.jp/kegg-bin/show_organism? } \\
\text { menu_type=pathway_maps\&org=dosa }\end{array}$ \\
\hline RICECYC & Metabolomics & $\begin{array}{l}\text { It is a catalog of known and/or predicted biochemical pathways from } \\
\text { rice }\end{array}$ & $\begin{array}{l}\text { http: } \\
\text { //pathway.gramene.org/gramene/ricecyc.shtml }\end{array}$ \\
\hline MapMan & Metabolomics & It is used in pathway analysis & https://mapman.gabipd.org/home \\
\hline Plant GSEA & Metabolomics & It is used for gene set enrichment analysis & $\begin{array}{l}\text { http://structuralbiology.cau.edu.cn/PlantGSEA } \\
\text { index.php }\end{array}$ \\
\hline AgriGo & Metabolomics & It is an ontology analysis tool & http://bioinfo.cau.edu.cn/agriGO/ \\
\hline KEGG Mapper & Metabolomics & It is a tool for KEGG pathway mapping & https://www.genome.jp/kegg/mapper.html \\
\hline MetaboAnalyst 5.0 & Metabolomics & $\begin{array}{l}\text { It is a comprehensive platform dedicated for metabolomics data } \\
\text { analysis }\end{array}$ & https://www.metaboanalyst.ca/ \\
\hline
\end{tabular}

Evolutionary Relationships) tool allows the classification of proteins (and their corresponding genes) to facilitate highthroughput analysis. This tool classifies proteins according to family/sub-family, molecular function, biological process, or pathway (Thomas et al., 2003; Mi et al., 2012). Finally, PANTHER uses the library of trees to predict the orthologs. Moreover, an online orthology analysis and annotation visualization tool- plant orthology browser (POB) allows interactive pairwise comparison and visualization of genomic traits via gene orthology. It currently hosts 20 genomes, and syntenic blocks are recognized for a pair of genomes using strand orientation and physical mapping (Tulpan and Leger, 2017).

Plants produce numerous metabolic compounds to sustain growth under normal or adverse conditions. In this direction, databases that support rice metabolome studies accelerate functional genomics research. The online platform MetaboLights hosts curated metabolite information. It offers a single access point for a number of metabolomic studies. This is a cross-species, cross-technique analysis which covers metabolite structures and their reference spectra (Haug et al., 2013). For cross-species comparative analysis, the plant metabolic network (PMN) database contains data from 22 species. It contains information related to genes, enzymes, compounds, reactions, and pathways involved in primary and secondary metabolism in plants (Schläpfer et al., 2017). The PMN hosts one multispecies reference database-PlantCyc and 126 species/taxonspecific databases. The rice metabolic database of $\mathrm{PMN}$ is called OryzaCyc (V 6.0). The OryzaCyc (V 6.0) houses 569 pathways consisting of 3345 reactions and 2614 compounds for 6325 enzymes. In a similar vein, RiceCyc is a catalog of known and/or predicted biochemical pathways from rice. It is developed, maintained, and curated by the Gramene database (Jaiswal et al., 2006). Gramene is an integrated data resource for comparative functional genomics which hosts 93 reference genomes, including rice (Naithani et al., 2016; TelloRuiz et al., 2021). Gramene provides information on metabolic networks, transport, genetic, signaling, and developmental pathways. Recently, Plant Reactome which is a comparative plant pathway knowledgebase of the Gramene project has been updated (Naithani et al., 2020; Tello-Ruiz et al., 2021). It utilizes rice as a reference plant for manual curation of pathways and currently hosts 298 reference pathways, including metabolic, transcriptional, transports, hormone, and plant developmental pathways (Naithani et al., 2020). Kyoto Encyclopedia of Genes and Genomes (KEGG) is a platform for analyzing a broad range of high-throughput datasets, including metabolome data. It helps in deciphering high-level functions and utilities of the biological system. KEGG is frequently updated (last updated 2021) and four databases (pathways, genes, compounds, and enzymes) perform the major functionalities. Small molecules and metabolite-related information can be assessed from the KEGG compounds database (Kanehisa et al., 2017). Also, the KEGG mapper is used to map a set of genes, proteins, or small molecules on network databases viz., KEGG pathways and KEGG modules. The four KEGG mapping tools include reconstruct, search, color, and join. Further, the MAPMAN tool is generally used for enrichment analysis or pathway mapping in rice. The tool consists of a scavenger module, the 
ImageAnnotator module, and the PageMan module. Processed high-throughput datasets are fetched into the MAPMAN tool for visualizing the data (in the form of a heat map) in the context of metabolic pathways. Multiple testing correction using either benjamini hochberg, benjamini yekutieli or bonferroni is performed as a part of statistical analysis by MAPMAN (Usadel et al., 2009a,b). For GO analysis, agriGO is a popular web-based platform (Tian et al., 2017). It focuses on agricultural species and currently supports 394 species and 865 datatypes. It uses analysis tools namely Singular Enrichment Analysis (SEA), Parametric Analysis of Gene set Enrichment (PAGE), BLAST4ID (Transfer IDs by BLAST), and SEACOMPARE (Cross comparison of SEA). Custom analysis tools on agriGO include custom direct acyclic graph (DAG) tree and Scatter Plot (Tian et al., 2017). Nonetheless, it is challenging to increase the GO annotations and corresponding terms in constantly accruing datasets. Thus, the gene set enrichment analysis (GSEA) method was devised to overcome the issue of low coverage of GO-annotated genes. GSEA is a computational method that establishes the biological meaning of input genes. This is performed by measuring the overlap between an input gene list and a backend gene set. A GSEA server-PlantGSEA utilizes 20290 defined gene sets from varied resources. PlantGSEA enables the GSEA for rice and three other model plants using a unique ID (usually Affymetrix probe ID or gene locus ID) as input. The output provides enrichment analysis with statistical significance and better visualization (Yi et al., 2013). The previously discussed PANTHER tool also extends its functionality for GO analysis (Mi et al., 2017). Thus, omics tools and databases supplement in-depth rice research for a better understanding of underpinning molecular mechanisms (Figure 2). A summary of relevant omics tools and databases is provided in Table 4.

\section{CONCLUSION AND FUTURE PROSPECTS}

Improving rice productivity mainly depends upon functional characterization and analyses of genes that are vital to agronomic traits. In rice research, high-throughput technologies had been

\section{REFERENCES}

Agrawal, G. K., and Rakwal, R. (2011). Rice proteomics: a move toward expanded proteome coverage to comparative and functional proteomics uncovers the mysteries of rice and plant biology. Proteomics 11, 1630-1649. doi: 10.1002/ pmic. 201000696

Agrawal, G. K., Jwa, N. S., Lebrun, M. H., Job, D., and Rakwal, R. (2010). Plant secretome: unlocking secrets of the secreted proteins. Proteomics 10, 799-827.

Agrawal, G. K., Sarkar, A., Righetti, P. G., Pedreschi, R., Carpentier, S., Wang, T., et al. (2013). A decade of plant proteomics and mass spectrometry: translation of technical advancements to food security and safety issues. Mass Spectromet. Rev. 32, 335-365. doi: 10.1002/mas.21365

Ahuja, I., Kissen, R., and Bones, A. M. (2012). Phytoalexins in defense against pathogens. Trends Plant Sci. 17, 73-90.

Alam, R., Sazzadur Rahman, M., Seraj, Z. I., Thomson, M. J., Ismail, A. M., Tumimbang-Raiz, E., et al. (2011). Investigation of seedling-stage salinity tolerance QTLs using backcross lines derived from Oryza sativa L. Pokkali. Plant Breed. 130, 430-437. employed for several years to gain insights into the mechanistic details of molecular pathways. Genomics provides information regarding the most dominant or recessive genes in rice varieties, while transcriptomics aids in elucidating complex expression networks of RNA in rice that can be imperative to yield or stress responses. Similarly, proteomics leads to ascertaining major proteins contributing to rice improvement, while metabolomics provides crucial signatures of metabolites related to rice quality and yield enrichment. Bioinformatics databases assimilate the data from omics sciences to generate the complete set of information about the factors contributing to the enhancement of quality, quantity, or stress responses in rice. Thus, the omics generated datasets can expedite gene discoveries and functional characterizations in rice for crop improvement. Also, plant system biology has deepened the understanding of metabolism, stress responses, and integrative omics research. Moreover, the advent of CRISPR/Cas9 genome editing technology and its combination with omics studies has widened the horizons of rice research. Rice omics research is the new avenue that offers great potential. An integrative omics platform offering access to complete bioinformatics data will help researchers to implement new techniques in forward/reverse genetics and breeding programs. Taken together, omics-based rice research along with the cutting-edge technologies holds great potential for rice yield enhancement and stress management.

\section{AUTHOR CONTRIBUTIONS}

MIA conceptualized and designed the study. ZI, MSI, and MIRK compiled the data and wrote the manuscript. All authors have read the manuscript and agreed for publication.

\section{ACKNOWLEDGMENTS}

The authors acknowledge all the contributors in the field of omics and rice improvement. The authors also extend their sincere apologies to the contributors of any relevant research work not cited in the present article due to space limitations.

Alexandrov, N., Tai, S., Wang, W., Mansueto, L., Palis, K., Fuentes, R. R., et al. (2015). SNP-Seek database of SNPs derived from 3000 rice genomes. Nucleic Acids Res. 43, D1023-D1027. doi: 10.1093/nar/gku1039

Altenhoff, A. M., Glover, N. M., Train, C.-M., Kaleb, K., Warwick Vesztrocy, A., Dylus, D., et al. (2018). The OMA orthology database in 2018: retrieving evolutionary relationships among all domains of life through richer web and programmatic interfaces. Nucleic Acids Res. 46, D477-D485. doi: 10.1093/nar/ gkx1019

Amoah, N. K. A., Akromah, R., Kena, A. W., Manneh, B., Dieng, I., and Bimpong, I. K. (2020). Mapping QTLs for tolerance to salt stress at the early seedling stage in rice (Oryza sativa L.) using a newly identified donor 'Madina Koyo'. Euphytica 216, 1-23.

Anacleto, R., Badoni, S., Parween, S., Butardo, V. M. Jr., Misra, G., Cuevas, R. P., et al. (2019). Integrating a genome-wide association study with a large-scale transcriptome analysis to predict genetic regions influencing the glycaemic index and texture in rice. Plant Biotechnol. J. 17, 1261-1275. doi: 10.1111/pbi. 13051 
Ansari, M. I., Jalil, S. U., Ansari, S. A., and Hasanuzzaman, M. (2021). GABA shunt: a key-player in mitigation of ROS during stress. Plant Growth Regulat. 2021, $1-19$.

Ansari, M. I., Lee, R. H., and Chen, S. C. G. (2005). A novel senescenceassociated gene encoding $\gamma$-aminobutyric acid (GABA): pyruvate transaminase is upregulated during rice leaf senescence. Physiol. Plant. 123, 1-8.

Ashikari, M., Lin, S., Yamamoto, T., Takashi, T., Nishimura, A., Angeles, E., et al. (2007). "Isolation of a QTL gene controlling grain number and QTL pyramiding to combine loci for grain number and plant height in rice," in Rice Genetics $V$. World Sci. 2007, 169-175.

Ashikari, M., Sakakibara, H., Lin, S., Yamamoto, T., Takashi, T., Nishimura, A., et al. (2005). Cytokinin oxidase regulates rice grain production. Science 309, 741-745.

Azizi, P., Osman, M., Hanafi, M. M., Sahebi, M., Yusop, M. R., and Taheri, S. (2019). Adaptation of the metabolomics profile of rice after Pyricularia oryzae infection. Plant Physiol. Biochem. 144, 466-479. doi: 10.1016/j.plaphy.2019.10.014

Bailey, T. L., Boden, M., Buske, F. A., Frith, M., Grant, C. E., Clementi, L., et al. (2009). MEME SUITE: tools for motif discovery and searching. Nucleic Acids Res. 37, W202-W208.

Baldrich, P., and San Segundo, B. (2016). MicroRNAs in rice innate immunity. Rice 9, 1-9.

Bao, J. (2014). Genes and QTLs for rice grain quality improvement. London: IntechOpen, 239-278.

Bao, J., Lee, S., Chen, C., Zhang, X., Zhang, Y., Liu, S., et al. (2005). Serial analysis of gene expression study of a hybrid rice strain (LYP9) and its parental cultivars. Plant Physiol. 138, 1216-1231. doi: 10.1104/pp.105.06 0988

Baranski, M. (2013). Golden rice. Arizona,AZ: Embryo Project Encyclopedia.

Barrera-Figueroa, B. E., Gao, L., Wu, Z., Zhou, X., Zhu, J., Jin, H., et al. (2012). High throughput sequencing reveals novel and abiotic stress-regulated microRNAs in the inflorescences of rice. BMC Plant Biol. 12:1-11. doi: 10.1186/1471-2229$12-132$

Baslam, M., and Mitsui, T. (2020). "Proteomic for Quality: Mining the Proteome as a Strategy to Elucidate the Protein Complex Applied for Quality Improvement," in The Future of Rice Demand: Quality Beyond Productivity, eds A. C. de Oliveira, C. Pegoraro, and V. E. Viana (Berlin: Springer), 473-494.

Bateman, A., Martin, M., O'donovan, C., Magrane, M., Apweiler, R., Alpi, E., et al. (2015). 440 Bingley M, et al. UniProt: A hub for protein information. Nucleic Acids Res. 43, D204-D441. doi: 10.1093/nar/gku989

Bekele, W. A., Wieckhorst, S., Friedt, W., and Snowdon, R. J. (2013). Highthroughput genomics in sorghum: from whole-genome resequencing to a SNP screening array. Plant Biotechnol. J. 11, 1112-1125. doi: 10.1111/pbi.1 2106

Bernier, J., Kumar, A., Ramaiah, V., Spaner, D., and Atlin, G. (2007). A large-effect QTL for grain yield under reproductive-stage drought stress in upland rice. Crop Sci. 47, 507-516.

Bernier, J., Serraj, R., Kumar, A., Venuprasad, R., Impa, S., Rp, V. G., et al. (2009). The large-effect drought-resistance QTL qtl12. 1 increases water uptake in upland rice. Field Crops Res. 110, 139-146.

Bimpong, I. K., Manneh, B., Diop, B., Ghislain, K., Sow, A., Amoah, N. K. A., et al. (2014a). New quantitative trait loci for enhancing adaptation to salinity in rice from Hasawi, a Saudi landrace into three African cultivars at the reproductive stage. Euphytica 200, 45-60.

Bimpong, I. K., Manneh, B., El-Namaky, R., Diaw, F., Amoah, N. K. A., Sanneh, B., et al. (2014b). Mapping QTLs related to salt tolerance in rice at the young seedling stage using 384-plex single nucleotide polymorphism SNP, marker sets. Mol. Plant Breed. 5:009.

Bin Rahman, A. R., and Zhang, J. (2016). Flood and drought tolerance in rice: opposite but may coexist. Food Energy Secur. 5, 76-88.

Bizimana, J. B., Luzi-Kihupi, A., Murori, R. W., and Singh, R. (2017). Identification of quantitative trait loci for salinity tolerance in rice (Oryza sativa L.) using IR29/Hasawi mapping population. J. Genet. 96, 571-582. doi: 10.1007/s12041017-0803-x

Blumenberg, M. (ed.) (2019). "Introductory chapter: Transcriptome analysis," in Transcriptome Analysis, (London: IntechOpen).

Bonilla, P., Dvorak, J., Mackell, D., Deal, K., and Gregorio, G. (2002). RFLP and SSLP mapping of salinity tolerance genes in chromosome 1 of rice (Oryza sativa L.) using recombinant inbred lines. Philipp. Agricult. Sci. 65, 68-76.
Bradbury, L. M., Gillies, S. A., Brushett, D. J., Waters, D. L., and Henry, R. J. (2008). Inactivation of an aminoaldehyde dehydrogenase is responsible for fragrance in rice. Plant Mol. Biol. 68, 439-449. doi: 10.1007/s11103-008-9381-x

Calingacion, M., Boualaphanh, C., Daygon, V., Anacleto, R., Hamilton, R. S., Biais, B., et al. (2012). A genomics and multi-platform metabolomics approach to identify new traits of rice quality in traditional and improved varieties. Metabolomics 8, 771-783.

Campo, S., Peris-Peris, C., Siré, C., Moreno, A. B., Donaire, L., Zytnicki, M., et al. (2013). Identification of a novel micro RNA (mi RNA) from rice that targets an alternatively spliced transcript of the $\mathrm{N}$ ramp6 ( $\mathrm{N}$ atural resistance-associated macrophage protein 6) gene involved in pathogen resistance. N. Phytol. 199, 212-227. doi: 10.1111/nph.12292

Cao, P., Jung, K.-H., Choi, D., Hwang, D., Zhu, J., and Ronald, P. C. (2012). The Rice Oligonucleotide Array Database: an atlas of rice gene expression. Rice 5, 1-9. doi: 10.1186/1939-8433-5-17

Catolos, M., Sandhu, N., Dixit, S., Shamsudin, N. A., Naredo, M. E., Mcnally, K. L., et al. (2017). Genetic loci governing grain yield and root development under variable rice cultivation conditions. Front. Plant Sci. 8:1763. doi: 10.3389/fpls. 2017.01763

Chakraborty, K., Guru, A., Jena, P., Ray, S., Guhey, A., Chattopadhyay, K., et al. (2021). Rice with SUB1 QTL possesses greater initial leaf gas film thickness leading to delayed perception of submergence stress. Ann. Bot. 127, 251-265. doi: 10.1093/aob/mcaa171

Chamam, A., Sanguin, H., Bellvert, F., Meiffren, G., Comte, G., Wisniewski-Dyé, F., et al. (2013). Plant secondary metabolite profiling evidences strain-dependent effect in the Azospirillum-Oryza sativa association. Phytochemistry 87, 65-77. doi: 10.1016/j.phytochem.2012.11.009

Chang, Q.-L., Xu, H.-J., Peng, Y.-L., and Fan, J. (2019). Subtractive hybridizationassisted screening and characterization of genes involved in the riceMagnaporthe oryzae interaction. Phytopathol. Res. 1, 1-13.

Chen, C. J., and Zhang, Z. (2018). iPat: intelligent prediction and association tool for genomic research. Bioinformatics 34, 1925-1927. doi: 10.1093/ bioinformatics/bty015

Chen, C.-J., Liu, Q., Zhang, Y.-C., Qu, L.-H., Chen, Y.-Q., and Gautheret, D. (2011). Genome-wide discovery and analysis of microRNAs and other small RNAs from rice embryogenic callus. RNA Biol. 8, 538-547. doi: 10.4161/rna.8.3.15199

Chen, R., Zhao, X., Shao, Z., Wei, Z., Wang, Y., Zhu, L., et al. (2007). Rice UDPglucose pyrophosphorylase1 is essential for pollen callose deposition and its cosuppression results in a new type of thermosensitive genic male sterility. Plant Cell 19, 847-861. doi: 10.1105/tpc.106.044123

Chen, W., Gao, Y., Xie, W., Gong, L., Lu, K., Wang, W., et al. (2014). Genomewide association analyses provide genetic and biochemical insights into natural variation in rice metabolism. Nat. Genet. 46, 714-721. doi: 10.1038/ng.3007

Chen, X., Deng, Z., Yu, C., Yan, C., and Chen, J. (2016). Secretome analysis of rice suspension-cultured cells infected by Xanthomonas oryzae pv. oryza (Xoo). Proteome Sci. 14, 1-10.

Chen, X., Tao, Y., Ali, A., Zhuang, Z., Guo, D., Guo, Q., et al. (2019). Transcriptome and proteome profiling of different colored rice reveals physiological dynamics involved in the flavonoid pathway. Int. J. Mol. Sci. 20:2463. doi: 10.3390/ ijms20102463

Chi, F., Yang, P., Han, F., Jing, Y., and Shen, S. (2010). Proteomic analysis of rice seedlings infected by Sinorhizobium meliloti 1021. Proteomics 10, 1861-1874. doi: $10.1002 /$ pmic.200900694

Chien, C.-H., Chow, C.-N., Wu, N.-Y., Chiang-Hsieh, Y.-F., Hou, P.-F., and Chang, W.-C. (2015). EXPath: a database of comparative expression analysis inferring metabolic pathways for plants. BMC Genom. 16(Suppl. 2):S6. doi: 10.1186/ 1471-2164-16-S2-S6

Chintakovid, N., Maipoka, M., Phaonakrop, N., Mickelbart, M. V., Roytrakul, S., and Chadchawan, S. (2017). Proteomic analysis of drought-responsive proteins in rice reveals photosynthesis-related adaptations to drought stress. Acta Physiol. Plant. 39, 1-13.

Cho, W. K., and Kim, J.-Y. (2009). Integrated analyses of the rice secretome. Plant Signal. Behav. 4, 345-347.

Choudhary, M. K., Basu, D., Datta, A., Chakraborty, N., and Chakraborty, S. (2009). Dehydration-responsive nuclear proteome of rice (Oryza sativa L.) illustrates protein network, novel regulators of cellular adaptation, and evolutionary perspective. Mol. Cell. Proteom. 8, 1579-1598. doi: 10.1074/mcp. M800601-MCP200 
Chow, C.-N., Zheng, H.-Q., Wu, N.-Y., Chien, C.-H., Huang, H.-D., Lee, T.-Y., et al. (2016). PlantPAN 2.0: an update of plant promoter analysis navigator for reconstructing transcriptional regulatory networks in plants. Nucleic Acids Res. 44, D1154-D1160. doi: 10.1093/nar/gkv1035

Chu, Q., Zhang, X., Zhu, X., Liu, C., Mao, L., Ye, C., et al. (2017). PlantcircBase: a database for plant circular RNAs. Mol. Plant 10, 1126-1128.

Consortium, U. (2019). UniProt: a worldwide hub of protein knowledge. Nucleic Acids Res. 47, D506-D515. doi: 10.1093/nar/gky1049

Das, G., Patra, J. K., and Baek, K.-H. (2017). Insight into MAS: a molecular tool for development of stress resistant and quality of rice through gene stacking. Front. Plant Sci. 8:985. doi: 10.3389/fpls.2017.00985

Dash, P. K., Rai, R., Rai, V., and Pasupalak, S. (2018). Drought induced signaling in rice: delineating canonical and non-canonical pathways. Front. Chem. 6:264. doi: 10.3389/fchem.2018.00264

Dash, S., Van Hemert, J., Hong, L., Wise, R. P., and Dickerson, J. A. (2012). PLEXdb: gene expression resources for plants and plant pathogens. Nucleic Acids Res. 40, D1194-D1201.

Daviss, B. (2005). Growing pains for metabolomics: the newest'omic science is producing results-and more data than researchers know what to do with. Scientist 19, 25-29.

Daygon, V. D., Calingacion, M., Forster, L. C., De Voss, J. J., Schwartz, B. D., Ovenden, B., et al. (2017). Metabolomics and genomics combine to unravel the pathway for the presence of fragrance in rice. Sci. Rep. 7, 1-12. doi: 10.1038/ s41598-017-07693-9

Decourcelle, M., Perez-Fons, L., Baulande, S., Steiger, S., Couvelard, L., Hem, S., et al. (2015). Combined transcript, proteome, and metabolite analysis of transgenic maize seeds engineered for enhanced carotenoid synthesis reveals pleotropic effects in core metabolism. J. Exp. Bot. 66, 3141-3150. doi: 10.1093/jxb/erv120

Delseny, M., Salses, J., Cooke, R., Sallaud, C., Regad, F., Lagoda, P., et al. (2001). Rice genomics: present and future. Plant Physiol. Biochem. 39, 323-334.

Deng, C., Ye, H., Fan, M., Pu, T., and Yan, J. (2017). The rice transcription factors OsICE confer enhanced cold tolerance in transgenic Arabidopsis. Plant Signal. Behav. 12:e1316442. doi: 10.1080/15592324.2017.1316442

Deng, P., Jiang, D., Dong, Y., Shi, X., Jing, W., and Zhang, W. (2015a). Physiological characterisation and fine mapping of a salt-tolerant mutant in rice (Oryza sativa). Funct. Plant Biol. 42, 1026-1035. doi: 10.1071/FP15126

Deng, P., Shi, X., Zhou, J., Wang, F., Dong, Y., Jing, W., et al. (2015b). Identification and Fine Mapping of a Mutation Conferring Salt-Sensitivity in Rice (Oryza sativa L.). Crop Sci. 55, 219-228.

Devi, S. R., Singh, K., Umakanth, B., Vishalakshi, B., Rao, K. V. S., Suneel, B., et al. (2020). Identification and characterization of a large effect QTL from Oryza glumaepatula revealed $\mathrm{Pi} 68(\mathrm{t})$ as putative candidate gene for rice blast resistance. Rice 13, 1-13. doi: 10.1186/s12284-020-00378-4

Dhakarey, R., Raorane, M. L., Treumann, A., Peethambaran, P. K., Schendel, R. R., Sahi, V. P., et al. (2017). Physiological and proteomic analysis of the rice mutant cpm2 suggests a negative regulatory role of jasmonic acid in drought tolerance. Front. Plant Sci. 8:1903. doi: 10.3389/fpls.2017.01903

Dhondt, S., Wuyts, N., and Inzé, D. (2013). Cell to whole-plant phenotyping: the best is yet to come. Trends Plant Sci. 18, 428-439. doi: 10.1016/j.tplants.2013. 04.008

Ding, Y., Chen, Z., and Zhu, C. (2011). Microarray-based analysis of cadmiumresponsive microRNAs in rice (Oryza sativa). J. Exp. Bot. 62, 3563-3573. doi: 10.1093/jxb/err046

Divya, D., Sahu, N., Reddy, P. S., Nair, S., and Bentur, J. (2021). RNA-Sequencing Reveals Differentially Expressed Rice Genes Functionally Associated with Defense against BPH and WBPH in RILs Derived from a Cross between RP2068 and TN1. Rice 14, 1-21. doi: 10.1186/s12284-021-00470-3

Dong, C., He, F., Berkowitz, O., Liu, J., Cao, P., Tang, M., et al. (2018). Alternative splicing plays a critical role in maintaining mineral nutrient homeostasis in rice (Oryza sativa). Plant Cell 30, 2267-2285. doi: 10.1105/tpc.18.00051

Dong, M., Gu, J., Zhang, L., Chen, P., Liu, T., Deng, J., et al. (2014). Comparative proteomics analysis of superior and inferior spikelets in hybrid rice during grain filling and response of inferior spikelets to drought stress using isobaric tags for relative and absolute quantification. J. Proteom. 109, 382-399.

Droc, G., Ruiz, M., Larmande, P., Pereira, A., Piffanelli, P., Morel, J. B., et al. (2006). OryGenesDB: a database for rice reverse genetics. Nucleic Acids Res. 34, D736-D740.
Du, H., Huang, F., Wu, N., Li, X., Hu, H., and Xiong, L. (2018). Integrative regulation of drought escape through ABA-dependent and-independent pathways in rice. Mol. Plant 11, 584-597. doi: 10.1016/j.molp.2018. 01.004

Du, J., Shen, T., Xiong, Q., Zhu, C., Peng, X., He, X., et al. (2020). Combined proteomics, metabolomics and physiological analyses of rice growth and grain yield with heavy nitrogen application before and after drought. BMC Plant Biol. 20:1-17. doi: 10.1186/s12870-020-02772-y

Du, S., Cui, M., Cai, Y., Xue, A., Hao, Y., Huang, X., et al. (2020). Metabolomic analysis of chilling response in rice (Oryza sativa L.) seedlings by extractive electrospray ionization mass spectrometry. Environ. Exp. Bot. 180:104231.

Edwards, J. D., Baldo, A., and Mueller, L. A. (2016). Ricebase: a breeding and genetics platform for rice, integrating individual molecular markers, pedigrees and whole-genome-based data. Database 2016:baw107. doi: 10.1093/database/ baw107

Emon, R. M., Islam, M. M., Halder, J., and Fan, Y. (2015). Genetic diversity and association mapping for salinity tolerance in Bangladeshi rice landraces. Crop J. 3, 440-444.

Ereful, N. C., Liu, L.-Y., Greenland, A., Powell, W., Mackay, I., and Leung, H. (2020). RNA-seq reveals differentially expressed genes between two indica inbred rice genotypes associated with drought-yield QTLs. Agronomy 10:621.

Fan, C., Xing, Y., Mao, H., Lu, T., Han, B., Xu, C., et al. (2006). GS3, a major QTL for grain length and weight and minor QTL for grain width and thickness in rice, encodes a putative transmembrane protein. Theoret. Appl. Genet. 112, 1164-1171. doi: 10.1007/s00122-006-0218-1

Feltus, F. A., Wan, J., Schulze, S. R., Estill, J. C., Jiang, N., and Paterson, A. H. (2004). An SNP resource for rice genetics and breeding based on subspecies indica and japonica genome alignments. Genome Res. 14, 1812-1819. doi: 10. $1101 /$ gr.2479404

Fu, J., Wu, H., Ma, S., Xiang, D., Liu, R., and Xiong, L. (2017). OsJAZ1 attenuates drought resistance by regulating JA and ABA signaling in rice. Front. Plant Sci. 8:2108. doi: 10.3389/fpls.2017.02108

Fukao, T., and Bailey-Serres, J. (2008). Submergence tolerance conferred by Sub1A is mediated by SLR1 and SLRL1 restriction of gibberellin responses in rice. PNAS 105, 16814-16819. doi: 10.1073/pnas.080782 1105

Fukushima, A., and Kusano, M. (2014). A network perspective on nitrogen metabolism from model to crop plants using integrated 'omics' approaches. J. Exp. Bot. 65, 5619-5630.

Gao, P., Bai, X., Yang, L., Lv, D., Pan, X., Li, Y., et al. (2011). osa-MIR393: a salinity-and alkaline stress-related microRNA gene. Mol. Biol. Rep. 38, 237-242. doi: 10.1007/s11033-010-0100-8

Gao, Z.-Y., Zhao, S.-C., He, W.-M., Guo, L.-B., Peng, Y.-L., Wang, J.J., et al. (2013). Dissecting yield-associated loci in super hybrid rice by resequencing recombinant inbred lines and improving parental genome sequences. PNAS 110, 14492-14497. doi: 10.1073/pnas.130657 9110

Gayen, D., Ghosh, S., Paul, S., Sarkar, S. N., Datta, S. K., and Datta, K. (2016). Metabolic regulation of carotenoid-enriched golden rice line. Front. Plant Sci. 7:1622. doi: 10.3389/fpls.2016.01622

Ghimire, K. H., Quiatchon, L. A., Vikram, P., Swamy, B. M., Dixit, S., Ahmed, H., et al. (2012). Identification and mapping of a QTL (qDTY1. 1) with a consistent effect on grain yield under drought. Field Crops Res. 131, 88-96.

Ghosh, S., Kanwar, P., and Jha, G. (2017). Alterations in rice chloroplast integrity, photosynthesis and metabolome associated with pathogenesis of Rhizoctonia solani. Sci. Rep. 7, 1-12. doi: 10.1038/srep41610

Goff, S. A., Ricke, D., Lan, T.-H., Presting, G., Wang, R., Dunn, M., et al. (2002). A draft sequence of the rice genome (Oryza sativa L. ssp. japonica). Science 296, 92-100.

Gong, L., Chen, W., Gao, Y., Liu, X., Zhang, H., Xu, C., et al. (2013). Genetic analysis of the metabolome exemplified using a rice population. PNAS 110, 20320-20325. doi: 10.1073/pnas.1319681110

Gour, P., Garg, P., Jain, R., Joseph, S. V., Tyagi, A. K., and Raghuvanshi, S. (2014). Manually curated database of rice proteins. Nucleic Acids Res. 42, D1214-D1221.

Graziano, S., Marmiroli, N., and Gullì, M. (2020). Proteomic analysis of reserve proteins in commercial rice cultivars. Food Sci. Nutrit. 8, 1788-1797. doi: 10. 1002/fsn3.1375 
Gregorio, G. B. (1997). Tagging salinity tolerance genes in rice using amplified fragment length polymorphism (AFLP). Ph. D. thesis. Los Baños: University of the Philippines.

Groen, S. C., Ćalić, I., Joly-Lopez, Z., Platts, A. E., Choi, J. Y., Natividad, M., et al. (2020). The strength and pattern of natural selection on gene expression in rice. Nature 578, 572-576.

Gu, H., Zhu, P., Jiao, Y., Meng, Y., and Chen, M. (2011). PRIN: a predicted rice interactome network. BMC Bioinformatics 12:1-13. doi: 10.1186/1471-210512-161

Gumi, A. M., Guha, P. K., Mazumder, A., Jayaswal, P., and Mondal, T. K. (2018). Characterization of OglDREB2A gene from African rice (Oryza glaberrima), comparative analysis and its transcriptional regulation under salinity stress. 3 Biotech 8, 1-16. doi: 10.1007/s13205-018-1098-1

Guo, H., Wu, T., Li, S., He, Q., Yang, Z., Zhang, W., et al. (2019). The methylation patterns and transcriptional responses to chilling stress at the seedling stage in rice. Int. J. Mol. Sci. 20:5089. doi: 10.3390/ijms20205089

Guo, S., Xu, Y., Liu, H., Mao, Z., Zhang, C., Ma, Y., et al. (2013). The interaction between OsMADS57 and OsTB1 modulates rice tillering via DWARF14. Nat. Commun. 4:1566. doi: 10.1038/ncomms 2542

Gupta, A., Rico-Medina, A., and Caño-Delgado, A. I. (2020). The physiology of plant responses to drought. Science 368, 266-269.

Gupta, P., and De, B. (2017). Metabolomics analysis of rice responses to salinity stress revealed elevation of serotonin, and gentisic acid levels in leaves of tolerant varieties. Plant Signal. Behav. 12:e1335845. doi: 10.1080/15592324. 2017.1335845

Hall, R. D. (2006). Plant metabolomics: from holistic hope, to hype, to hot topic. N. Phytol. 169, 453-468. doi: 10.1111/j.1469-8137.2005.01632.x

Hamada, K., Hongo, K., Suwabe, K., Shimizu, A., Nagayama, T., Abe, R., et al. (2011). OryzaExpress: an integrated database of gene expression networks and omics annotations in rice. Plant Cell Physiol. 52, 220-229. doi: 10.1093/pcp/ pcq195

Hamzelou, S., Pascovici, D., Kamath, K. S., Amirkhani, A., Mckay, M., Mirzaei, M., et al. (2020). Proteomic responses to drought vary widely among eight diverse genotypes of rice (Oryza sativa). Int. J. Mol. Sci. 21:363. doi: 10.3390/ ijms 21010363

Han, C., He, D., Li, M., and Yang, P. (2014a). In-depth proteomic analysis of rice embryo reveals its important roles in seed germination. Plant Cell Physiol. 55, 1826-1847. doi: 10.1093/pcp/pcu114

Han, C., Yang, P., Sakata, K., and Komatsu, S. (2014b). Quantitative proteomics reveals the role of protein phosphorylation in rice embryos during early stages of germination. J. Proteome Res. 13, 1766-1782. doi: 10.1021/pr40 $1295 \mathrm{c}$

Haq, T. U., Gorham, J., Akhtar, J., Akhtar, N., and Steele, K. A. (2010). Dynamic quantitative trait loci for salt stress components on chromosome 1 of rice. Funct. Plant Biol. 37, 634-645.

Haug, K., Salek, R. M., Conesa, P., Hastings, J., De Matos, P., Rijnbeek, M., et al. (2013). MetaboLights-an open-access general-purpose repository for metabolomics studies and associated meta-data. Nucleic Acids Res. 41, D781D786. doi: 10.1093/nar/gks1004

Heather, J. M., and Chain, B. (2016). The sequence of sequencers: The history of sequencing DNA. Genomics 107, 1-8.

Helmy, M., Sugiyama, N., Tomita, M., and Ishihama, Y. (2012). The rice proteogenomics database OryzaPG-DB: development, expansion, and new features. Front. Plant Sci. 3:65. doi: 10.3389/fpls.2012.00065

Helmy, M., Tomita, M., and Ishihama, Y. (2011). OryzaPG-DB: rice proteome database based on shotgun proteogenomics. BMC Plant Biol. 11:63. doi: 10. 1186/1471-2229-11-63

Higo, K., Ugawa, Y., Iwamoto, M., and Korenaga, T. (1999). Plant cis-acting regulatory DNA elements (PLACE) database: 1999. Nucleic Acids Res. 27, 297-300. doi: 10.1093/nar/27.1.297

Ho, C.-L., Wu, Y., Shen, H.-B., Provart, N. J., and Geisler, M. (2012). A predicted protein interactome for rice. Rice 5, 1-14.

Hrdlickova, R., Toloue, M., and Tian, B. (2017). RNA-Seq methods for transcriptome analysis. Wiley Interdiscipl. Rev. RNA 8:e1364.

Hruz, T., Laule, O., Szabo, G., Wessendorp, F., Bleuler, S., Oertle, L., et al. (2008). Genevestigator v3: a reference expression database for the meta-analysis of transcriptomes. Adv. Bioinformat. 2008:420747. doi: 10.1155/2008/420747
Hu, C., Shi, J., Quan, S., Cui, B., Kleessen, S., Nikoloski, Z., et al. (2014). Metabolic variation between japonica and indica rice cultivars as revealed by non-targeted metabolomics. Sci. Rep. 4, 1-10. doi: 10.1038/srep05067

Hu, H., Dai, M., Yao, J., Xiao, B., Li, X., Zhang, Q., et al. (2006). Overexpressing a NAM, ATAF, and CUC (NAC) transcription factor enhances drought resistance and salt tolerance in rice. PNAS 103, 12987-12992. doi: 10.1073/pnas. 0604882103

Hu, H., You, J., Fang, Y., Zhu, X., Qi, Z., and Xiong, L. (2008). Characterization of transcription factor gene SNAC2 conferring cold and salt tolerance in rice. Plant Mol. Biol. 67, 169-181. doi: 10.1007/s11103-008-9309-5

Huang, J., Yang, X., Wang, M.-M., Tang, H.-J., Ding, L.-Y., Shen, Y., et al. (2007). A novel rice $\mathrm{C} 2 \mathrm{H} 2$-type zinc finger protein lacking DLN-box/EAR-motif plays a role in salt tolerance. Biochim. Biophys. Acta Gene Struct. Exp. 1769, 220-227. doi: 10.1016/j.bbaexp.2007.02.006

Huang, L., Wang, Y., Wang, W., Zhao, X., Qin, Q., Sun, F., et al. (2018). Characterization of transcription factor gene OsDRAP1 conferring drought tolerance in rice. Front. Plant Sci. 9:94. doi: 10.3389/fpls.2018.00094

Huang, X., Feng, Q., Qian, Q., Zhao, Q., Wang, L., Wang, A., et al. (2009). High-throughput genotyping by whole-genome resequencing. Genome Res. 19, 1068-1076.

Huang, X., Qian, Q., Liu, Z., Sun, H., He, S., Luo, D., et al. (2009). Natural variation at the DEP1 locus enhances grain yield in rice. Nat. Genet. 41, 494-497. doi: 10.1038/ng.352

Huang, S. Q., Peng, J., Qiu, C. X., and Yang, Z. M. (2009). Heavy metal-regulated new microRNAs from rice. J. Inorganic Biochem. 103, 282-287. doi: 10.1016/j. jinorgbio.2008.10.019

Huang, X., Lu, T., and Han, B. (2013). Resequencing rice genomes: an emerging new era of rice genomics. Trends Genet. 29, 225-232. doi: 10.1016/j.tig.2012.12. 001

Iqbal, Z., Iqbal, M. S., Ahmad, A., Memon, A. G., and Ansari, M. I. (2020a). New prospects on the horizon: genome editing to engineer plants for desirable traits. Curr. Plant Biol. 2020:100171.

Iqbal, Z., Shariq Iqbal, M., Singh, S. P., and Buaboocha, T. (2020b). $\mathrm{Ca} 2+/$ calmodulin complex triggers CAMTA transcriptional machinery under stress in plants: signaling cascade and molecular regulation. Front. Plant Sci. 11:598327. doi: $10.3389 /$ fpls.2020.598327

Izawa, T., and Shimamoto, K. (1996). Becoming a model plant: the importance of rice to plant science. Trends Plant Sci. 1, 95-99.

Jaiswal, D. K., Ray, D., Choudhary, M. K., Subba, P., Kumar, A., Verma, J., et al. (2013). Comparative proteomics of dehydration response in the rice nucleus: New insights into the molecular basis of genotype-specific adaptation. Proteomics 13, 3478-3497. doi: 10.1002/pmic.201300284

Jaiswal, P., Ni, J., Yap, I., Ware, D., Spooner, W., Youens-Clark, K., et al. (2006). Gramene: a bird's eye view of cereal genomes'. Nucleic Acids Res. 34, D717D723. doi: 10.1093/nar/gkj154

Jan, A., Maruyama, K., Todaka, D., Kidokoro, S., Abo, M., Yoshimura, E., et al. (2013). OsTZF1, a CCCH-tandem zinc finger protein, confers delayed senescence and stress tolerance in rice by regulating stress-related genes. Plant Physiol. 161, 1202-1216. doi: 10.1104/pp.112.205385

Jasim Aljumaili, S., Rafii, M., Latif, M., Sakimin, S. Z., Arolu, I. W., and Miah, G. (2018). Genetic diversity of aromatic rice germplasm revealed by SSR markers. BioMed Res. Int. 2018:7658032.

Jeong, J. S., Kim, Y. S., Baek, K. H., Jung, H., Ha, S.-H., Do Choi, Y., et al. (2010). Root-specific expression of OsNAC10 improves drought tolerance and grain yield in rice under field drought conditions. Plant Physiol. 153, 185-197. doi: 10.1104/pp.110.154773

Jha, G., Rajeshwari, R., and Sonti, R. V. (2007). Functional interplay between two Xanthomonas oryzae pv. oryzae secretion systems in modulating virulence on rice. Mol. Plant Microbe Interact. 20, 31-40. doi: 10.1094/MPMI-20-0031

Ji, L., Zhou, P., Zhu, Y., Liu, F., Li, R., and Qiu, Y. (2017). Proteomic analysis of Rice seedlings under cold stress. Protein J. 36, 299-307.

Jian, X., Zhang, L., Li, G., Zhang, L., Wang, X., Cao, X., et al. (2010). Identification of novel stress-regulated microRNAs from Oryza sativa L. Genomics 95, 47-55. doi: 10.1016/j.ygeno.2009.08.017

Jiang, H., Feng, Y., Qiu, L., Gao, G., Zhang, Q., and He, Y. (2020). Identification of Blast Resistance QTLs Based on Two Advanced Backcross Populations in Rice. Rice 13, 1-12. doi: 10.1186/s12284-020-00392-6 
Jiang, W., Jin, Y.-M., Lee, J., Lee, K.-I., Piao, R., Han, L., et al. (2011). Quantitative trait loci for cold tolerance of rice recombinant inbred lines in low temperature environments. Mol. Cells 32, 579-587.

Jiang, Y., Cai, Z., Xie, W., Long, T., Yu, H., and Zhang, Q. (2012). Rice functional genomics research: progress and implications for crop genetic improvement. Biotechnol. Adv. 30, 1059-1070.

Jiao, Y., Wang, Y., Xue, D., Wang, J., Yan, M., Liu, G., et al. (2010). Regulation of OsSPL14 by OsmiR156 defines ideal plant architecture in rice. Nat. Genet. 42:541. doi: 10.1038/ng.591

Jin, Y.-M., Piao, R., Yan, Y.-F., Chen, M., Wang, L., He, H., et al. (2018). Overexpression of a new zinc finger protein transcription factor OsCTZFP8 improves cold tolerance in rice. Int. J. Genom. 2018:5480617. doi: 10.1155/2018/ 5480617

Jing, W., Deng, P., Cao, C., and Zhang, W. (2017). Fine mapping of qSKC-1, a major quantitative trait locus for shoot $\mathrm{K}+$ concentration, in rice seedlings grown under salt stress. Breed. Sci. 2017:16190. doi: 10.1270/jsbbs.16190

Johnson, C., Bowman, L., Adai, A. T., Vance, V., and Sundaresan, V. (2007). CSRDB: a small RNA integrated database and browser resource for cereals. Nucleic Acids Res. 35, D829-D833. doi: 10.1093/nar/gkl991

Joshi, R., Wani, S. H., Singh, B., Bohra, A., Dar, Z. A., Lone, A. A., et al. (2016). Transcription factors and plants response to drought stress: current understanding and future directions. Front. Plant Sci. 7:1029. doi: 10.3389/fpls. 2016.01029

Junot, C., and Fenaille, F. (2019). "Metabolomics using Fourier transform mass spectrometry," in Fundamentals and Applications of Fourier Transform Mass Spectrometry, eds P. Schmitt-Kopplin and B. Kanawati (Amsterdam: Elsevier), 325-356.

Kandasamy, S., Loganathan, K., Muthuraj, R., Duraisamy, S., Seetharaman, S., Thiruvengadam, R., et al. (2009). Understanding the molecular basis of plant growth promotional effect of Pseudomonas fluorescens on rice through protein profiling. Proteome Sci. 7, 1-8. doi: 10.1186/1477-5956-7-47

Kandaswamy, R., Ramasamy, M. K., Palanivel, R., and Balasundaram, U. (2019). Impact of Pseudomonas putida RRF3 on the root transcriptome of rice plants: Insights into defense response, secondary metabolism and root exudation. J. Biosci. 44, 1-13.

Kanehisa, M., Furumichi, M., Tanabe, M., Sato, Y., and Morishima, K. (2017). KEGG: new perspectives on genomes, pathways, diseases and drugs. Nucleic Acids Res. 45, D353-D361.

Kar, M. M., and Raichaudhuri, A. (2021). Role of microRNAs in mediating biotic and abiotic stress in plants. Plant Gene 26:100277.

Karmakar, S., Datta, K., Molla, K. A., Gayen, D., Das, K., Sarkar, S. N., et al. (2019). Proteo-metabolomic investigation of transgenic rice unravels metabolic alterations and accumulation of novel proteins potentially involved in defence against Rhizoctonia solani. Sci. Rep. 9, 1-16. doi: 10.1038/s41598-019-46885-3

Kaul, S., Koo, H. L., Jenkins, J., Rizzo, M., Rooney, T., Tallon, L. J., et al. (2000). Analysis of the genome sequence of the flowering plant Arabidopsis thaliana. Nature 408, 796-815.

Kawahara, Y., De La Bastide, M., Hamilton, J. P., Kanamori, H., Mccombie, W. R., Ouyang, S., et al. (2013). Improvement of the Oryza sativa Nipponbare reference genome using next generation sequence and optical map data. Rice 6 , 1-10. doi: 10.1186/1939-8433-6-4

Kawahara, Y., Oono, Y., Wakimoto, H., Ogata, J., Kanamori, H., Sasaki, H., et al. (2016). TENOR: database for comprehensive mRNA-Seq experiments in rice. Plant Cell Physiol. 57, e7-e7. doi: 10.1093/pcp/pcv179

Khan, M. H., Dar, Z. A., and Dar, S. A. (2015). Breeding strategies for improving rice yield-a review. Agricult. Sci. 6:467.

Khan, M. I. R., Jalil, S. U., Chopra, P., Chhillar, H., Ferrante, A., Khan, N. A., et al. (2021). Role of GABA in plant growth, development and senescence. Plant Gene 2021:100283.

Kim, S. T., Kim, S. G., Agrawal, G. K., Kikuchi, S., and Rakwal, R. (2014). Rice proteomics: a model system for crop improvement and food security. Proteomics 14, 593-610. doi: 10.1002/pmic.201300388

Kim, H., Lee, K., Hwang, H., Bhatnagar, N., Kim, D.-Y., Yoon, I. S., et al. (2014). Overexpression of PYL5 in rice enhances drought tolerance, inhibits growth, and modulates gene expression. J. Exp. Bot. 65, 453-464. doi: 10.1093/jxb/ert397

Kim, S.-M., and Reinke, R. F. (2018). Identification of QTLs for tolerance to hypoxia during germination in rice. Euphytica 214, 1-10.
Kim, Y. J., Lee, H. M., Wang, Y., Wu, J., Kim, S. G., Kang, K. Y., et al. (2013). Depletion of abundant plant R $\mathrm{u}$ B is CO protein using the protamine sulfate precipitation method. Proteomics 13, 2176-2179. doi: 10.1002/pmic.201200555

Kim, Y., Chung, Y. S., Lee, E., Tripathi, P., Heo, S., and Kim, K.-H. (2020). Root response to drought stress in rice (Oryza sativa L.). Int. J. Mol. Sci. 21:1513.

Komatsu, S., and Tanaka, N. (2005). Rice proteome analysis: a step toward functional analysis of the rice genome. Proteomics 5, 938-949.

Kozomara, A., Birgaoanu, M., and Griffiths-Jones, S. (2019). miRBase: from microRNA sequences to function. Nucleic Acids Res. 47, D155-D162.

Kremling, K. A., Chen, S.-Y., Su, M.-H., Lepak, N. K., Romay, M. C., Swarts, K. L., et al. (2018). Dysregulation of expression correlates with rare-allele burden and fitness loss in maize. Nature 555, 520-523. doi: 10.1038/nature25966

Krishnamurthy, S., Pundir, P., Warraich, A. S., Rathor, S., Lokeshkumar, B., Singh, N. K., et al. (2020). Introgressed saltol QTL lines improves the salinity tolerance in rice at seedling stage. Front. Plant Sci. 11:833. doi: 10.3389/fpls.2020.00833

Kudo, T., Akiyama, K., Kojima, M., Makita, N., Sakurai, T., and Sakakibara, H. (2013). UniVIO: a multiple omics database with hormonome and transcriptome data from rice. Plant Cell Physiol. 54, e9-e9. doi: 10.1093/pcp/ pct003

Kulkarni, S. R., Balachandran, S., Ulaganathan, K., Balakrishnan, D., Praveen, M., Prasad, A. H., et al. (2020). Molecular mapping of QTLs for yield related traits in recombinant inbred line (RIL) population derived from the popular rice hybrid KRH-2 and their validation through SNP genotyping. Sci. Rep. 10, 1-21. doi: 10.1038/s41598-020-70637-3

Kumar, A., and Dash, P. K. (2019). “Transcriptome Analysis for Abiotic Stresses in Rice (Oryza sativa L,” in Transcriptome Analysis, ed. M. Blumenberg (London: IntechOpen).

Kumar, A., Basu, S., Ramegowda, V., and Pereira, A. (2017). Mechanisms of drought tolerance in rice. Cambridgeshire: Burleigh Dodds Science Publishing Limited, $131-163$.

Kumar, A., Bernier, J., Verulkar, S., Lafitte, H., and Atlin, G. (2008). Breeding for drought tolerance: direct selection for yield, response to selection and use of drought-tolerant donors in upland and lowland-adapted populations. Field Crops Res. 107, 221-231.

Kumar, I. S., and Nadarajah, K. (2020). A Meta-Analysis of Quantitative Trait Loci Associated with Multiple Disease Resistance in Rice (Oryza sativa L.). Plants 9:1491. doi: 10.3390/plants9111491

Kumar, V., Singh, A., Mithra, S. A., Krishnamurthy, S., Parida, S. K., Jain, S., et al. (2015). Genome-wide association mapping of salinity tolerance in rice (Oryza sativa). DNA Res. 22, 133-145.

Kurotani, A., Yamada, Y., Shinozaki, K., Kuroda, Y., and Sakurai, T. (2015). Plant-PrAS: a database of physicochemical and structural properties and novel functional regions in plant proteomes. Plant Cell Physiol. 56, e11-e11. doi: $10.1093 / \mathrm{pcp} / \mathrm{pcu} 176$

Kyndt, T., Denil, S., Haegeman, A., Trooskens, G., De Meyer, T., Van Criekinge, W., et al. (2012). Transcriptome analysis of rice mature root tissue and root tips in early development by massive parallel sequencing. J. Exp. Bot. 63, 2141-2157. doi: $10.1093 /$ jxb/err435

Lakra, N., Kaur, C., Singla-Pareek, S. L., and Pareek, A. (2019). Mapping the 'early salinity response'triggered proteome adaptation in contrasting rice genotypes using iTRAQ approach. Rice 12, 1-22. doi: 10.1186/s12284-018-0259-5

Lawas, L. M. F., Li, X., Erban, A., Kopka, J., Jagadish, S. K., Zuther, E., et al. (2019). Metabolic responses of rice cultivars with different tolerance to combined drought and heat stress under field conditions. GigaScience 8:giz050.

Lee, J., Bricker, T. M., Lefevre, M., Pinson, S. R., and Oard, J. H. (2006). Proteomic and genetic approaches to identifying defence-related proteins in rice challenged with the fungal pathogen Rhizoctonia solani. Mol. Plant Pathol. 7, 405-416. doi: 10.1111/j.1364-3703.2006.00350.x

Lee, J., Lee, Y., Kim, M., Ham, T.-H., Jo, S.-M., and Kwon, S.-W. (2017). Quantitative shotgun proteomic analysis of cold-stressed mature rice anthers. Plant Biotechnol. Rep. 11, 417-427.

Lee, T., Oh, T., Yang, S., Shin, J., Hwang, S., Kim, C. Y., et al. (2015). RiceNet v2: an improved network prioritization server for rice genes. Nucleic Acids Res. 43, W122-W127. doi: 10.1093/nar/gkv253

Lee, T.-H., Kim, Y.-K., Pham, T. T. M., Song, S. I., Kim, J.-K., Kang, K. Y., et al. (2009). RiceArrayNet: a database for correlating gene expression from transcriptome profiling, and its application to the analysis of coexpressed genes in rice. Plant Physiol. 151, 16-33. doi: 10.1104/pp.109.139030 
Lescot, M., Déhais, P., Thijs, G., Marchal, K., Moreau, Y., Van De Peer, Y., et al. (2002). PlantCARE, a database of plant cis-acting regulatory elements and a portal to tools for in silico analysis of promoter sequences. Nucleic Acids Res. 30, 325-327. doi: 10.1093/nar/30.1.325

Li, J., Thomson, M., and Mccouch, S. R. (2004). Fine mapping of a grain-weight quantitative trait locus in the pericentromeric region of rice chromosome 3 . Genetics 168, 2187-2195. doi: 10.1534/genetics.104.034165

Li, Y., Nie, Y., Zhang, Z., Ye, Z., Zou, X., Zhang, L., et al. (2014). Comparative proteomic analysis of methyl jasmonate-induced defense responses in different rice cultivars. Proteomics 14, 1088-1101. doi: 10.1002/pmic.201300104

Li, J.-Y., Wang, J., and Zeigler, R. S. (2014). The 3,000 rice genomes project: new opportunities and challenges for future rice research. Gigascience 3, 2217X2043X. doi: 10.1186/2047-217X-3-8

Li, N., Liu, H., Sun, J., Zheng, H., Wang, J., Yang, L., et al. (2018). Transcriptome analysis of two contrasting rice cultivars during alkaline stress. Sci. Rep. 8, 1-16.

Li, R., Chaicherdsakul, T., Kunathigan, V., Roytrakul, S., Paemanee, A., and Kittisenachai, S. (2020). Shotgun Proteomic Analysis of Germinated Rice (Oryza sativa L.) under Salt Stress. Appl. Sci. Engine. Prog. 13, 76-85.

Li, S., Xie, K., Li, W., Zou, T., Ren, Y., Wang, S., et al. (2012). Re-sequencing and genetic variation identification of a rice line with ideal plant architecture. Rice 5, 1-7. doi: 10.1186/1939-8433-5-18

Li, T., Li, H., Zhang, Y.-X., and Liu, J.-Y. (2011). Identification and analysis of seven $\mathrm{H} 2 \mathrm{O} 2$-responsive miRNAs and 32 new miRNAs in the seedlings of rice (Oryza sativa L. ssp. indica). Nucleic Acids Res. 39, 2821-2833. doi: 10.1093/nar/ gkq1047

Li, Y., Ye, Z., Nie, Y., Zhang, J., Wang, G.-L., and Wang, Z. (2015). Comparative phosphoproteome analysis of Magnaporthe oryzae-responsive proteins in susceptible and resistant rice cultivars. J. Proteom. 115, 66-80. doi: 10.1016/j. jprot.2014.12.007

Li, Y., Zhao, S.-L., Li, J.-L., Hu, X.-H., Wang, H., Cao, X.-L., et al. (2017). Osa-miR169 negatively regulates rice immunity against the blast fungus Magnaporthe oryzae. Front. Plant Sci. 8:2. doi: 10.3389/fpls.2017.00002

Liang, Y., Meng, L., Lin, X., Cui, Y., Pang, Y., Xu, J., et al. (2018). QTL and QTL networks for cold tolerance at the reproductive stage detected using selective introgression in rice. PLoS One 13:e0200846. doi: 10.1371/journal. pone. 0200846

Liang, Z., Wang, L., and Pan, Q. (2016). A new recessive gene conferring resistance against rice blast. Rice 9, 1-6. doi: 10.1186/s12284-016-0120-7

Liao, J.-L., Zhou, H.-W., Zhang, H.-Y., Zhong, P.-A., and Huang, Y.-J. (2014). Comparative proteomic analysis of differentially expressed proteins in the early milky stage of rice grains during high temperature stress. J. Exp. Bot. 65, 655-671.

Lin, D.-G., Chou, S.-Y., Wang, A. Z., Wang, Y.-W., Kuo, S.-M., Lai, C.-C., et al. (2014). A proteomic study of rice cultivar TNG67 and its high aroma mutant SA0420. Plant Sci. 214, 20-28. doi: 10.1016/j.plantsci.2013.09.010

Lin, H., Zhu, M., Yano, M., Gao, J., Liang, Z., Su, W., et al. (2004). QTLs for Na+ and $\mathrm{K}+$ uptake of the shoots and roots controlling rice salt tolerance. Theoret. Appl. Genet. 108, 253-260. doi: 10.1007/s00122-003-1421-y

Lin, Z., Zhang, X., Wang, Z., Jiang, Y., Liu, Z., Alexander, D., et al. (2017). Metabolomic analysis of pathways related to rice grain chalkiness by a notchedbelly mutant with high occurrence of white-belly grains. BMC Plant Biol. 17:39. doi: 10.1186/s12870-017-0985-7

Liu, C., Mao, B., Ou, S., Wang, W., Liu, L., Wu, Y., et al. (2014). OsbZIP71, a bZIP transcription factor, confers salinity and drought tolerance in rice. Plant Mol. Biol. 84, 19-36.

Liu, C. W., Chang, T. S., Hsu, Y. K., Wang, A. Z., Yen, H. C., Wu, Y. P., et al. (2014). Comparative proteomic analysis of early salt stress responsive proteins in roots and leaves of rice. Proteomics 14, 1759-1775. doi: 10.1002/pmic.201300276

Liu, K., Wang, L., Xu, Y., Chen, N., Ma, Q., Li, F., et al. (2007). Overexpression of OsCOIN, a putative cold inducible zinc finger protein, increased tolerance to chilling, salt and drought, and enhanced proline level in rice. Planta 226, 1007-1016. doi: 10.1007/s00425-007-0548-5

Liu, Q., Su, Y., Zhu, Y., Peng, K., Hong, B., Wang, R., et al. (2019). Manipulating osa-MIR156f expression by D18 promoter to regulate plant architecture and yield traits both in seasonal and ratooning rice. Biol. Proced. Online 21, 1-14. doi: 10.1186/s12575-019-0110-4

Liu, Y., Lu, S., Liu, K., Wang, S., Huang, L., and Guo, L. (2019). Proteomics: A powerful tool to study plant responses to biotic stress. Plant Methods 15, 1-20.
Liu, W.-T., Chen, P.-W., Chen, L.-C., Yang, C.-C., Chen, S.-Y., Huang, G., et al. (2017). Suppressive effect of microRNA319 expression on rice plant height. Theoret. Appl. Genet. 130, 1507-1518. doi: 10.1007/s00122-017-2905-5

Llorente, C., Jimenez, R., Brotman, Y., Fernie, A. R., and Sreenivasulu, N. (2019). "Rice Grain Quality Benchmarking Through Profiling of Volatiles and Metabolites in Grains Using Gas Chromatography Mass Spectrometry," in Rice Grain Quality, ed. S. Nese (Berlin: Springer), 187-199. doi: 10.1007/978-14939-8914-0_11

Lowe, R., Shirley, N., Bleackley, M., Dolan, S., and Shafee, T. (2017). Transcriptomics technologies. PLoS Computat. Biol. 13:e1005457. doi: 10.1371/ journal.pcbi.1005457

Lu, T., Lu, G., Fan, D., Zhu, C., Li, W., Zhao, Q., et al. (2010). Function annotation of the rice transcriptome at single-nucleotide resolution by RNA-seq. Genome Res. 20, 1238-1249. doi: 10.1101/gr.106120.110

Lu, Y., Feng, Z., Liu, X., Bian, L., Xie, H., Zhang, C., et al. (2018). MiR393 and miR390 synergistically regulate lateral root growth in rice under different conditions. BMC Plant Biol. 18:1-12. doi: 10.1186/s12870-018-1488-x

Luo, Y.-C., Zhou, H., Li, Y., Chen, J.-Y., Yang, J.-H., Chen, Y.-Q., et al. (2006). Rice embryogenic calli express a unique set of microRNAs, suggesting regulatory roles of microRNAs in plant post-embryogenic development. FEBS Lett. 580, 5111-5116. doi: 10.1016/j.febslet.2006.08.046

Lv, D.-K., Bai, X., Li, Y., Ding, X.-D., Ge, Y., Cai, H., et al. (2010). Profiling of cold-stress-responsive miRNAs in rice by microarrays. Gene 459, 39-47. doi: 10.1016/j.gene.2010.03.011

Ma, Z., Wang, L., Zhao, M., Gu, S., Wang, C., Zhao, J., et al. (2020). iTRAQ proteomics reveals the regulatory response to Magnaporthe oryzae in durable resistant vs. susceptible rice genotypes. PLoS One 15:e0227470. doi: 10.1371/ journal.pone.0227470

Ma, H., Sheng, C., Qiao, L., Zhao, H., and Niu, D. (2020). A comparative proteomic approach to identify defence-related proteins between resistant and susceptible rice cultivars challenged with the fungal pathogen Rhizoctonia solani. Plant Growth Regulat. 90, 73-88.

Ma, X., Xia, H., Liu, Y., Wei, H., Zheng, X., Song, C., et al. (2016). Transcriptomic and metabolomic studies disclose key metabolism pathways contributing to well-maintained photosynthesis under the drought and the consequent drought-tolerance in rice. Front. Plant Sci. 7:1886. doi: 10.3389/fpls.2016.01886

Maksup, S., Pongpakpian, S., and Roytrakul, S. (2020). Proteomics of seed nutrition-associated proteins in germinated brown rice in four Thai rice cultivars analyzed by GeLC-MS/MS. Walailak J. Sci. Technol. 18:6953.

Mallikarjuna, G., Mallikarjuna, K., Reddy, M., and Kaul, T. (2011). Expression of OsDREB2A transcription factor confers enhanced dehydration and salt stress tolerance in rice (Oryza sativa L.). Biotechnol. Lett. 33, 1689-1697. doi: 10.1007/ s10529-011-0620-x

Matsaunyane, L. B., and Dubery, I. A. (2018). "Molecular Approaches to Address Intended and Unintended Effects and Substantial Equivalence of Genetically Modified Crops," in Transgenic Crops-Emerging Trends and Future Perspectives, eds M. S. Khan and K. A. Malik (London: IntechOpen).

McCouch, S. R., Wright, M. H., Tung, C.-W., Maron, L. G., Mcnally, K. L., Fitzgerald, M., et al. (2016). Open access resources for genome-wide association mapping in rice. Nat. Commun. 7, 1-14.

McCouch, S. R., Zhao, K., Wright, M., Tung, C.-W., Ebana, K., Thomson, M., et al. (2010). Development of genome-wide SNP assays for rice. Breed. Sci. 60, 524-535.

McNally, K. L., Childs, K. L., Bohnert, R., Davidson, R. M., Zhao, K., Ulat, V. J., et al. (2009). Genomewide SNP variation reveals relationships among landraces and modern varieties of rice. PNAS 106, 12273-12278. doi: 10.1073/pnas. 0900992106

Mei, H., Xu, J., Li, Z., Yu, X., Guo, L., Wang, Y., et al. (2006). QTLs influencing panicle size detected in two reciprocal introgressive line (IL) populations in rice (Oryza sativa L.). Theoret. Appl. Genet. 112, 648-656. doi: 10.1007/s00122-0050167-0

Meng, Q., Gupta, R., Min, C. W., Kwon, S. W., Wang, Y., Je, B. I., et al. (2019). Proteomics of Rice-Magnaporthe oryzae interaction: what have we learned so far? Front. Plant Sci. 10:1383. doi: 10.3389/fpls.2019.01383

Mi, H., Huang, X., Muruganujan, A., Tang, H., Mills, C., Kang, D., et al. (2017). PANTHER version 11: expanded annotation data from Gene Ontology and Reactome pathways, and data analysis tool enhancements. Nucleic Acids Res. 45, D183-D189. doi: 10.1093/nar/gkw1138 
Mi, H., Muruganujan, A., and Thomas, P. D. (2012). PANTHER in 2013: modeling the evolution of gene function, and other gene attributes, in the context of phylogenetic trees. Nucleic Acids Res. 41, D377-D386. doi: 10.1093/nar/gks1118

Mishra, K. K., Vikram, P., Yadaw, R. B., Swamy, B. M., Dixit, S., Cruz, M. T. S., et al. (2013). qDTY 12.1: a locus with a consistent effect on grain yield under drought in rice. BMC Genet. 14:1-10. doi: 10.1186/1471-2156-14-12

Miura, K., Ikeda, M., Matsubara, A., Song, X.-J., Ito, M., Asano, K., et al. (2010). OsSPL14 promotes panicle branching and higher grain productivity in rice. Nat. Genet. 42, 545-549. doi: 10.1038/ng.592

Mohammadinezhad, G., Singh, R., Arzani, A., Rezaei, A., Sabouri, H., and Gregorio, G. (2010). Evaluation of salinity tolerance in rice genotypes. Int. J. Plant Product. 4, 199-208.

Mohan, V., Spiegelman, D., Sudha, V., Gayathri, R., Hong, B., Praseena, K., et al. (2014). Effect of brown rice, white rice, and brown rice with legumes on blood glucose and insulin responses in overweight Asian Indians: a randomized controlled trial. Diabet. Technol. Therapeut. 16, 317-325. doi: 10.1089/dia.2013. 0259

Mondal, S., Khan, M. I. R., Entila, F., Dixit, S., Cruz, P. C. S., Ali, M. P., et al. (2020). Responses of AG1 and AG2 QTL introgression lines and seed pre-treatment on growth and physiological processes during anaerobic germination of rice under flooding. Sci. Rep. 10, 1-15. doi: 10.1038/s41598-020-67240-x

Mondal, T. K., Panda, A. K., Rawal, H. C., and Sharma, T. R. (2018). Discovery of microRNA-target modules of African rice (Oryza glaberrima) under salinity stress. Sci. Rep. 8, 1-11. doi: 10.1038/s41598-017-18206-Z

Moon, S.-J., Min, M. K., Kim, J., Kim, D. Y., Yoon, I. S., Kwon, T. R., et al. (2019). Ectopic expression of OsDREB1G, a member of the OsDREB1 subfamily, confers cold stress tolerance in rice. Front. Plant Sci. 10:297. doi: 10.3389/fpls. 2019.00297

Moradi, F., Ismail, A., Egdane, J., and Gregorio, G. (2003). Salinity tolerance of rice during reproductive development and association with tolerance at the seedling stage. Ind. J. Plant Physiol. 8, 105-116. doi: 10.1093/aob/mcm052

Morris, R. T., O'connor, T. R., and Wyrick, J. J. (2008). Osiris: an integrated promoter database for Oryza sativa L. Bioinformatics 24, 2915-2917. doi: 10. 1093/bioinformatics/btn537

Moustafa, K., and Cross, J. (2016). Genetic approaches to study plant responses to environmental stresses: an overview. Biology 5:20.

Nadarajah, K., and Kumar, I. S. (2019). Drought response in rice: The miRNA story. Int. J. Mol. Sci. 20:3766. doi: 10.3390/ijms20153766

Nagaki, K., Cheng, Z., Ouyang, S., Talbert, P. B., Kim, M., Jones, K. M., et al. (2004). Sequencing of a rice centromere uncovers active genes. Nat. Genet. 36, 138-145.

Naithani, S., Gupta, P., Preece, J., D'eustachio, P., Elser, J. L., Garg, P., et al. (2020). Plant Reactome: a knowledgebase and resource for comparative pathway analysis. Nucleic Acids Res. 48, D1093-D1103.

Naithani, S., Preece, J., D'eustachio, P., Gupta, P., Amarasinghe, V., Dharmawardhana, P. D., et al. (2016). Plant Reactome: a resource for plant pathways and comparative analysis. Nucleic Acids Res. 2016:gkw932.

Nakashima, K., Tran, L. S. P., Van Nguyen, D., Fujita, M., Maruyama, K., Todaka, D., et al. (2007). Functional analysis of a NAC-type transcription factor OsNAC6 involved in abiotic and biotic stress-responsive gene expression in rice. Plant J. 51, 617-630. doi: 10.1111/j.1365-313X.2007.03168.x

Nam, K. H., Shin, H. J., Pack, I. S., Park, J. H., Kim, H. B., and Kim, C. G. (2016). Metabolomic changes in grains of well-watered and drought-stressed transgenic rice. J. Sci. Food Agricult. 96, 807-814. doi: 10.1002/jsfa.7152

Niones, J. M. (2004). Five mapping of the salinity tolerance gene on chromosome 1 of rice (Oryza sativa L.) using near-isogenic lines. Geneva: FAO.

Norvienyeku, J., Lin, L., Waheed, A., Chen, X., Bao, J., Aliyu, S. R., et al. (2021). Bayogenin 3-O-cellobioside confers non-cultivar-specific defence against the rice blast fungus Pyricularia oryzae. Plant Biotechnol. J. 19:589. doi: 10.1111/ pbi.13488

Obayashi, T., Aoki, Y., Tadaka, S., Kagaya, Y., and Kinoshita, K. (2018). ATTED-II in 2018: a plant coexpression database based on investigation of the statistical property of the mutual rank index. Plant Cell Physiol. 59, e3-e3.

Ogata, Y., Suzuki, H., Sakurai, N., and Shibata, D. (2010). CoP: a database for characterizing co-expressed gene modules with biological information in plants. Bioinformatics 26, 1267-1268. doi: 10.1093/bioinformatics/btq121

Ohyanagi, H., Ebata, T., Huang, X., Gong, H., Fujita, M., Mochizuki, T., et al. (2016). OryzaGenome: genome diversity database of wild Oryza species. Plant Cell Physiol. 57, e1-e1.
Ohyanagi, H., Tanaka, T., Sakai, H., Shigemoto, Y., Yamaguchi, K., Habara, T., et al. (2006). The Rice Annotation Project Database (RAP-DB): hub for Oryza sativa ssp. japonica genome information. Nucleic Acids Res. 34, D741-D744. doi: 10.1093/nar/gkj094

Oikawa, A., Matsuda, F., Kusano, M., Okazaki, Y., and Saito, K. (2008). Rice metabolomics. Rice 1, 63-71.

Okazaki, Y., and Saito, K. (2016). Integrated metabolomics and phytochemical genomics approaches for studies on rice. GigaScience 5, s13742-s13016.

Ouyang, S., Zhu, W., Hamilton, J., Lin, H., Campbell, M., Childs, K., et al. (2007). The TIGR rice genome annotation resource: improvements and new features. Nucleic Acids Res. 35, D883-D887. doi: 10.1093/nar/gkl976

Pandey, A., and Sonti, R. V. (2010). Role of the FeoB protein and siderophore in promoting virulence of Xanthomonas oryzae pv. oryzae on rice. J. Bacteriol. 192, 3187-3203. doi: 10.1128/JB.01558-09

Pandey, A., Rajamani, U., Verma, J., Subba, P., Chakraborty, N., Datta, A., et al. (2010). Identification of extracellular matrix proteins of rice (Oryza sativa L.) involved in dehydration-responsive network: a proteomic approach. J. Proteome Res. 9, 3443-3464. doi: 10.1021/pr901098p

Pandit, A., Rai, V., Bal, S., Sinha, S., Kumar, V., Chauhan, M., et al. (2010). Combining QTL mapping and transcriptome profiling of bulked RILs for identification of functional polymorphism for salt tolerance genes in rice (Oryza sativa L.). Mol. Genet. Genom. 284, 121-136. doi: 10.1007/s00438-010-0551-6

Pantalião, G. F., Vianello, R. P., Bueno, L. G., Mendonça, J. A., Coelho, A. S. G., Cordeiro, A. C. C., et al. (2020). Development of SNP markers for grain yield screening of Brazilian rice cultivars. Pesquisa Agropecuária Brasileira 55:1643.

Papatheodorou, I., Fonseca, N. A., Keays, M., Tang, Y. A., Barrera, E., Bazant, W., et al. (2018). Expression Atlas: gene and protein expression across multiple studies and organisms. Nucleic Acids Res. 46, D246-D251.

Park, J.-R., Yang, W.-T., Kwon, Y.-S., Kim, H.-N., Kim, K.-M., and Kim, D.-H. (2019). Assessment of the Genetic Diversity of Rice Germplasms Characterized by Black-Purple and Red Pericarp Color Using Simple Sequence Repeat Markers. Plants 8:471. doi: 10.3390/plants8110471

Parkinson, J., and Blaxter, M. (2009). Expressed sequence tags: an overview. Expressed Sequence Tags 2009, 1-12.

Parmar, S., Gharat, S. A., Tagirasa, R., Chandra, T., Behera, L., Dash, S. K., et al. (2020). Identification and expression analysis of miRNAs and elucidation of their role in salt tolerance in rice varieties susceptible and tolerant to salinity. PLoS One 15:e0230958. doi: 10.1371/journal.pone.0230958

Peng Yuan, D., Xu, X. F., Hong, W.-J., Wang, S. T., Jia, X. T., Liu, Y., et al. (2020). Transcriptome analysis of rice leaves in response to Rhizoctonia solani infection and reveals a novel regulatory mechanism. Plant Biotechnol. Rep. 14, 559-573.

Qi, L., Sun, Y., Li, J., Su, L., Zheng, X., Wang, X., et al. (2017). Identify QTLs for grain size and weight in common wild rice using chromosome segment substitution lines across six environments. Breed. Sci. 2017:16082. doi: 10.1270/ jsbbs. 16082

Que, S., Li, K., Chen, M., Wang, Y., Yang, Q., Zhang, W., et al. (2012). Phospho Rice: a meta-predictor of rice-specific phosphorylation sites. Plant Methods 8, 1-9. doi: 10.1186/1746-4811-8-5

Quek, X. C., Thomson, D. W., Maag, J. L., Bartonicek, N., Signal, B., Clark, M. B., et al. (2015). lncRNAdb v2. 0: expanding the reference database for functional long noncoding RNAs. Nucleic Acids Res. 43, D168-D173. doi: 10.1093/nar/ gku988

Rahman, H., Ramanathan, V., Nallathambi, J., Duraialagaraja, S., and Muthurajan, R. (2016). Over-expression of a NAC 67 transcription factor from finger millet (Eleusine coracana L.) confers tolerance against salinity and drought stress in rice. BMC Biotechnol. 16:7-20. doi: 10.1186/s12896-016-0261-1

Raineri, J., Wang, S., Peleg, Z., Blumwald, E., and Chan, R. L. (2015). The rice transcription factor OsWRKY47 is a positive regulator of the response to water deficit stress. Plant Mol. Biol. 88, 401-413. doi: 10.1007/s11103-015-0329-7

Ranawake, A. L., Manangkil, O. E., Yoshida, S., Ishii, T., Mori, N., and Nakamura, C. (2014). Mapping QTLs for cold tolerance at germination and the early seedling stage in rice (Oryza sativa L.). Biotechnol. Biotechnol. Equipm. 28, 989-998.

Rao, V. S., Srinivas, K., Sujini, G., and Kumar, G. (2014). Protein-protein interaction detection: methods and analysis. Int. J. Proteom. 2014:147648.

Raza, A., Razzaq, A., Mehmood, S. S., Zou, X., Zhang, X., Lv, Y., et al. (2019). Impact of climate change on crops adaptation and strategies to tackle its outcome: A review. Plants 8:34. doi: 10.3390/plants8020034 
Raza, Q., Riaz, A., Saher, H., Bibi, A., Raza, M. A., Ali, S. S., et al. (2020). Grain Fe and $\mathrm{Zn}$ contents linked SSR markers based genetic diversity in rice. PLoS One 15:e0239739. doi: 10.1371/journal.pone.0239739

Reig-Valiente, J. L., Marqués, L., Talón, M., and Domingo, C. (2018). Genome-wide association study of agronomic traits in rice cultivated in temperate regions. BMC Genom. 19:1-11. doi: 10.1186/s12864-018-5086-y

Ren, Z., Qi, D., Pugh, N., Li, K., Wen, B., Zhou, R., et al. (2019). Improvements to the rice genome annotation through large-scale analysis of RNA-Seq and proteomics data sets. Mol. Cell. Proteom. 18, 86-98. doi: 10.1074/mcp.RA118. 000832

Ren, Z.-H., Gao, J.-P., Li, L.-G., Cai, X.-L., Huang, W., Chao, D.-Y., et al. (2005). A rice quantitative trait locus for salt tolerance encodes a sodium transporter. Nat. Genet. 37, 1141-1146.

Rouard, M., Guignon, V., Aluome, C., Laporte, M.-A., Droc, G., Walde, C., et al. (2011). GreenPhylDB v2. 0: comparative and functional genomics in plants. Nucleic Acids Res. 39, D1095-D1102. doi: 10.1093/nar/gkq811

Roy, S. C., and Lachagari, V. B. R. (2017). Assessment of SNP and InDel Variations Among Rice Lines of Tulaipanji x Ranjit. Rice Sci. 24, 336-348.

Sabot, F., Picault, N., El-Baidouri, M., Llauro, C., Chaparro, C., Piegu, B., et al. (2011). Transpositional landscape of the rice genome revealed by paired-end mapping of high-throughput re-sequencing data. Plant J. 66, 241-246. doi: 10.1111/j.1365-313X.2011.04492.x

Sahebi, M., Hanafi, M. M., Azizi, P., Hakim, A., Ashkani, S., and Abiri, R. (2015). Suppression subtractive hybridization versus next-generation sequencing in plant genetic engineering: challenges and perspectives. Mol. Biotechnol. 57, 880-903. doi: 10.1007/s12033-015-9884-z

Sakai, H., Lee, S. S., Tanaka, T., Numa, H., Kim, J., Kawahara, Y., et al. (2013). Rice Annotation Project Database (RAP-DB): an integrative and interactive database for rice genomics. Plant Cell Physiol. 54, e6-e6. doi: 10.1093/pcp/pcs183

Sapkota, A., Liu, X., Zhao, X.-M., Cao, Y., Liu, J., Liu, Z.-P., et al. (2011). DIPOS: database of interacting proteins in Oryza sativa. Mol. BioSyst. 7, 2615-2621. doi: $10.1039 / \mathrm{clmb} 05120 \mathrm{~b}$

Sasaki, T. (2005). The map-based sequence of the rice genome. Nature 436, 793-800.

Sato, Y., Namiki, N., Takehisa, H., Kamatsuki, K., Minami, H., Ikawa, H., et al. (2013a). RiceFREND: a platform for retrieving coexpressed gene networks in rice. Nucleic Acids Res. 41, D1214-D1221. doi: 10.1093/nar/gks1122

Sato, Y., Takehisa, H., Kamatsuki, K., Minami, H., Namiki, N., Ikawa, H., et al. (2013b). RiceXPro version 3.0: expanding the informatics resource for rice transcriptome. Nucleic Acids Res. 41, D1206-D1213. doi: 10.1093/nar/gks1125

Schläpfer, P., Zhang, P., Wang, C., Kim, T., Banf, M., Chae, L., et al. (2017). Genome-wide prediction of metabolic enzymes, pathways, and gene clusters in plants. Plant Physiol. 173, 2041-2059.

Septiningsih, E., Prasetiyono, J., Lubis, E., Tai, T., Tjubaryat, T., Moeljopawiro, S., et al. (2003). Identification of quantitative trait loci for yield and yield components in an advanced backcross population derived from the Oryza sativa variety IR64 and the wild relative O. rufipogon. Theoret. Appl. Genet. 107, 1419-1432. doi: 10.1007/s00122-003-1373-2

Sew, Y. S., Aizat, W. M., Ab Razak, M. S. F., Zainal-Abidin, R.-A., Simoh, S., and Abu-Bakar, N. (2020). Comprehensive proteomics data on whole rice grain of selected pigmented and non-pigmented rice varieties using SWATH-MS approach. Data Brief 31:105927. doi: 10.1016/j.dib.2020.105927

Shah, T. R., and Misra, A. (2011). "Proteomics," in Challenges in Delivery of Therapeutic Genomics and Proteomics, ed. A. Misra (Amsterdam: Elsevier), 387-427.

Shanmugavadivel, P., Sv, A. M., Prakash, C., Ramkumar, M., Tiwari, R., Mohapatra, T., et al. (2017). High resolution mapping of QTLs for heat tolerance in rice using a 5K SNP array. Rice 10, 1-11. doi: 10.1186/s12284-017-0167-0

Shen, Y.-J., Jiang, H., Jin, J.-P., Zhang, Z.-B., Xi, B., He, Y.-Y., et al. (2004). Development of genome-wide DNA polymorphism database for map-based cloning of rice genes. Plant Physiol. 135, 1198-1205. doi: 10.1104/pp.103.038463

Sheteiwy, M. S., Shao, H., Qi, W., Hamoud, Y. A., Shaghaleh, H., Khan, N. U., et al. (2019). GABA-alleviated oxidative injury induced by salinity, osmotic stress and their combination by regulating cellular and molecular signals in rice. Int. J. Mol. Sci. 20:5709. doi: 10.3390/ijms20225709

Shomura, A., Izawa, T., Ebana, K., Ebitani, T., Kanegae, H., Konishi, S., et al. (2008). Deletion in a gene associated with grain size increased yields during rice domestication. Nat. Genet. 40, 1023-1028. doi: 10.1038/ng.169
Song, S., Tian, D., Zhang, Z., Hu, S., and Yu, J. (2018). Rice genomics: over the past two decades and into the future. Genomics Proteom. Bioinformat. 16, 397-404.

Song, E.-H., Jeong, J., Park, C. Y., Kim, H.-Y., Kim, E.-H., Bang, E., et al. (2018). Metabotyping of rice (Oryza sativa L.) for understanding its intrinsic physiology and potential eating quality. Food Res. Int. 111, 20-30. doi: 10.1016/j.foodres. 2018.05.003

Song, J.-M., Lei, Y., Shu, C.-C., Ding, Y., Xing, F., Liu, H., et al. (2018). Rice information GateWay: a comprehensive bioinformatics platform for Indica Rice genomes. Mol. Plant 11, 505-507. doi: 10.1016/j.molp.2017. 10.003

Song, X.-J., Huang, W., Shi, M., Zhu, M.-Z., and Lin, H.-X. (2007). A QTL for rice grain width and weight encodes a previously unknown RING-type E3 ubiquitin ligase. Nat. Genet. 39, 623-630. doi: 10.1038/ng2014

Sonnhammer, E. L., and Östlund, G. (2015). InParanoid 8: orthology analysis between 273 proteomes, mostly eukaryotic. Nucleic Acids Res. 43, D234-D239. doi: 10.1093/nar/gku1203

Stein, J. C., Yu, Y., Copetti, D., Zwickl, D. J., Zhang, L., Zhang, C., et al. (2018). Genomes of 13 domesticated and wild rice relatives highlight genetic conservation, turnover and innovation across the genus Oryza. Nat. Genet. 50, $285-296$.

Suharti, W. S., Nose, A., and Zheng, S.-H. (2016). Metabolite profiling of sheath blight disease resistance in rice: in the case of positive ion mode analysis by CE/TOF-MS. Plant Product. Sci. 19, 279-290.

Sun, C., Hu, Z., Zheng, T., Lu, K., Zhao, Y., Wang, W., et al. (2017). RPAN: rice pan-genome browser for 23000 rice genomes. Nucleic Acids Res. 45, 597-605. doi: 10.1093/nar/gkw958

Sun, L., Wang, J., Song, K., Sun, Y., Qin, Q., and Xue, Y. (2019). Transcriptome analysis of rice (Oryza sativa L.) shoots responsive to cadmium stress. Sci. Rep. $9,1-10$.

Sun, S.-J., Guo, S.-Q., Yang, X., Bao, Y.-M., Tang, H.-J., Sun, H., et al. (2010). Functional analysis of a novel Cys2/His2-type zinc finger protein involved in salt tolerance in rice. J. Exp. Bot. 61, 2807-2818. doi: 10.1093/jxb/erq120

Sun, Y., Shi, Y., Liu, G., Yao, F., Zhang, Y., Yang, C., et al. (2020). Natural variation in the OsbZIP18 promoter contributes to branched-chain amino acid levels in rice. N. Phytol. 228, 1548-1558. doi: 10.1111/nph.16800

Swamy, B. M., Vikram, P., Dixit, S., Ahmed, H., and Kumar, A. (2011). Meta-analysis of grain yield QTL identified during agricultural drought in grasses showed consensus. BMC Genomics 12:319. doi: 10.1186/1471-216412-319

Szklarczyk, D., Morris, J. H., Cook, H., Kuhn, M., Wyder, S., Simonovic, M., et al. (2016). The STRING database in 2017: quality-controlled protein-protein association networks, made broadly accessible. Nucleic Acids Res. 2016:gkw937. doi: 10.1093/nar/gkw937

Takasaki, H., Maruyama, K., Kidokoro, S., Ito, Y., Fujita, Y., Shinozaki, K., et al. (2010). The abiotic stress-responsive NAC-type transcription factor OsNAC5 regulates stress-inducible genes and stress tolerance in rice. Mol. Genet. Genom. 284, 173-183. doi: 10.1007/s00438-010-0557-0

Takeda, T., Suwa, Y., Suzuki, M., Kitano, H., Ueguchi-Tanaka, M., Ashikari, M., et al. (2003). The OsTB1 gene negatively regulates lateral branching in rice. Plant J. 33, 513-520.

Takehisa, H., Sato, Y., Igarashi, M., Abiko, T., Antonio, B. A., Kamatsuki, K., et al. (2012). Genome-wide transcriptome dissection of the rice root system: implications for developmental and physiological functions. Plant J. 69, 126140. doi: 10.1111/j.1365-313X.2011.04777.x

Tang, L., Zhang, F., Liu, A., Sun, J., Mei, S., Wang, X., et al. (2019). GenomeWide Association Analysis Dissects the Genetic Basis of the Grain Carbon and Nitrogen Contents in Milled Rice. Rice 12, 1-16. doi: 10.1186/s12284-0190362-2

Tang, N., Zhang, H., Li, X., Xiao, J., and Xiong, L. (2012). Constitutive activation of transcription factor OsbZIP46 improves drought tolerance in rice. Plant Physiol. 158, 1755-1768.

Tello-Ruiz, M. K., Naithani, S., Gupta, P., Olson, A., Wei, S., Preece, J., et al. (2021). Gramene 2021: harnessing the power of comparative genomics and pathways for plant research. Nucleic Acids Res. 49, D1452-D1463. doi: 10.1093/ nar/gkaa979

Thomas, P. D., Campbell, M. J., Kejariwal, A., Mi, H., Karlak, B., Daverman, R., et al. (2003). PANTHER: a library of protein families and subfamilies indexed by function. Genome Res. 13, 2129-2141. doi: 10.1101/gr.772403 
Thomson, M. J., De Ocampo, M., Egdane, J., Rahman, M. A., Sajise, A. G., Adorada, D. L., et al. (2010). Characterizing the Saltol quantitative trait locus for salinity tolerance in rice. Rice 3, 148-160.

Tian, D., Yang, L., Chen, Z., Chen, Z., Wang, F., Zhou, Y., et al. (2018). Proteomic analysis of the defense response to Magnaporthe oryzae in rice harboring the blast resistance gene Piz-t. Rice 11, 1-13. doi: 10.1186/s12284-018-0240-3

Tian, T., Liu, Y., Yan, H., You, Q., Yi, X., Du, Z., et al. (2017). agriGO v2. 0: a GO analysis toolkit for the agricultural community, 2017 update. Nucleic Acids Res. 45, W122-W129. doi: 10.1093/nar/gkx382

Tomcal, M., Stiffler, N., and Barkan, A. (2013). POGs2: a web portal to facilitate cross-species inferences about protein architecture and function in plants. PLoS One 8:e82569. doi: 10.1371/journal.pone.0082569

Tulpan, D., and Leger, S. (2017). The Plant Orthology Browser: An Orthology and Gene-Order Visualizer for Plant Comparative Genomics. Plant Genome 10:0078. doi: 10.3835/plantgenome2016.08.0078

Uawisetwathana, U., and Karoonuthaisiri, N. (2019). Metabolomics for rice quality and traceability: feasibility and future aspects. Curr. Opin. Food Sci. 28, 58-66.

Upadhyaya, H., and Panda, S. K. (2019). "Drought stress responses and its management in rice," in Advances in Rice Research for Abiotic Stress Tolerance, eds M. Hasanuzzaman, M. Fujita, K. Nahar, and J. K. Biswas (Amsterdam: Elsevier), 177-200.

Usadel, B., Obayashi, T., Mutwil, M., Giorgi, F. M., Bassel, G. W., Tanimoto, M., et al. (2009a). Co-expression tools for plant biology: opportunities for hypothesis generation and caveats. Plant Cell Environ. 32, 1633-1651. doi: 10.1111/j.1365-3040.2009.02040.x

Usadel, B., Poree, F., Nagel, A., Lohse, M., Czedik-Eysenberg, A., and Stitt, M. (2009b). A guide to using MapMan to visualize and compare Omics data in plants: a case study in the crop species, Maize. Plant Cell Environ. 32, 1211-1229. doi: 10.1111/j.1365-3040.2009.01978.x

Usman, B., Nawaz, G., Zhao, N., Liu, Y., and Li, R. (2020). Generation of high yielding and fragrant rice (Oryza sativa L.) Lines by CRISPR/Cas9 targeted mutagenesis of three homoeologs of cytochrome P450 gene family and OsBADH2 and transcriptome and proteome profiling of revealed changes triggered by mutations. Plants 9:788. doi: 10.3390/plants9060788

Valette, M., Rey, M., Gerin, F., Comte, G., and Wisniewski-Dyé, F. (2020). A common metabolomic signature is observed upon inoculation of rice roots with various rhizobacteria. J. Integrat. Plant Biol. 62, 228-246. doi: 10.1111/jipb. 12810

Venuprasad, R., Bool, M., Quiatchon, L., and Atlin, G. (2012a). A QTL for rice grain yield in aerobic environments with large effects in three genetic backgrounds. Theoret. Appl. Genet. 124, 323-332. doi: 10.1007/s00122-011-1707-4

Venuprasad, R., Bool, M., Quiatchon, L., Cruz, M. S., Amante, M., and Atlin, G. (2012b). A large-effect QTL for rice grain yield under upland drought stress on chromosome 1. Mol. Breed. 30, 535-547.

Venuprasad, R., Dalid, C., Del Valle, M., Zhao, D., Espiritu, M., Cruz, M. S., et al. (2009). Identification and characterization of large-effect quantitative trait loci for grain yield under lowland drought stress in rice using bulk-segregant analysis. Theoret. Appl. Genet. 120, 177-190. doi: 10.1007/s00122-0091168-1

Venuprasad, R., Lafitte, H. R., and Atlin, G. N. (2007). Response to direct selection for grain yield under drought stress in rice. Crop Sci. 47, 285-293.

Vikram, P., Swamy, B. M., Dixit, S., Ahmed, H. U., Cruz, M. T. S., Singh, A. K., et al. (2011). qDTY 1.1, a major QTL for rice grain yield under reproductive-stage drought stress with a consistent effect in multiple elite genetic backgrounds. BMC Genet. 12:89. doi: 10.1186/1471-2156-12-89

Vikram, P., Swamy, B. M., Dixit, S., Trinidad, J., Sta Cruz, M. T., Maturan, P. C., et al. (2016). Linkages and interactions analysis of major effect drought grain yield QTLs in rice. PLoS One 11:e0151532. doi: 10.1371/journal.pone.0151532

Vo, K. T. X., Rahman, M. M., Rahman, M. M., Trinh, K. T. T., Kim, S. T., and Jeon, J.-S. (2021). Proteomics and Metabolomics Studies on the Biotic Stress Responses of Rice: an Update. Rice 14, 1-16. doi: 10.1186/s12284-021-00461-4

Volante, A., Tondelli, A., Desiderio, F., Abbruscato, P., Menin, B., Biselli, C., et al. (2020). Genome wide association studies for japonica rice resistance to blast in field and controlled conditions. Rice 13, 1-17. doi: 10.1186/s12284-020-00431-2

Wan, X., Wan, J., Jiang, L., Wang, J., Zhai, H., Weng, J., et al. (2006). QTL analysis for rice grain length and fine mapping of an identified QTL with stable and major effects. Theoret. Appl. Genet. 112, 1258-1270.
Wang, J., Wang, J., Wang, X., Li, R., and Chen, B. (2018). Proteomic response of hybrid wild rice to cold stress at the seedling stage. PLoS One 13:e198675. doi: 10.1371/journal.pone.0198675

Wang, Z., Xia, Y., Lin, S., Wang, Y., Guo, B., Song, X., et al. (2018). Osa-miR164a targets Os NAC 60 and negatively regulates rice immunity against the blast fungus Magnaporthe oryzae. Plant J. 95, 584-597.

Wang, D. R., Agosto-Pérez, F. J., Chebotarov, D., Shi, Y., Marchini, J., Fitzgerald, M., et al. (2018). An imputation platform to enhance integration of rice genetic resources. Nat. Commun. 9, 1-10. doi: 10.1038/s41467-018-05538-1

Wang, L., Xie, W., Chen, Y., Tang, W., Yang, J., Ye, R., et al. (2010). A dynamic gene expression atlas covering the entire life cycle of rice. Plant J. 61, 752-766. doi: 10.1111/j.1365-313X.2009.04100.x

Wang, M., Lu, X., Xu, G., Yin, X., Cui, Y., Huang, L., et al. (2016). OsSGL, a novel pleiotropic stress-related gene enhances grain length and yield in rice. Sci. Rep. 6, 1-12. doi: 10.1038/srep38157

Wang, Q., Guan, Y., Wu, Y., Chen, H., Chen, F., and Chu, C. (2008). Overexpression of a rice OsDREB1F gene increases salt, drought, and low temperature tolerance in both Arabidopsis and rice. Plant Mol. Biol. 67, 589602. doi: 10.1007/s11103-008-9340-6

Wang, S., Wu, K., Yuan, Q., Liu, X., Liu, Z., Lin, X., et al. (2012). Control of grain size, shape and quality by OsSPL16 in rice. Nat. Genet. 44:950.

Wang, S.-T., Sun, X.-L., Hoshino, Y., Yu, Y., Jia, B., Sun, Z.-W., et al. (2014). MicroRNA319 positively regulates cold tolerance by targeting OsPCF6 and OsTCP21 in rice (Oryza sativa L.). PLoS One 9:e91357. doi: 10.1371/journal. pone.0091357

Wang, Y., Huang, L., Du, F., Wang, J., Zhao, X., Li, Z., et al. (2021). Comparative transcriptome and metabolome profiling reveal molecular mechanisms underlying OsDRAP1-mediated salt tolerance in rice. Sci. Rep. 11, 1-11. doi: 10.1038/s41598-021-84638-3

Wang, Y., Wang, J., Zhao, X., Yang, S., Huang, L., Du, F., et al. (2020). Overexpression of the Transcription Factor Gene OsSTAP1 Increases Salt Tolerance in Rice. Rice 13, 1-12. doi: 10.1186/s12284-020-00405-4

Wang, Y.-J., Zhang, Z.-G., He, X.-J., Zhou, H.-L., Wen, Y.-X., Dai, J.-X., et al. (2003). A rice transcription factor OsbHLH1 is involved in cold stress response. Theoret. Appl. Genet. 107, 1402-1409. doi: 10.1007/s00122-003-1378-x

Wang, Z., Gerstein, M., and Snyder, M. (2009). RNA-Seq: a revolutionary tool for transcriptomics. Nat. Rev. Genet. 10, 57-63.

Wanichthanarak, K., Boonchai, C., Kojonna, T., Chadchawan, S., Sangwongchai, W., and Thitisaksakul, M. (2020). Deciphering rice metabolic flux reprograming under salinity stress via in silico metabolic modeling. Computat. Struct. Biotechnol. J. 18, 3555-3566. doi: 10.1016/j.csbj.2020.11.023

Wei, J., Wang, A., Li, R., Qu, H., and Jia, Z. (2018). Metabolome-wide association studies for agronomic traits of rice. Heredity 120, 342-355. doi: 10.1038/s41437017-0032-3

Winter, D., Vinegar, B., Nahal, H., Ammar, R., Wilson, G. V., and Provart, N. J. (2007). An "Electronic Fluorescent Pictograph" browser for exploring and analyzing large-scale biological data sets. PLoS One 2:e718. doi: 10.1371/journal. pone. 0000718

Wongpia, A., Roytrakul, S., Nomura, M., Tajima, S., Lomthaisong, K., Mahatheeranont, S., et al. (2016). Proteomic Analysis of Isogenic Rice Reveals Proteins Correlated with Aroma Compound Biosynthesis at Different Developmental Stages. Mol. Biotechnol. 58, 117-129. doi: 10.1007/s12033-0159906-x

Wu, J., Wang, Y., Park, S.-Y., Kim, S. G., Yoo, J. S., Park, S., et al. (2016). Secreted alpha-N-Arabinofuranosidase B protein is required for the full virulence of Magnaporthe oryzae and triggers host Defences. PLoS One 11:e0165149. doi: 10.1371/journal.pone.0165149

Wu, J., Yamagata, H., Hayashi-Tsugane, M., Hijishita, S., Fujisawa, M., Shibata, M., et al. (2004). Composition and structure of the centromeric region of rice chromosome 8. Plant Cell 16, 967-976.

Xia, K., Wang, R., Ou, X., Fang, Z., Tian, C., Duan, J., et al. (2012). OsTIR1 and OsAFB2 downregulation via OsmiR393 overexpression leads to more tillers, early flowering and less tolerance to salt and drought in rice. PLoS One 7:e30039. doi: 10.1371/journal.pone.0030039

Xia, L., Zou, D., Sang, J., Xu, X., Yin, H., Li, M., et al. (2017). Rice Expression Database (RED): An integrated RNA-Seq-derived gene expression database for rice. J. Genet. Genom. 44, 235-241. doi: 10.1016/j.jgg.2017.05.003 
Xiao, B., Huang, Y., Tang, N., and Xiong, L. (2007). Over-expression of a LEA gene in rice improves drought resistance under the field conditions. Theoret. Appl. Genet. 115, 35-46. doi: 10.1007/s00122-007-0538-9

Xie, K., Shen, J., Hou, X., Yao, J., Li, X., Xiao, J., et al. (2012). Gradual increase of miR156 regulates temporal expression changes of numerous genes during leaf development in rice. Plant Physiol. 158, 1382-1394. doi: 10.1104/pp.111.190488

Xie, K., Wu, C., and Xiong, L. (2006). Genomic organization, differential expression, and interaction of SQUAMOSA promoter-binding-like transcription factors and microRNA156 in rice. Plant Physiol. 142, 280-293. doi: 10.1104/pp.106.084475

Xie, Z., Wang, C., Zhu, S., Wang, W., Xu, J., and Zhao, X. (2020). Characterizing the metabolites related to rice salt tolerance with introgression lines exhibiting contrasting performances in response to saline conditions. Plant Growth Regulat. 92, 157-167.

Xu, D., Mou, G., Wang, K., and Zhou, G. (2014). MicroRNAs responding to southern rice black-streaked dwarf virus infection and their target genes associated with symptom development in rice. Virus Res. 190, 60-68. doi: 10. 1016/j.virusres.2014.07.007

Xu, D.-Q., Huang, J., Guo, S.-Q., Yang, X., Bao, Y.-M., Tang, H.-J., et al. (2008). Overexpression of a TFIIIA-type zinc finger protein gene ZFP252 enhances drought and salt tolerance in rice (Oryza sativa L.). FEBS Lett. 582, 1037-1043. doi: 10.1016/j.febslet.2008.02.052

Xu, E., Chen, M., He, H., Zhan, C., Cheng, Y., Zhang, H., et al. (2017). Proteomic analysis reveals proteins involved in seed imbibition under salt stress in rice. Front. Plant Sci. 7:2006. doi: 10.3389/fpls.2016.02006

$\mathrm{Xu}$, K., Xu, X., Fukao, T., Canlas, P., Maghirang-Rodriguez, R., Heuer, S., et al. (2006). SublA is an ethylene-response-factor-like gene that confers submergence tolerance to rice. Nature 442, 705-708.

Xue, L.-J., Zhang, J.-J., and Xue, H.-W. (2009). Characterization and expression profiles of miRNAs in rice seeds. Nucleic Acids Res. 37, 916-930.

Yadav, A. K., Kumar, A., Grover, N., Ellur, R. K., Krishnan, S. G., Bollinedi, H., et al. (2020). Marker aided introgression of 'Saltol', a major QTL for seedling stage salinity tolerance into an elite Basmati rice variety 'Pusa Basmati 1509'. Sci. Rep. 10, 1-15. doi: 10.1038/s41598-020-70664-0

Yadav, M. K., Ngangkham, U., Subudhi, H., Bag, M. K., Adak, T., Munda, S., et al. (2017). Correction: Use of molecular markers in identification and characterization of resistance to rice blast in India. PLoS One 12:e0179467. doi: 10.1371/journal.pone.0179467

Yadav, S., Sandhu, N., Singh, V. K., Catolos, M., and Kumar, A. (2019). Genotypingby-sequencing based QTL mapping for rice grain yield under reproductive stage drought stress tolerance. Sci. Rep. 9, 1-12.

Yamamoto, Y. Y., and Obokata, J. (2007). PPDB: a plant promoter database. Nucleic Acids Res. 36, D977-D981.

Yan, B., Liu, R., Li, Y., Wang, Y., Gao, G., Zhang, Q., et al. (2014). QTL analysis on rice grain appearance quality, as exemplifying the typical events of transgenic or backcrossing breeding. Breed. Sci. 64, 231-239.

Yang, A., Dai, X., and Zhang, W.-H. (2012). A R2R3-type MYB gene, OsMYB2, is involved in salt, cold, and dehydration tolerance in rice. J. Exp. Bot. 63, 2541-2556. doi: 10.1093/jxb/err431

Yang, C., Li, D., Mao, D., Liu, X., Ji, C., Li, X., et al. (2013). Overexpression of micro RNA 319 impacts leaf morphogenesis and leads to enhanced cold tolerance in rice (O ryza sativa L.). Plant Cell Environ. 36, 2207-2218. doi: $10.1111 /$ pce. 12130

Yang, J., Li, D., Liu, H., Liu, Y., Huang, M., Wang, H., et al. (2020). Identification of QTLs involved in cold tolerance during the germination and bud stages of rice (Oryza sativa L.) via a high-density genetic map. Breed. Sci. 70, 292-302. doi: $10.1270 /$ jsbbs.19127

Yang, Y., and Ma, H. (2009). Western blotting and ELISA techniques. Researcher 1, 67-86.

Yano, K., Yamamoto, E., Aya, K., Takeuchi, H., Lo, P.-C., Hu, L., et al. (2016). Genome-wide association study using whole-genome sequencing rapidly identifies new genes influencing agronomic traits in rice. Nat. Genet. 48:927. doi: 10.1038/ng.3596

Yasmin, S., Hafeez, F. Y., Mirza, M. S., Rasul, M., Arshad, H. M., Zubair, M., et al. (2017). Biocontrol of bacterial leaf blight of rice and profiling of secondary metabolites produced by rhizospheric Pseudomonas aeruginosa BRp3. Front. Microbiol. 8:1895. doi: 10.3389/fmicb.2017.01895
Ye, X., Al-Babili, S., Klöti, A., Zhang, J., Lucca, P., Beyer, P., et al. (2000). Engineering the provitamin A ( $\beta$-carotene) biosynthetic pathway into (carotenoid-free) rice endosperm. Science 287, 303-305. doi: 10.1126/science. 287.5451.303

Yi, X., Du, Z., and Su, Z. (2013). PlantGSEA: a gene set enrichment analysis toolkit for plant community. Nucleic Acids Res. 41, W98-W103. doi: 10.1093/nar/ gkt281

Yi, X., Zhang, Z., Ling, Y., Xu, W., and Su, Z. (2015). PNRD: a plant non-coding RNA database. Nucleic Acids Res. 43, D982-D989.

Yim, W. C., Yu, Y., Song, K., Jang, C. S., and Lee, B.-M. (2013). PLANEX: the plant co-expression database. BMC Plant Biol. 13:83. doi: 10.1186/1471-2229-13-83

Yonemaru, J.-I., Ebana, K., and Yano, M. (2014). HapRice, an SNP haplotype database and a web tool for rice. Plant Cell Physiol. 55, e9-e9. doi: 10.1093/pcp/ pct188

Yoshino, K., Numajiri, Y., Teramoto, S., Kawachi, N., Tanabata, T., Tanaka, T., et al. (2019). Towards a deeper integrated multi-omics approach in the root system to develop climate-resilient rice. Mol. Breed. 39, 1-19.

Yu, H., Jiao, B., Lu, L., Wang, P., Chen, S., Liang, C., et al. (2018). NetMineran ensemble pipeline for building genome-wide and high-quality gene co-expression network using massive-scale RNA-seq samples. PLoS One 13:e0192613. doi: 10.1371/journal.pone.0192613

Yu, J., Hu, S., Wang, J., Wong, G. K.-S., Li, S., Liu, B., et al. (2002). A draft sequence of the rice genome (Oryza sativa L. ssp. indica). Science 296, 79-92.

Yu, X., Yang, T., Qi, Q., Du, Y., Shi, J., Liu, X., et al. (2021). Comparison of the contents of phenolic compounds including flavonoids and antioxidant activity of rice (Oryza sativa) and Chinese wild rice (Zizania latifolia). Food Chem. 344:128600. doi: 10.1016/j.foodchem.2020.128600

Yuan, C., Meng, X., Li, X., Illing, N., Ingle, R. A., Wang, J., et al. (2017). PceRBase: a database of plant competing endogenous RNA. Nucleic Acids Res. 45, D1009D1014. doi: 10.1093/nar/gkw916

Zainal-Abidin, R.-A., Abu-Bakar, N., Sew, Y.-S., Simoh, S., and Mohamed-Hussein, Z.-A. (2019). Discovery of Functional SNPs via Genome-Wide Exploration of Malaysian Pigmented Rice Varieties. Int. J. Genom. 2019:4168045. doi: 10.1155/ 2019/4168045

Zainal-Abidin, R.-A., Zainal, Z., Mohamed-Hussein, Z.-A., Abu-Bakar, N., Ab Razak, M. S. F., Simoh, S., et al. (2020). RNA-seq data from whole rice grains of pigmented and non-pigmented Malaysian rice varieties. Data Brief 30:105432. doi: 10.1016/j.dib.2020.105432

Zarei, I., Luna, E., Leach, J. E., Mcclung, A., Vilchez, S., Koita, O., et al. (2018). Comparative rice bran metabolomics across diverse cultivars and functional rice gene-bran metabolite relationships. Metabolites 8:63. doi: 10 . 3390/metabo8040063

Zhang, J., Zhou, Z., Bai, J., Tao, X., Wang, L., Zhang, H., et al. (2020). Disruption of MIR396e and MIR396f improves rice yield under nitrogen-deficient conditions. Natl. Sci. Rev. 7, 102-112.

Zhang, F., Huang, L., Zeng, D., Cruz, C. V., Li, Z., and Zhou, Y. (2020). Comparative proteomic analysis reveals novel insights into the interaction between rice and Xanthomonas oryzae pv. oryzae. BMC Plant Biol. 20:1-14. doi: 10.1186/s12870-020-02769-7

Zhang, H., Ma, H., Xie, X., Ji, J., Dong, Y., Du, Y., et al. (2014). Comparative proteomic analyses reveal that the regulators of G-protein signaling proteins regulate amino acid metabolism of the rice blast fungus Magnaporthe oryzae. Proteomics 14, 2508-2522. doi: 10.1002/pmic.201400173

Zhang, J., Zhang, H., Srivastava, A. K., Pan, Y., Bai, J., Fang, J., et al. (2018). Knockdown of rice microRNA166 confers drought resistance by causing leaf rolling and altering stem xylem development. Plant Physiol. 176, 2082-2094. doi: 10.1104/pp.17.01432

Zhang, X., Yin, F., Xiao, S., Jiang, C., Yu, T., Chen, L., et al. (2019). Proteomic analysis of the rice (Oryza officinalis) provides clues on molecular tagging of proteins for brown planthopper resistance. BMC Plant Biol. 19:1-11. doi: 10.1186/s12870-018-1622-9

Zhang, Y., Zang, Q., Xu, B., Zheng, W., Ban, R., Zhang, H., et al. (2016). IsomiR Bank: a research resource for tracking IsomiRs. Bioinformatics 32, 2069-2071. doi: 10.1093/bioinformatics/btw070

Zhang, Y.-C., Yu, Y., Wang, C.-Y., Li, Z.-Y., Liu, Q., Xu, J., et al. (2013). Overexpression of microRNA OsmiR397 improves rice yield by increasing 
grain size and promoting panicle branching. Nat. Biotechnol. 31, 848-852. doi: $10.1038 /$ nbt.2646

Zhao, B., Ge, L., Liang, R., Li, W., Ruan, K., Lin, H., et al. (2009). Members of miR-169 family are induced by high salinity and transiently inhibit the NF-YA transcription factor. BMC Mol. Biol. 10:1-10. doi: 10.1186/1471-219910-29

Zhao, B., Liang, R., Ge, L., Li, W., Xiao, H., Lin, H., et al. (2007). Identification of drought-induced microRNAs in rice. Biochem. Biophys. Res. Commun. 354, 585-590. doi: 10.1016/j.bbrc.2007.01.022

Zhao, H., Yao, W., Ouyang, Y., Yang, W., Wang, G., Lian, X., et al. (2015). RiceVarMap: a comprehensive database of rice genomic variations. Nucleic Acids Res. 43, D1018-D1022. doi: 10.1093/nar/g ku894

Zhao, X.-Q., Wang, W.-S., Zhang, F., Zhang, T., Zhao, W., Fu, B.-Y., et al. (2013). Temporal profiling of primary metabolites under chilling stress and its association with seedling chilling tolerance of rice (Oryza sativa L.). Rice 6, 1-13. doi: 10.1186/1939-8433-6-23

Zhao, Y. F., Peng, T., Sun, H. Z., Teotia, S., Wen, H. L., Du, Y. X., et al. (2019). miR1432-Os ACOT (Acyl-CoA thioesterase) module determines grain yield via enhancing grain filling rate in rice. Plant Biotechnol. J. 17, 712-723. doi: 10.1111/pbi.13009

Zhao, Y., Wen, H., Teotia, S., Du, Y., Zhang, J., Li, J., et al. (2017). Suppression of microRNA159 impacts multiple agronomic traits in rice (Oryza sativa L.). BMC Plant Biol. 17:1-13. doi: 10.1186/s12870-017-1171-7

Zheng, H., Zhao, H., Liu, H., Wang, J., and Zou, D. (2015). QTL analysis of Na+ and $\mathrm{K}+$ concentrations in shoots and roots under $\mathrm{NaCl}$ stress based on linkage and association analysis in japonica rice. Euphytica 201, 109-121.

Zheng, W., Ma, L., Zhao, J., Li, Z., Sun, F., and Lu, X. (2013). Comparative transcriptome analysis of two rice varieties in response to rice stripe virus and small brown planthoppers during early interaction. PLoS One 8:e82126. doi: 10.1371 /journal.pone.0082126
Zhou, J., Wang, F., Deng, P., Jing, W., and Zhang, W. (2013). Characterization and mapping of a salt-sensitive mutant in rice (Oryza sativa L.). J. Integrat. Plant Biol. 55, 504-513. doi: 10.1111/jipb.12048

Zhou, L., Liu, Y., Liu, Z., Kong, D., Duan, M., and Luo, L. (2010). Genome-wide identification and analysis of drought-responsive microRNAs in Oryza sativa. J. Exp. Bot. 61, 4157-4168. doi: 10.1093/jxb/erq237

Zhou, Y., Tang, J., Walker, M. G., Zhang, X., Wang, J., Hu, S., et al. (2003). Gene identification and expression analysis of 86,136 Expressed Sequence Tags (EST) from the rice genome. Genomics Proteom. Bioinformat. 1, 26-42. doi: 10.1016/ s1672-0229(03)01005-2

Zhu, Q.-H., Upadhyaya, N. M., Gubler, F., and Helliwell, C. A. (2009). Overexpression of miR172 causes loss of spikelet determinacy and floral organ abnormalities in rice (Oryza sativa). BMC Plant Biol. 9:149. doi: 10.1186/14712229-9-149

Conflict of Interest: The authors declare that the research was conducted in the absence of any commercial or financial relationships that could be construed as a potential conflict of interest.

Publisher's Note: All claims expressed in this article are solely those of the authors and do not necessarily represent those of their affiliated organizations, or those of the publisher, the editors and the reviewers. Any product that may be evaluated in this article, or claim that may be made by its manufacturer, is not guaranteed or endorsed by the publisher.

Copyright (c) 2021 Iqbal, Iqbal, Khan and Ansari. This is an open-access article distributed under the terms of the Creative Commons Attribution License (CC BY). The use, distribution or reproduction in other forums is permitted, provided the original author(s) and the copyright owner(s) are credited and that the original publication in this journal is cited, in accordance with accepted academic practice. No use, distribution or reproduction is permitted which does not comply with these terms. 